Supporting Information for

\title{
Pillararene-Peptide Nanogels and Their Biomimetic Mineralization Hybrids for Heterogeneous Catalysis
}

Yitao Wu, Qi Li, Jiajun Cao, Yang Liu, Zeju Wang, Liqing Shangguan, Huangtianzhi Zhu,*

Department of Chemistry, Zhejiang University, Hangzhou 310027, P. R. China; Fax: +86-571-8795-3189;

Email: htzzhu@zju.edu.cn

\section{Table of Content (44 pages)}

1. Materials S2

2. Methods S3

3. Characterizations of P6-CYYY S5

4. Characterizations of PPN S8

5. Characterizations of DPB $\quad \mathrm{S} 14$

6. Characterizations of Pt/PPN S17

7. Catalytic reduction of p-nitrophenol

8. Characterizations of recycled Pt/PPN S26

9. Characterizations of substrate scope $\quad \mathrm{S} 30$

10. Comparison table $\mathrm{S} 43$

11. Reference $\mathrm{S} 44$ 


\section{Materials}

All reagents and solvents are commercially available and were used without further purification. A tyrosine-rich short peptide with a Cys- $\operatorname{Tyr}(t \mathrm{Bu})-\operatorname{Tyr}(t \mathrm{Bu})-\operatorname{Tyr}(t \mathrm{Bu})$ sequence was purchased from TOP-peptide (China) Co-Ltd and the $\operatorname{Tyr}(t \mathrm{Bu})$ unit is 2-amino-3-(4-(tert-butoxy)phenyl)propanoic acid. The per-bromoethyl pillar[6]arene (BrP6) was synthesized as described previously. ${ }^{\mathrm{S} 1}{ }^{1} \mathrm{H}$ NMR spectra were recorded with a Bruker Avance DMX 400 spectrophotometer, Bruker Avance DMX 500 spectrophotometer or Bruker Avance DMX 600 spectrophotometer using the deuterated solvent as the lock and the residual solvent or TMS as the internal reference. Mass spectra were obtained on a Bruker Esquire 3000 plus mass spectrometer (Bruker-Franzen Analytik GmbH Bremen, Germany) equipped with an ESI interface and an ion trap analyzer. Transmission electron microscopic investigations were carried out on a HITACHI HT-7700 instrument. Scanning electron microscopic investigations, energy dispersive X-ray spectroscopy (EDX) analysis and elemental mapping were carried out on a JEOL 6390LV instrument. UV-Vis spectra of solution samples were obtained on a Shimadzu UV-2550 instrument at room temperature. The fluorescence experiments were conducted on a RF-5301 spectrofluorophotometer (Shimadzu Corporation, Japan). Gel permeation chromatography (GPC) was recorded on a ACCUPREP MPS spectrophotometer. Dynamic light scattering measurements were performed on a goniometer ALV/CGS-3 using a UNIPHASE He-Ne laser operating at $632.8 \mathrm{~nm}$. X-ray photoelectron spectrum (XPS) was carried out using an ESCALAB X-ray photoelectron spectrometer. Gas chromatographic analysis: GC measurements were carried out using an Agilent 7890B instrument configured with an FID detector and a DB-624 column $(30 \mathrm{~m} \times 0.53 \mathrm{~mm} \times 3.0 \mu \mathrm{m})$. Samples were analyzed using headspace injections and were performed by incubating the sample at $100{ }^{\circ} \mathrm{C}$ for $10 \mathrm{~min}$ followed by sampling $1.00 \mathrm{~mL}$ of the headspace. The total volume of the container is $10 \mathrm{~mL}$; the mass of the solid in the container is about 10 $\mathrm{mg}$; the total volume of the headspace is $1 \mathrm{~mL}$. The following GC method was used: the oven was programmed from $60{ }^{\circ} \mathrm{C}$, and ramped in $5{ }^{\circ} \mathrm{C} \mathrm{min}{ }^{-1}$ increments to $200{ }^{\circ} \mathrm{C}$ with $5 \mathrm{~min}$ hold; the total run time was $25 \mathrm{~min}$; the injection temperature was $250{ }^{\circ} \mathrm{C}$; the detector temperature was $280{ }^{\circ} \mathrm{C}$ with nitrogen, air, and make-up flow-rates of 35,350 , and $35 \mathrm{~mL} \mathrm{~min}^{-1}$, respectively; helium (carrier gas) flow-rate was $3.0 \mathrm{~mL} \mathrm{~min}{ }^{-1}$. The samples were injected in the split mode (30:1). PXRD data were collected on a Rigaku Ultimate-IV X-Ray diffractometer operating at $40 \mathrm{kV} / 30 \mathrm{~mA}$ using the $\mathrm{Cu} \mathrm{K} \alpha$ line $\left(\lambda=1.5418 \AA\right.$ ) . Data were measured over the range $5-45^{\circ}$ in $5 \%$ min steps over $8 \mathrm{~min}$. TGA analysis was carried out using a Q5000IR analyzer (TA Instruments) with an automated vertical overhead thermobalance. The samples were heated at $10{ }^{\circ} \mathrm{C} / \mathrm{min}$ using $\mathrm{N}_{2}$ as the protective gas. Fourier transform infrared (FT-IR) spectra were recorded on a Thermo Nicolet iS10 spectrometer. Raman spectra were collected on a LabRamHRUV spectrometer. Inductively coupled plasma mass spectrometry (ICP-MS) analysis were recorded on a NexION 2000. Elemental analysis (EA) were collected on a Vario Micro spectrometer. 


\section{Methods}

\section{Preparation of the pillararene-peptide nanogel (PPN)}

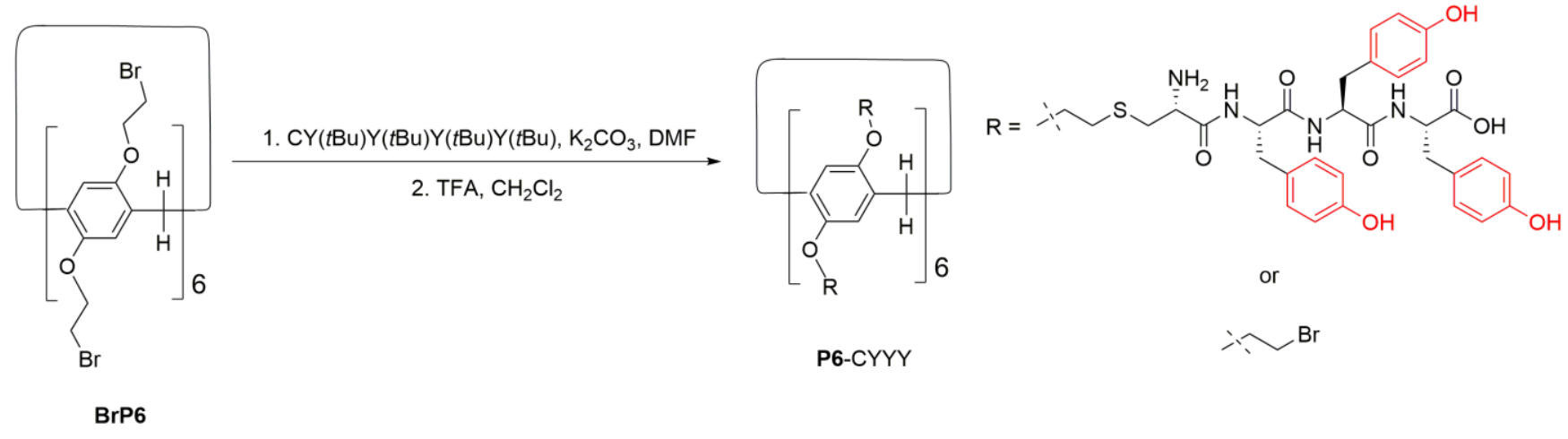

Scheme S1. Synthetic route of P6-CYYY.

Synthesis of the peptide-bearing pillar[6]arene derivative (P6-CYYY): BrP6 (40.0 mg, $20.0 \mu \mathrm{mol}$, 1.00 eq.), Cys- $\operatorname{Tyr}(t \mathrm{Bu})-\operatorname{Tyr}(t \mathrm{Bu})-\operatorname{Tyr}(t \mathrm{Bu})(315 \mathrm{mg}, 400 \mu \mathrm{mol}, 20.0$ eq. $)$ and $\mathrm{K}_{2} \mathrm{CO}_{3}(221 \mathrm{mg}, 1.60 \mathrm{mmol}$, 80.0 eq.) were mixed in dry DMF $(10.0 \mathrm{~mL})$ and stirred for $24 \mathrm{~h}$ at $60{ }^{\circ} \mathrm{C}$ under nitrogen atmosphere. The resulting yellowish solution was cooled to room temperature then filtered. The collected filtrate was added to $100 \mathrm{~mL}$ of $5 \% \mathrm{HCl}$ solution and filtered then washed with water. The product was dialyzed against DMF to remove excess monomer, giving a yield of $75.2 \%$ (267 mg).

The collected P6-Cys- $\operatorname{Tyr}(t \mathrm{Bu})-\operatorname{Tyr}(t \mathrm{Bu})-\operatorname{Tyr}(t \mathrm{Bu})(123 \mathrm{mg})$ was dissolved in $\mathrm{CH}_{2} \mathrm{Cl}_{2}(15.0 \mathrm{~mL})$ and trifluoroacetic acid $(600 \mu \mathrm{L})$ was added dropwise in nitrogen atmosphere and stirred for $24 \mathrm{~h}$ at room temperature. Ammonia solution was added to the resulting solution dropwise until the $\mathrm{pH}$ was about 7.0. The solution was evaporated by a rotary evaporator to remove the excess solvent. A light yellow solid was obtained as P6-CYYY(87.0 mg), yield 70.7\%.

In a typical synthesis of PPN, $1.00 \mathrm{~mL}$ of P6-CYYY solutions with different concentrations were prepared by mixing $200 \mu \mathrm{L}$ of $1.00 \mathrm{mM}$ aqueous $\mathrm{Ru}(\mathrm{bpy})_{3} \mathrm{Cl}_{2}, 600 \mu \mathrm{L}$ of $10.0 \mathrm{mM}$ aqueous ammonium persulfate, and $200 \mu \mathrm{L}$ of P6-CYYY with various concentration $0.500 \sim 150 \mathrm{mg} / \mathrm{mL}$ dissolved in a $\mathrm{pH}=$ 10.0 ammonia buffer. The effective concentrations of P6-CYYY were $0.100 \sim 30.0 \mathrm{mg} / \mathrm{mL}$. Then the mixture in a quartz tube with a cap was immediately exposed to a white light laser (5 A, Leoptics LE-SP Series Light Source Controller, China) for $30 \mathrm{~min}$ at the room temperature. The product was separated by centrifugation at 10,000 rpm/min for 2 min and repeatedly washed with water three times.

\section{Morphology observation}

TEM investigations were carried out on a JEM-1200EX instrument. A $10 \mu \mathrm{L}$ aliquot of the washed nanogel solution was spotted on a carbon-coated copper grid. The samples were blotted away after 1 min incubation, followed by washing with water, and dried in a vacuum oven before imaging. SEM investigations were carried out on a JEOL 6390LV instrument. The solution of nanogels were dropped on a piece of Silica wafer, and then dried for imaging at room temperature for $24 \mathrm{~h}$. 


\section{Characterization of dityrosine bonds}

UV-vis and fluorescence spectra were collected on a Shimadzu UV-2550 instrument and a Shimadzu RF-5301 spectrofluorophotometer at room temperature, respectively, after the formation of nanogels.

\section{Size analysis of PPN}

Dynamic light scattering (DLS) was carried out on a Malvern Nanosizer S instrument at room temperature to measure the size of PPN. For each measurement, $500 \mu \mathrm{L}$ of the prepared PPN solution with desired concentration was loaded in a disposable UV-Cuvette micro.

\section{Preparation of Pt/PPN hybrid}

Firstly, an aqueous stock solution of $\mathrm{PtCl}_{2}(0.250 \mathrm{mM})$ was prepared. A $1.00 \mathrm{~mL}$ of aqueous metal precursor solution was mixed with a $1.00 \mathrm{~mL}$ of as-prepared PPN solution (obtained from $1.00 \mathrm{mg} / \mathrm{mL}$ of P6-CYYY) with $1.00 \mathrm{mg} / \mathrm{mL}$ of concentration. The mixture was placed in dark for 30 min to soak the metal ions, and then purified by repeated centrifugation (10,000 rpm for $2 \mathrm{~min}$ ) and washing with water to remove free Pt(II). The metal-loaded PPN was exposed under UV lamp (365 nm wavelength) for $30 \mathrm{~min}$. The sample was analyzed by X-ray photoelectron spectroscopy (XPS, VG ESCALAB MARK II), UV-vis spectroscopy (UV-vis, Shimadzu UV-2550), transmission electron microscope (TEM, JEM-1200EX instrument) and scanning electron microscope (SEM, JEOL 6390LV instrument).

\section{Elemental mapping image of Pt/PPN hybrid}

A $1.00 \mathrm{mg} / \mathrm{mL}$ of $\mathbf{P P N}$ and Pt/PPN solution were prepared. The Pt/PPN solution was dropped on a piece of Silica wafer, and then dried for imaging at $-20{ }^{\circ} \mathrm{C}$ for $24 \mathrm{~h}$. Elemental mapping and Energy Dispersive X-Ray Spectroscopy (EDX) investigations were carried out on a JEOL 6390LV instrument.

\section{Catalytic performance of Pt/PPN hybrid}

In order to test the catalytic reduction of nitro-aromatic compounds to amino-aromatic compounds, a solution containing $1.00 \mathrm{~mL}$ of $1.00 \mathrm{mM}$ aqueous substrate, $1.00 \mathrm{~mL}$ of $1.00 \mathrm{mg} / \mathrm{mL} \mathrm{Pt} / \mathbf{P P N}$ and $1.00 \mathrm{~mL}$ of $50.0 \mathrm{mM}$ aqueous $\mathrm{NaBH}_{4}$ were prepared under room temperature. Time-dependent $\mathrm{UV}$ absorption was recorded to monitor the reduction. For the GC-MS measurement, $1.00 \mathrm{~mL}$ of ethyl acetate was additionally introduced into the reaction mixture to extract the product in situ and the mixture was analyzed by a GCT Premier GC-TOFMA instrument. The amino products were analyzed by Bruker Avance DMX 400 spectrophotometer or Bruker Avance DMX 600 spectrophotometer. 
3. Characterizations of P6-CYYY

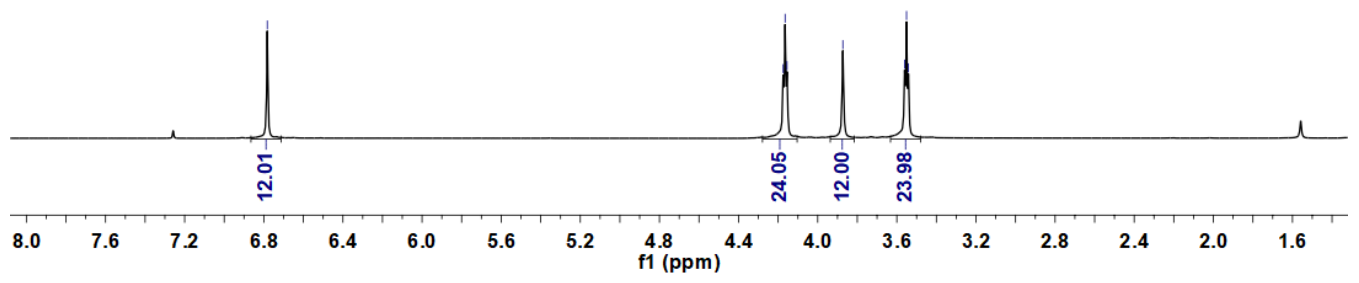

Figure S1. ${ }^{1} \mathrm{H}$ NMR spectrum (600 MHz, chloroform- $d$, $\left.298 \mathrm{~K}\right)$ of BrP6

(a)

\section{)}

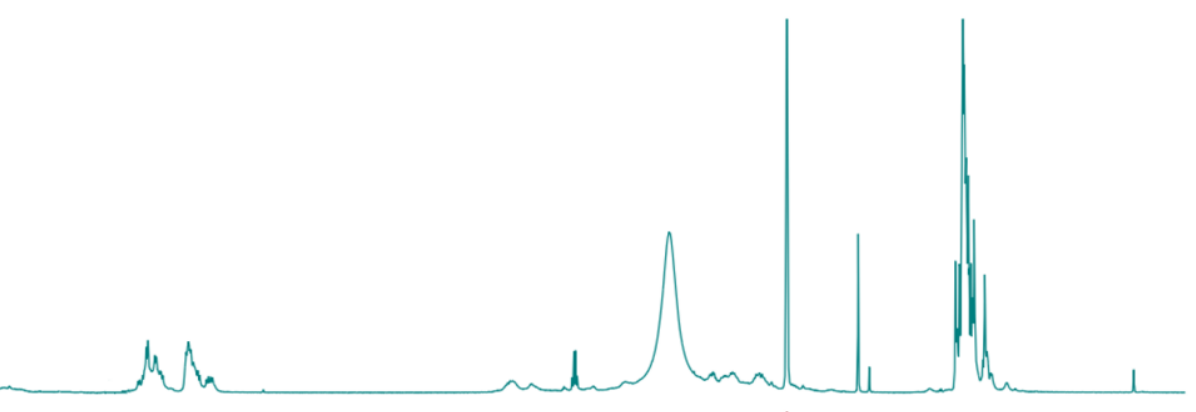

(b)

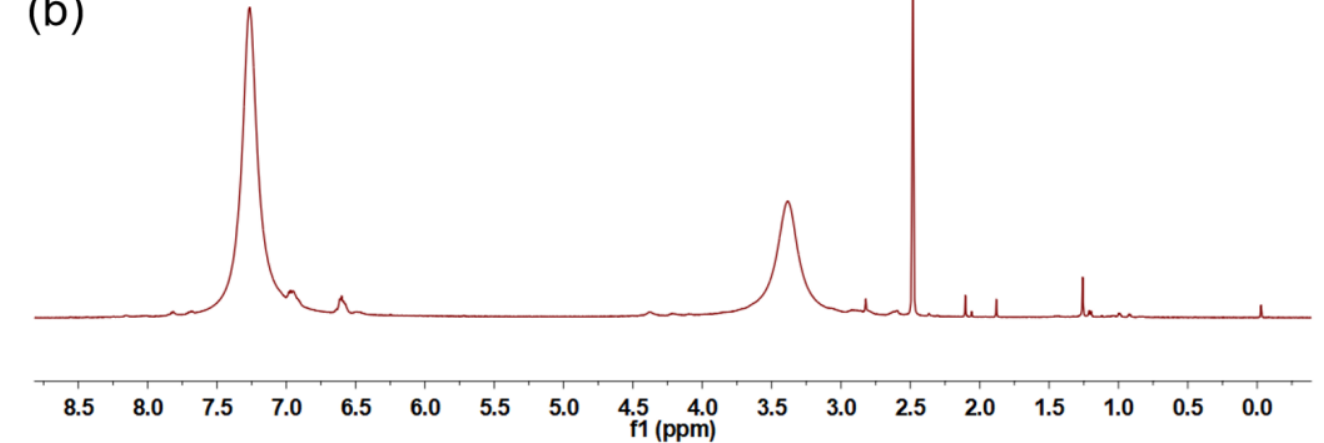

Figure S2. ${ }^{1} \mathrm{H}$ NMR spectra $\left(600 \mathrm{MHz}, \mathrm{DMSO}-d_{6}, 298 \mathrm{~K}\right)$ of (a) purchased CY $(t \mathrm{Bu}) \mathrm{Y}(t \mathrm{Bu}) \mathrm{Y}(t \mathrm{Bu})$ and $(\mathrm{b})$ CYYY. 


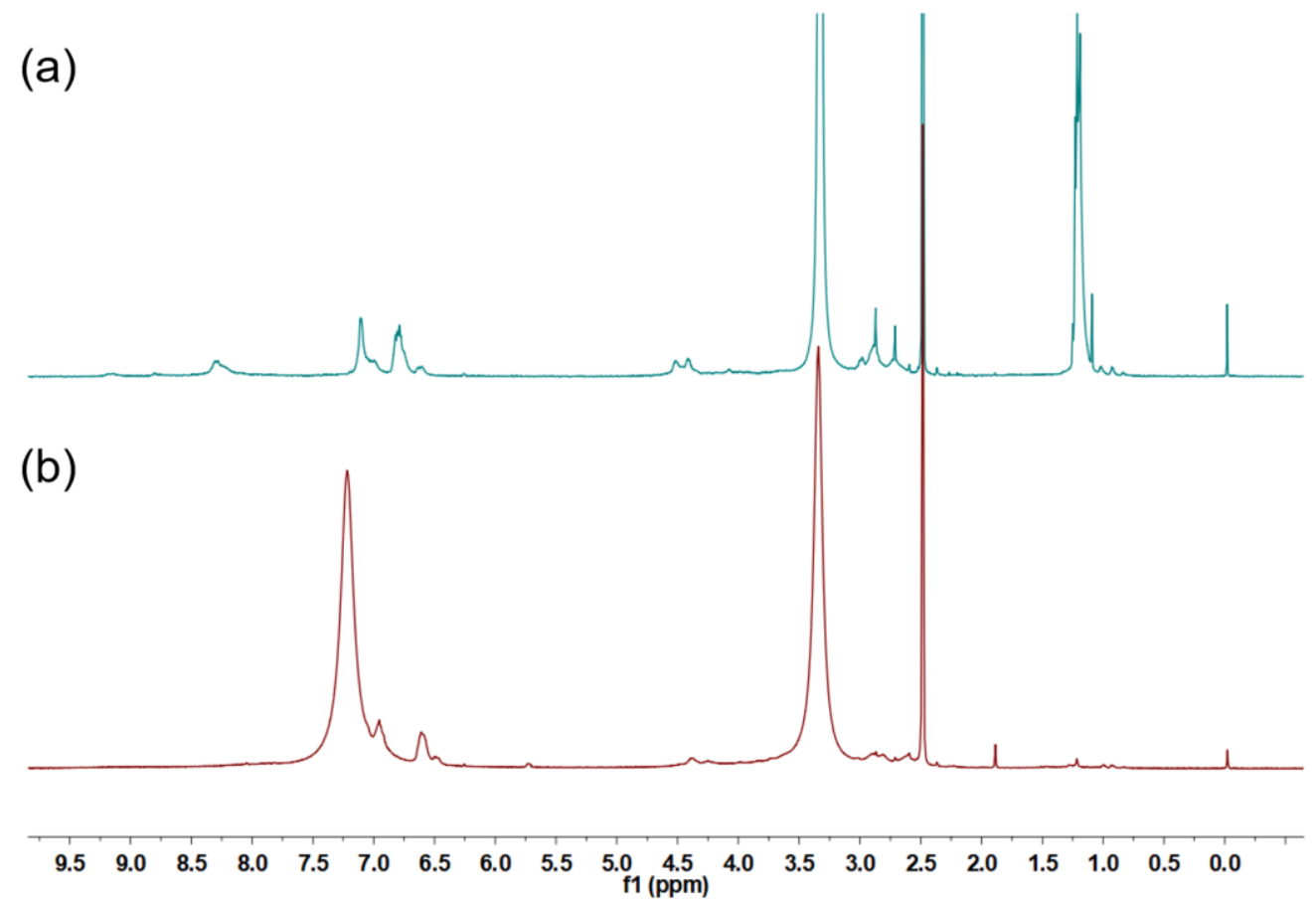

Figure S3. ${ }^{1} \mathrm{H}$ NMR spectra (600 MHz, DMSO- $\left.d_{6}, 298 \mathrm{~K}\right)$ of (a) P6-CY $(t \mathrm{Bu}) \mathrm{Y}(t \mathrm{Bu}) \mathrm{Y}(t \mathrm{Bu})$ and (b) P6-CYYY.

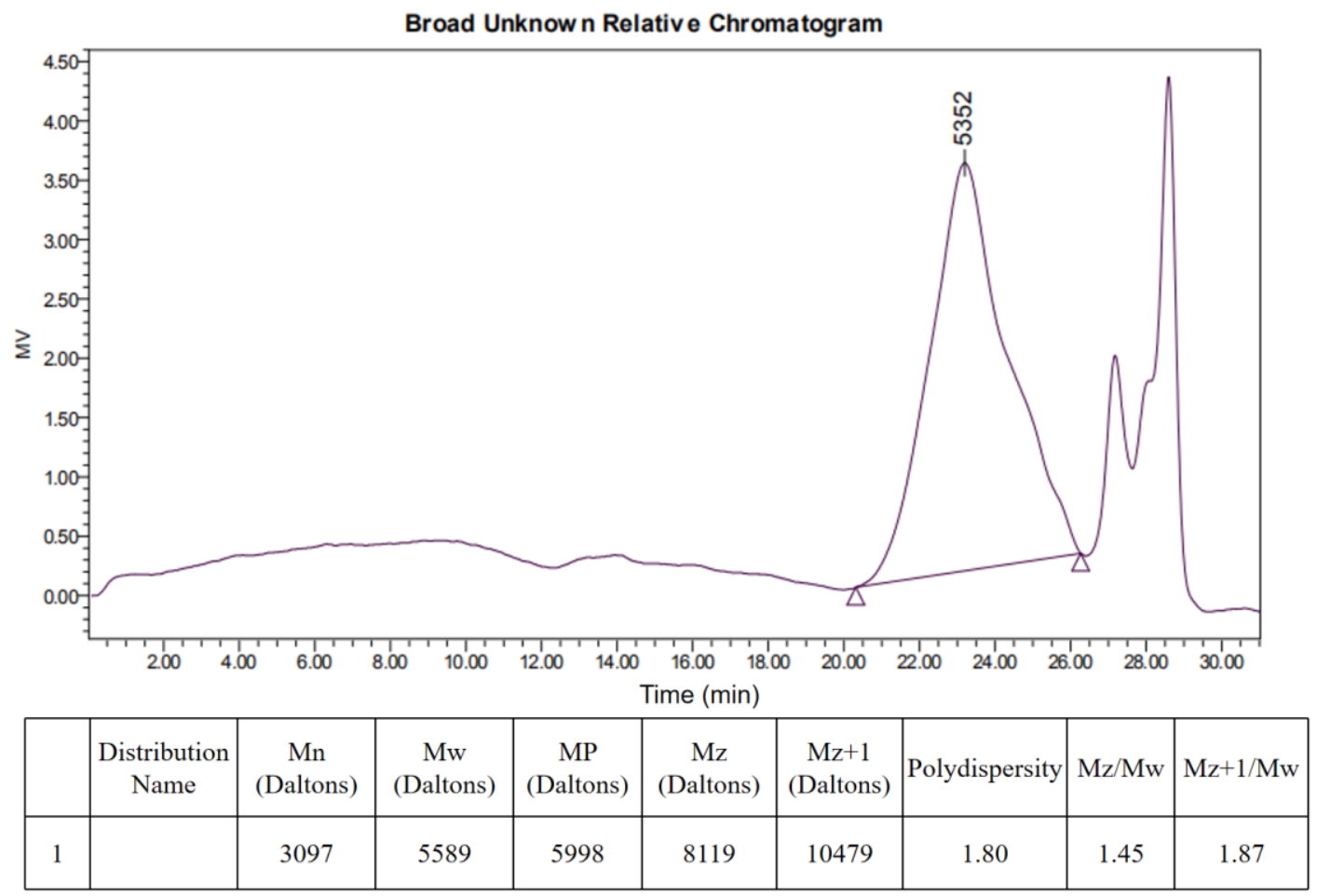

Figure S4. GPC spectrum of P6-CY $(t \mathrm{Bu}) \mathrm{Y}(t \mathrm{Bu}) \mathrm{Y}(t \mathrm{Bu})$. 


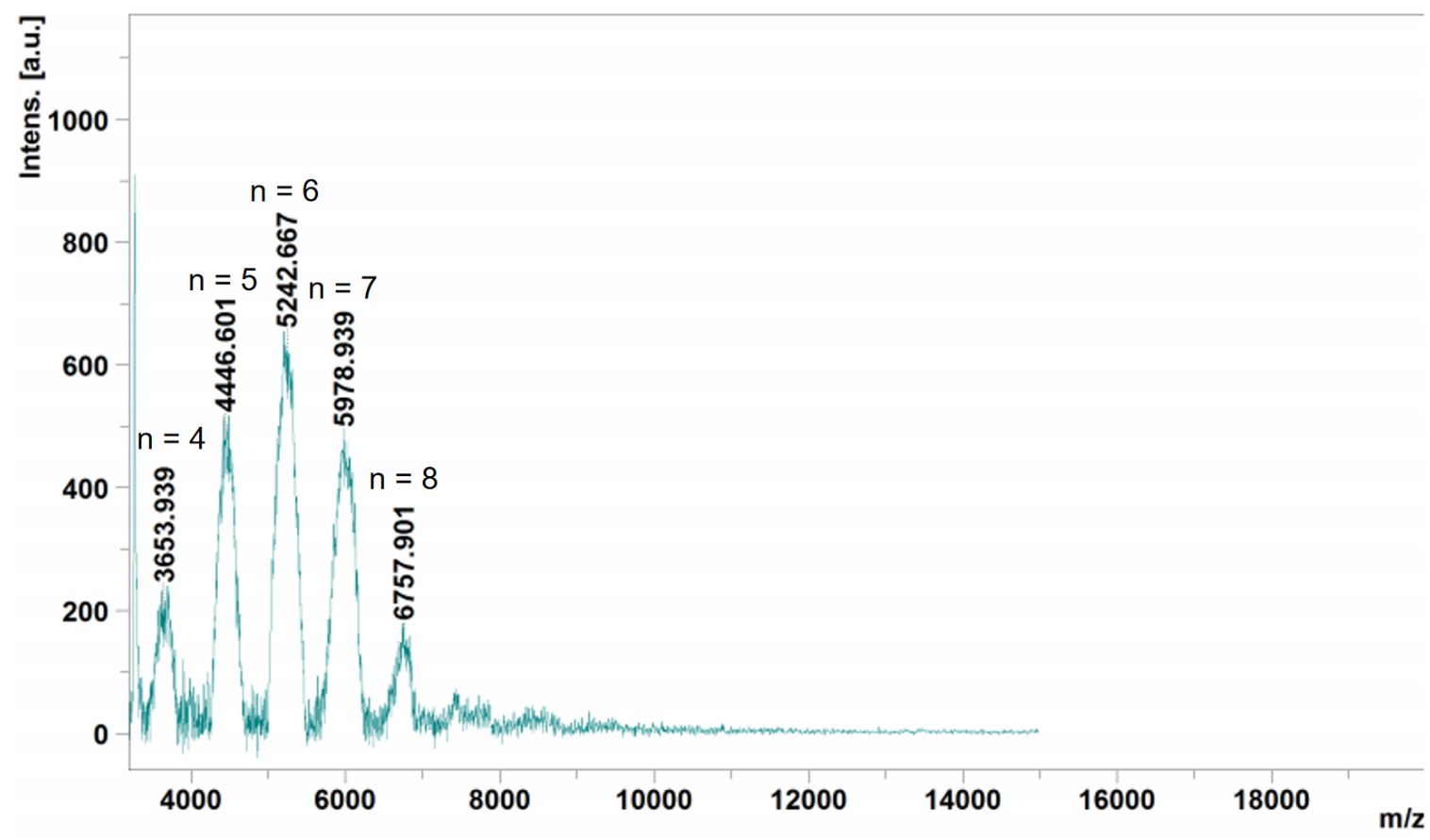

Figure S5. MALDI-TOF spectrum of $\mathbf{P 6}-\mathrm{CY}(t \mathrm{Bu}) \mathrm{Y}(t \mathrm{Bu}) \mathrm{Y}(t \mathrm{Bu})$. The numbers of peptide chains $(\mathrm{n}=4,5$, $6,7,8)$ attached on the pillar[6]arene are shown in the spectrum.

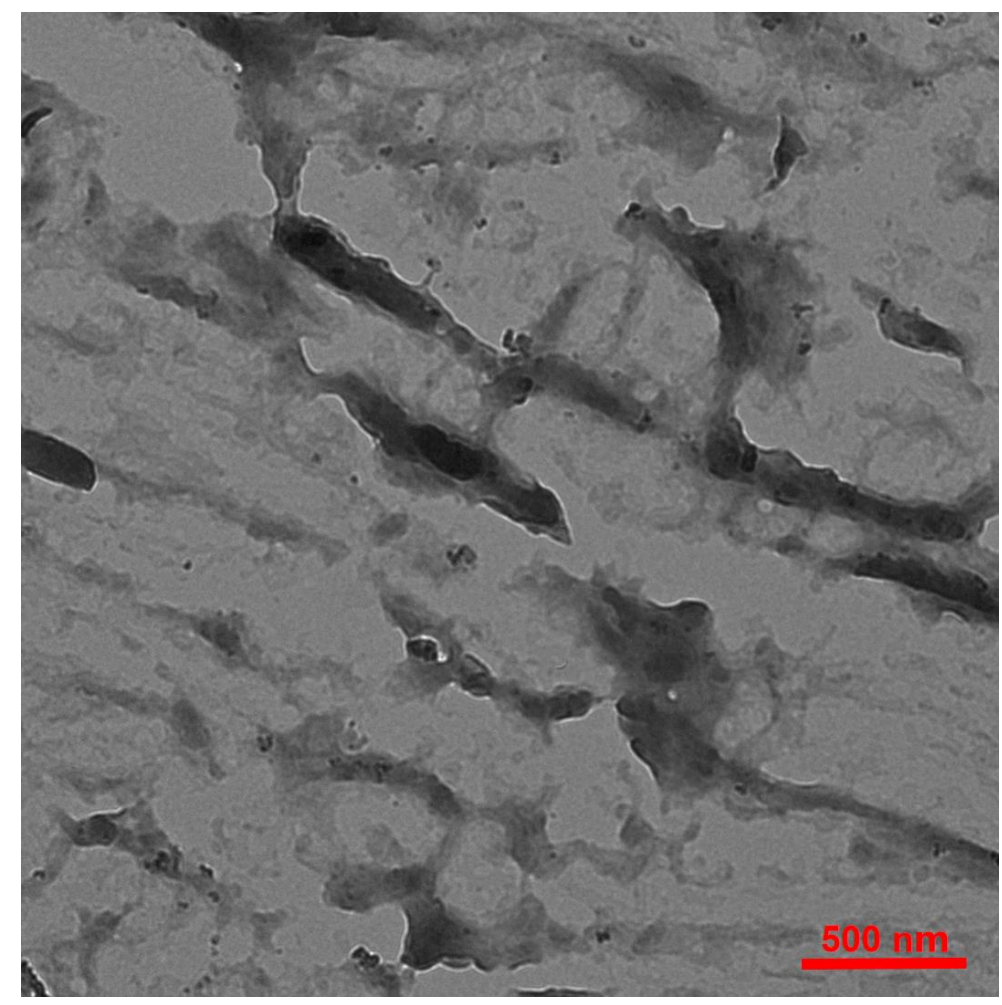

Figure S6. TEM image of P6-CYYY (1.00 mg/mL). 
Figure S7. SEM image of P6-CYYY (1.00 mg/mL).

\section{Characterizations of $\boldsymbol{P P N}$}

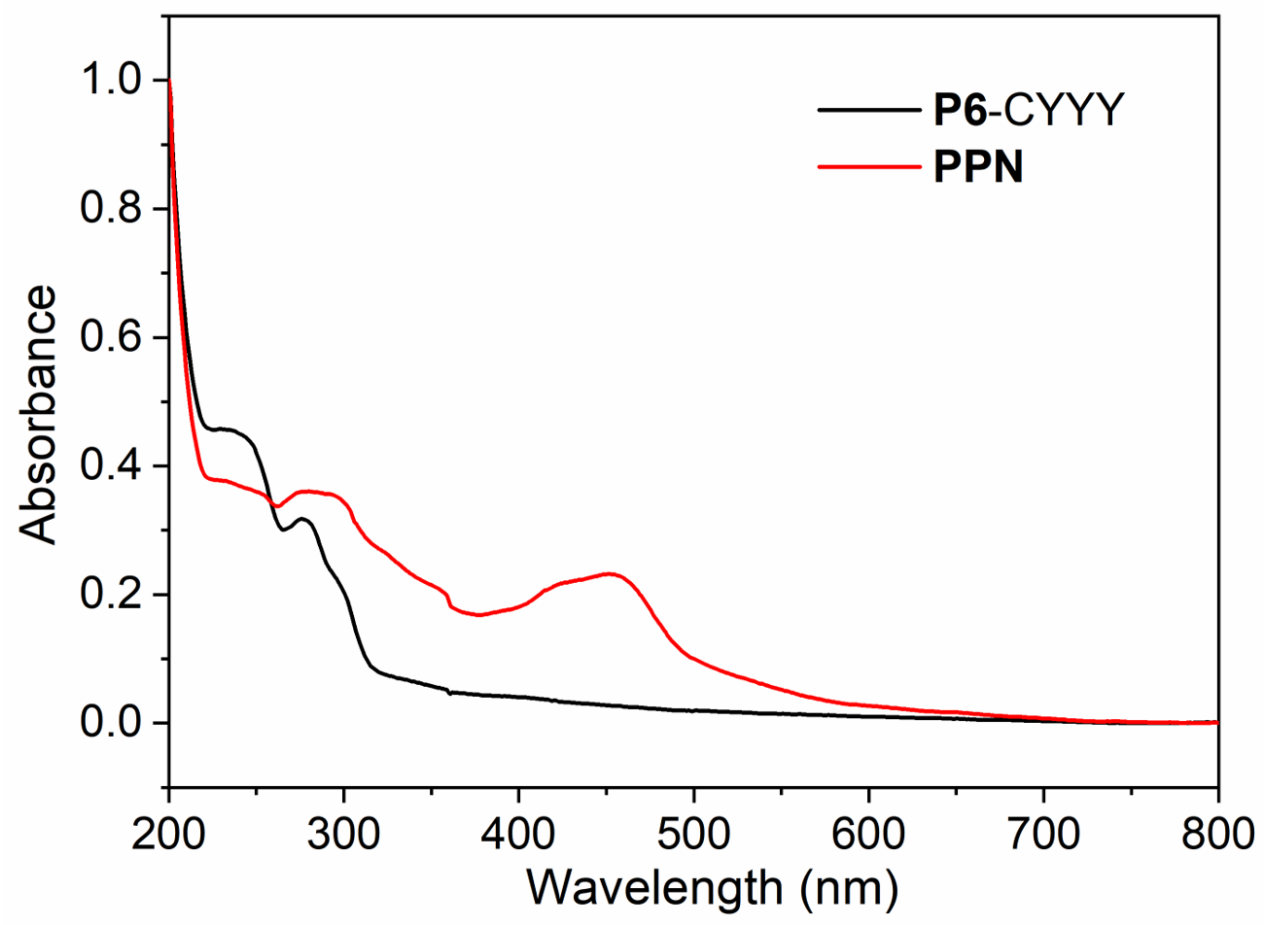

Figure S8 UV-vis spectra of P6-CYYY and PPN (1.00 mg/mL). 


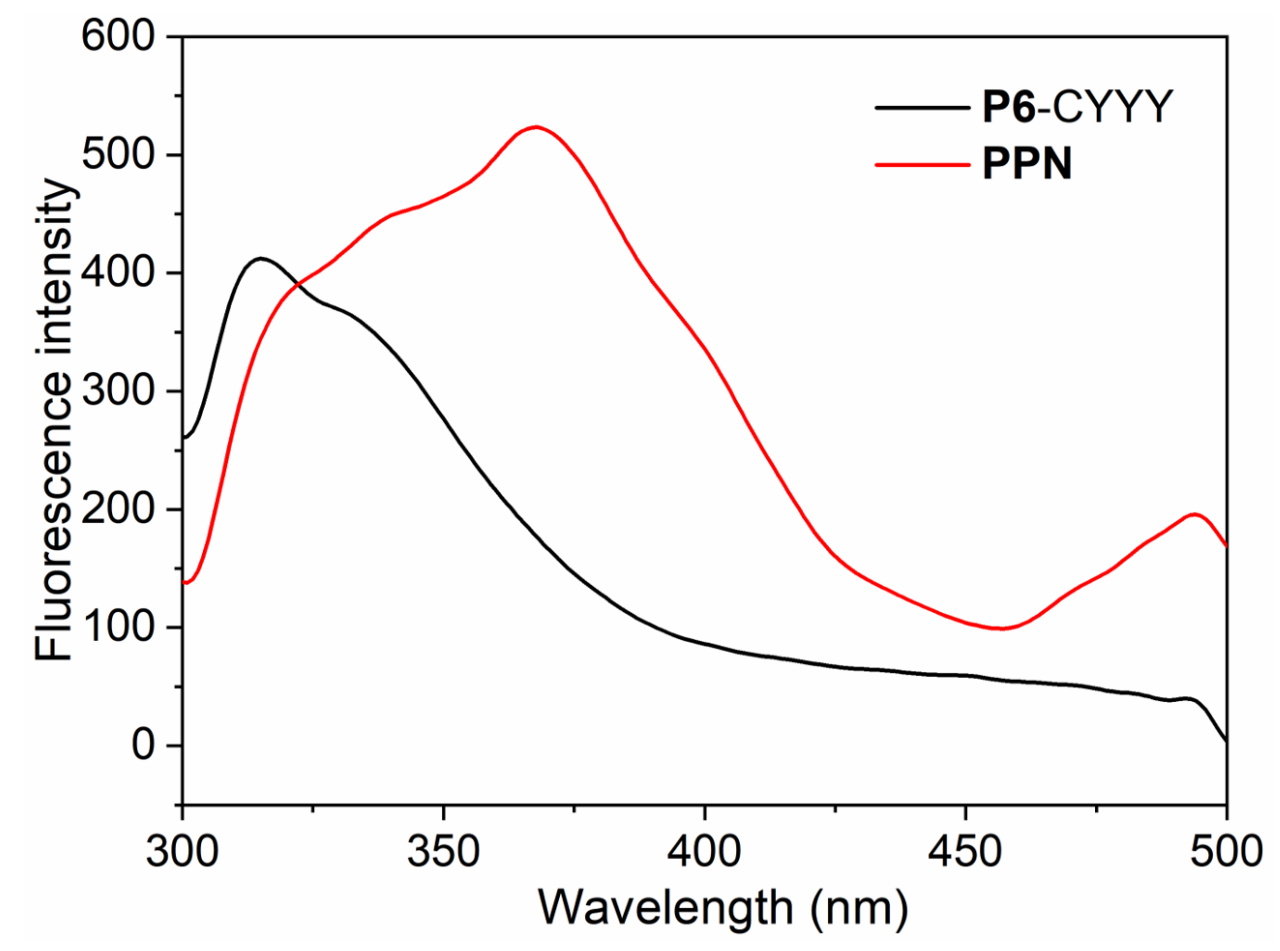

Figure S9. Fluorescence spectra of P6-CYYY and PPN (1.00 mg/mL).

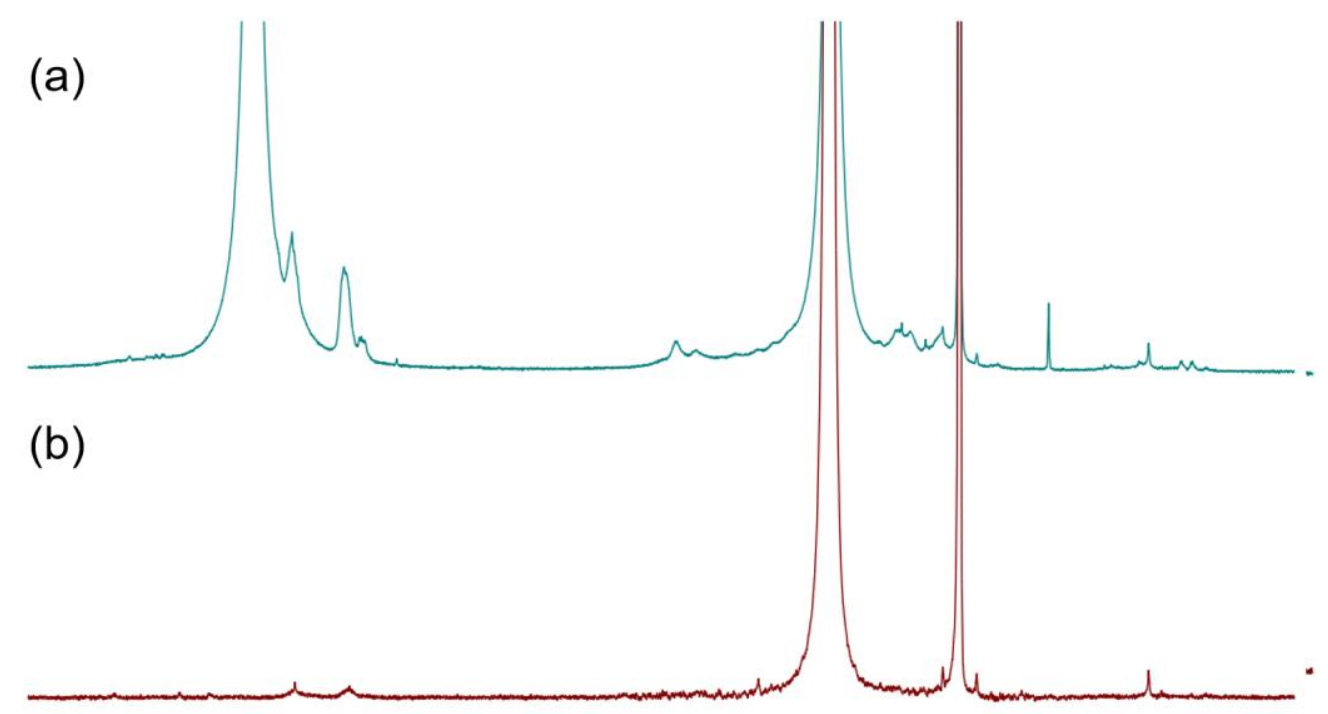

$\begin{array}{llllllllllllllll}8.5 & 8.0 & 7.5 & 7.0 & 6.5 & 6.0 & 5.5 & 5.0 \underset{\mathrm{f} 1(\mathrm{ppm})}{4.5} & 4.0 & 3.5 & 3.0 & 2.5 & 2.0 & 1.5 & 1.0 & 0.5\end{array}$

Figure S10. ${ }^{1} \mathrm{H}$ NMR spectra (600 MHz, DMSO- $d_{6}, 298 \mathrm{~K}$ ) of (a) P6-CYYY and (b) PPN. 


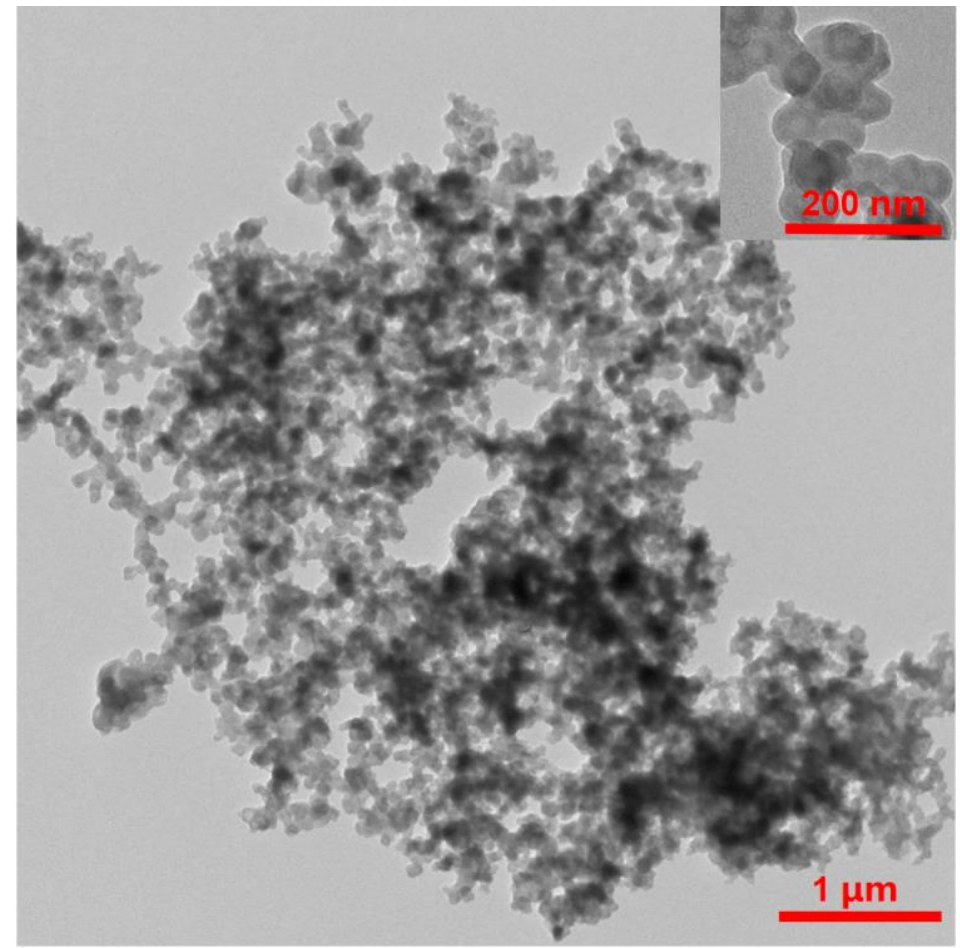

Figure S11. TEM image of PPN, produced from $0.500 \mathrm{mg} / \mathrm{mL}$ of P6-CYYY.

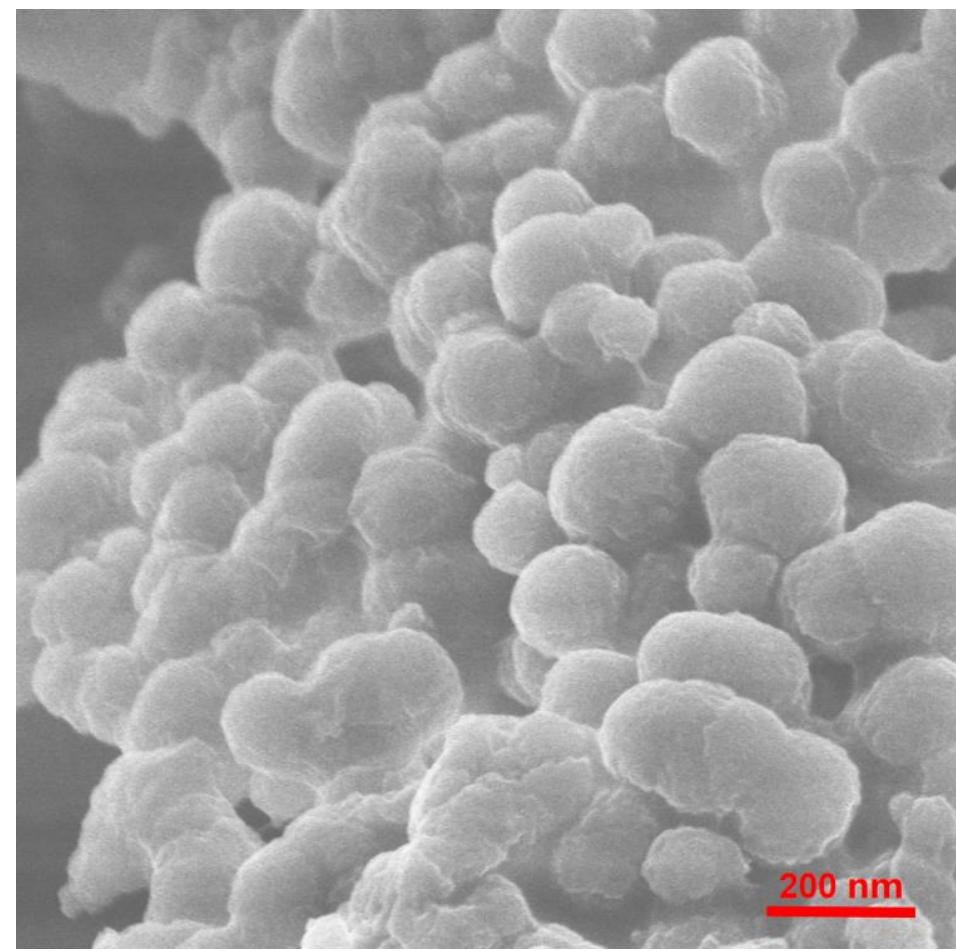

Figure S12. SEM image of PPN, produced from $0.500 \mathrm{mg} / \mathrm{mL}$ of P6-CYYY. 


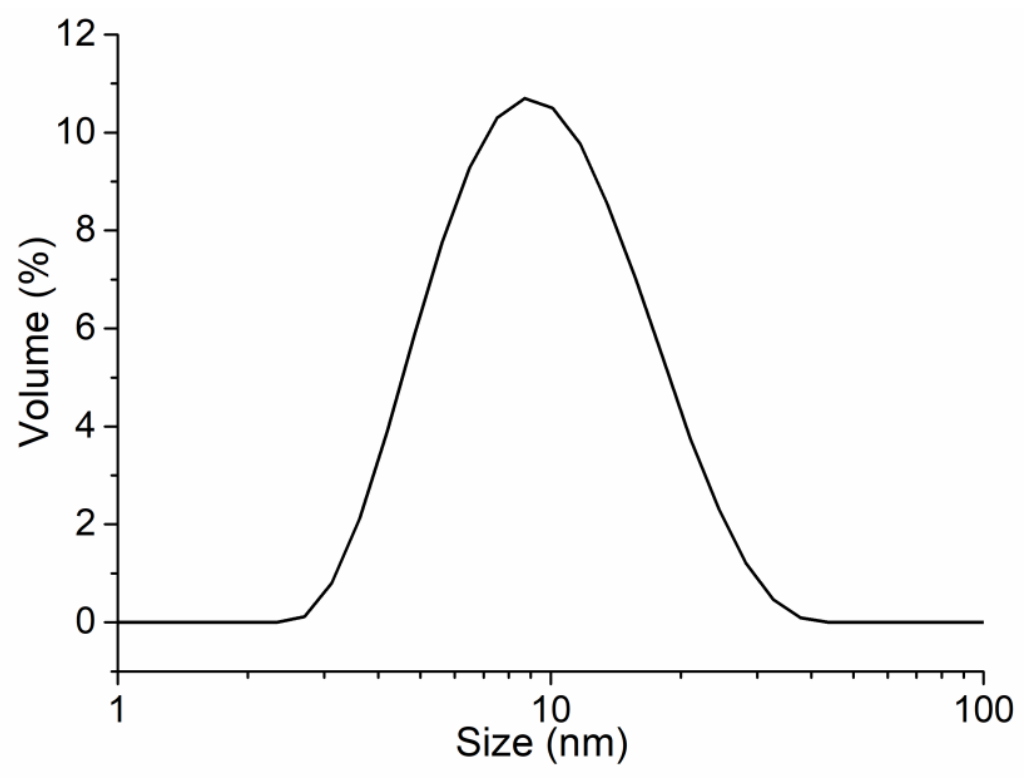

Figure S13. Size distribution of PPN measured by DLS, produced from $0.500 \mathrm{mg} / \mathrm{mL}$ of P6-CYYY. The size of the nanoparticles was $10.6 \pm 0.500 \mathrm{~nm}$.

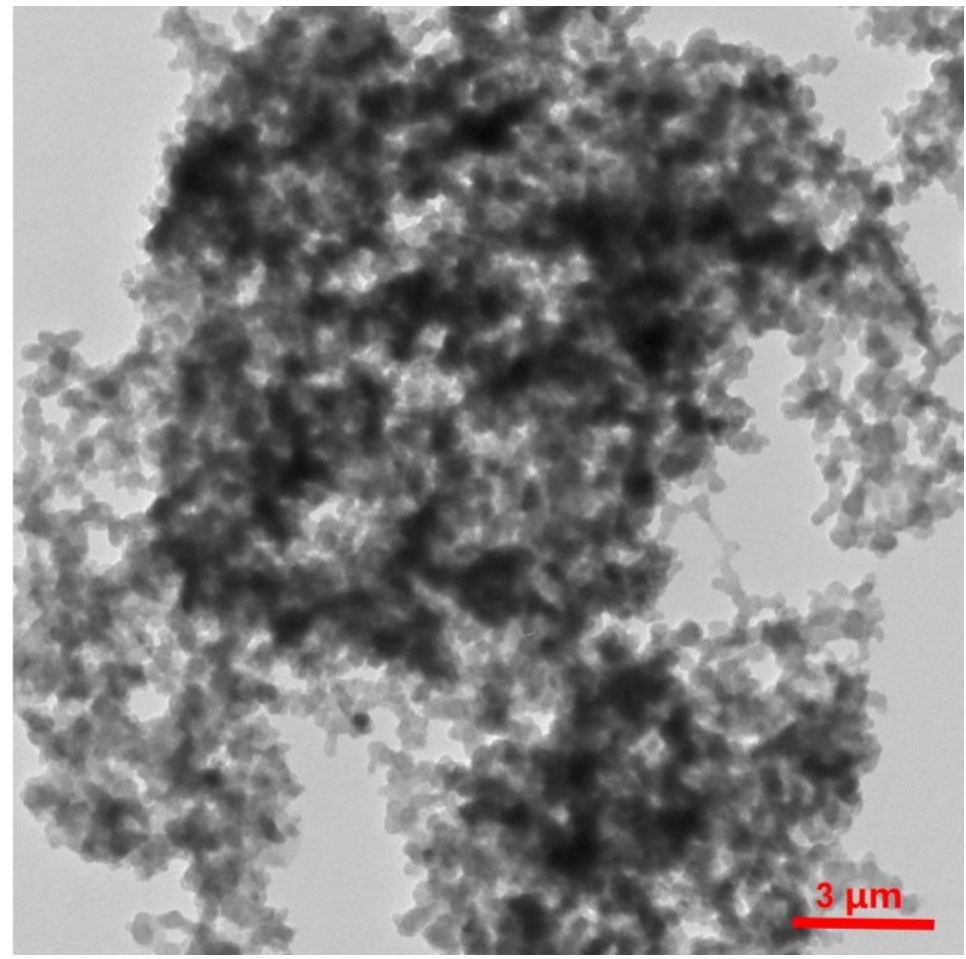

Figure S14. TEM image of ill-defined PPN nanostructures. The high concentration of P6-CYYY (30.0 $\mathrm{mg} / \mathrm{mL}$ ) led to aggregates of ill-defined nanostructures. 


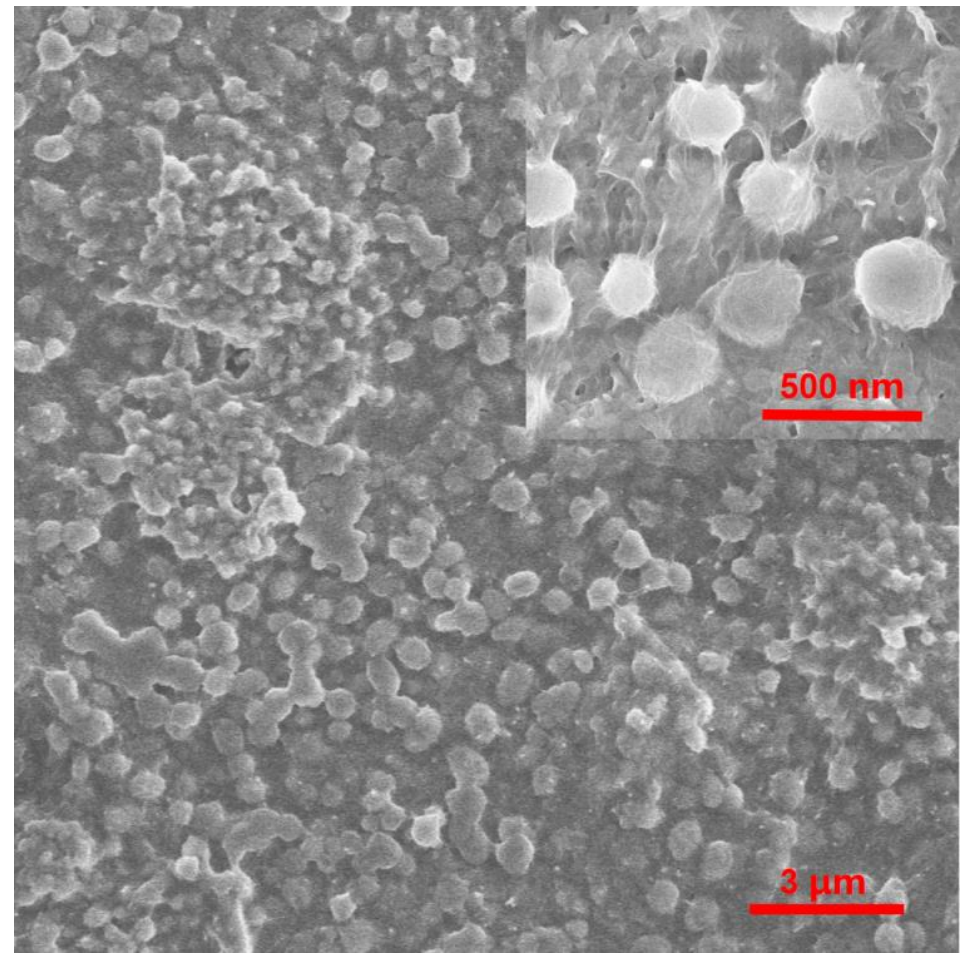

Figure S15. SEM image of ill-defined PPN nanostructures. The high concentration of P6-CYYY (30.0 $\mathrm{mg} / \mathrm{mL}$ ) led to aggregates of ill-defined nanostructures.

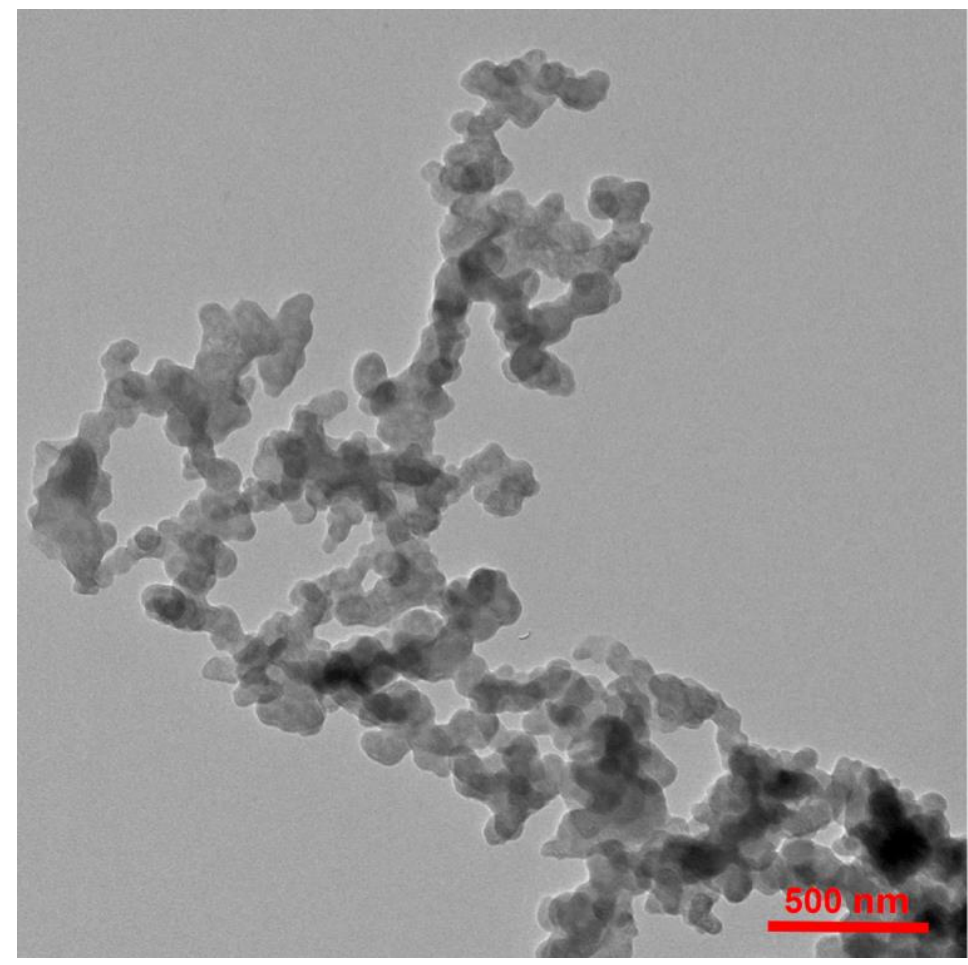

Figure S16. TEM image of ill-defined PPN nanostructures. The low concentration of P6-CYYY (0.100 $\mathrm{mg} / \mathrm{mL}$ ) led to irregular morphology of ill-defined nanostructures. 


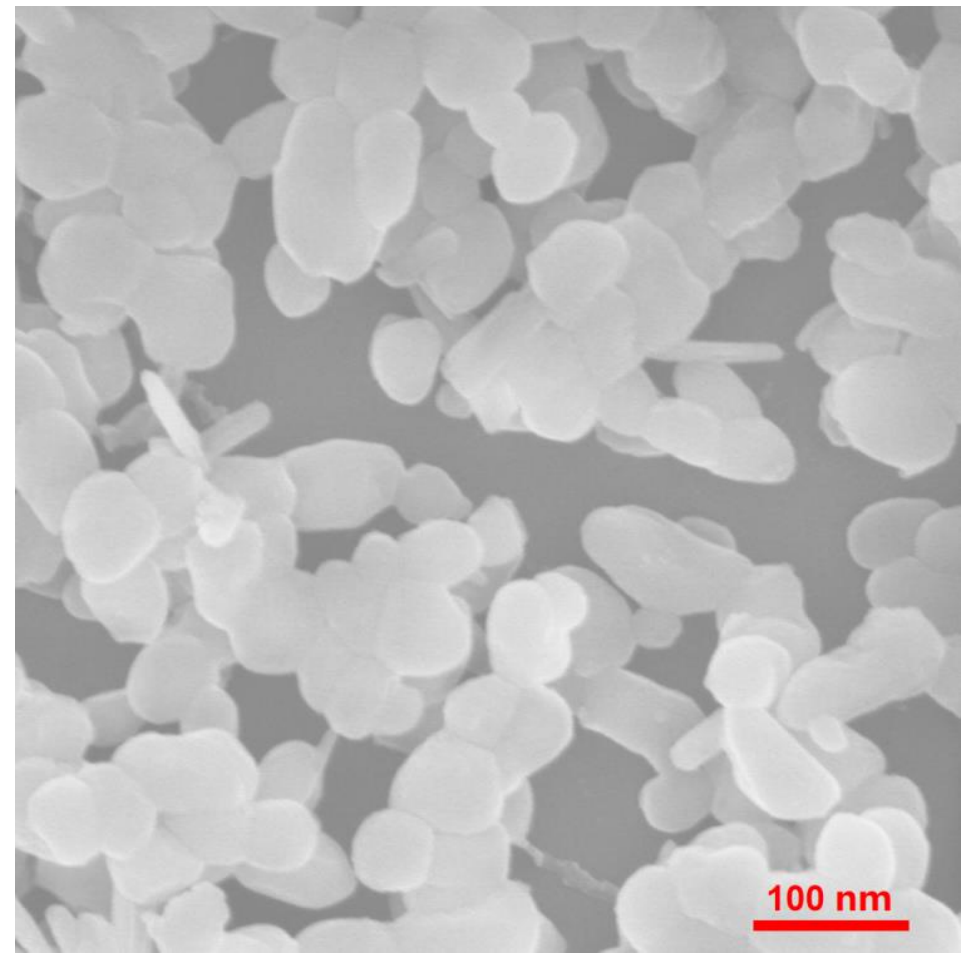

Figure S17. SEM image of ill-defined PPN nanostructures. The low concentration of P6-CYYY (0.100 $\mathrm{mg} / \mathrm{mL}$ ) led to irregular morphology of ill-defined nanostructures.

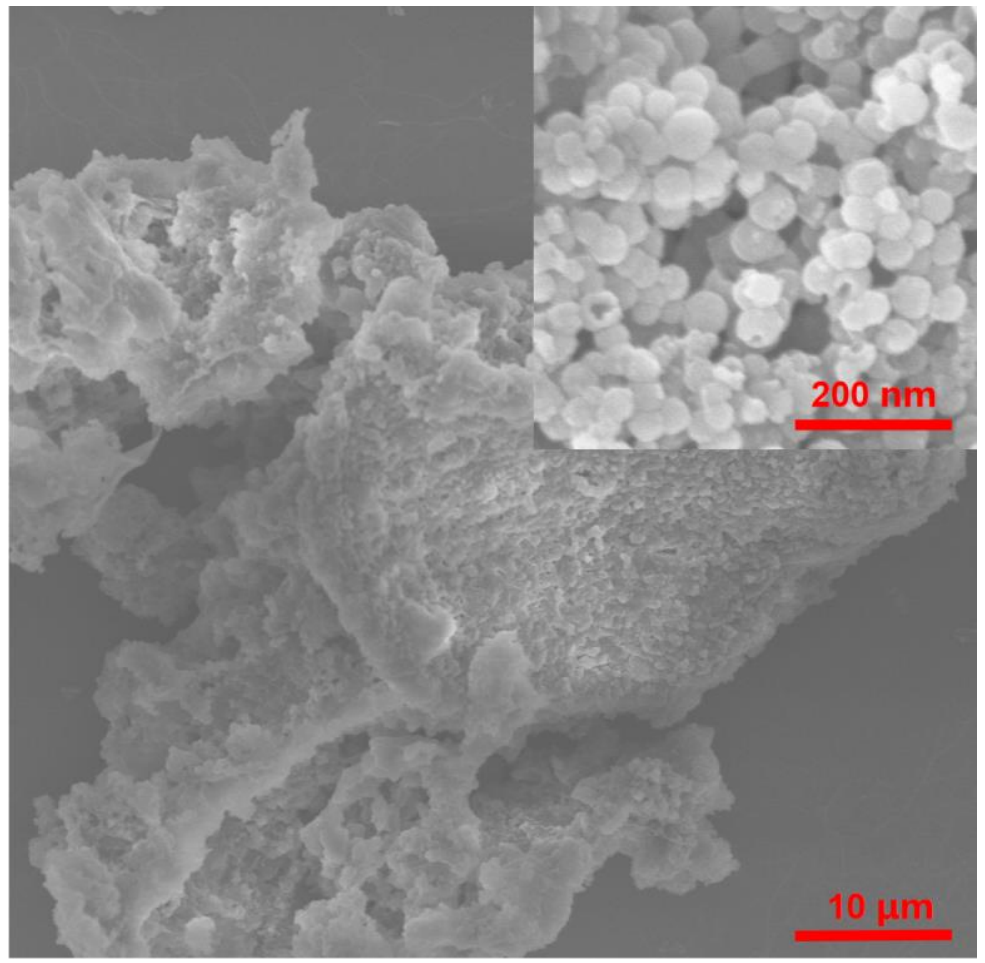

Figure S18. SEM image of PPN nanostructures produced from $1.00 \mathrm{mg} / \mathrm{mL}$ of P6-CYYY, indicating that PPN could be produced in a large scale. 
5. Characterizations of $\boldsymbol{D P B}$

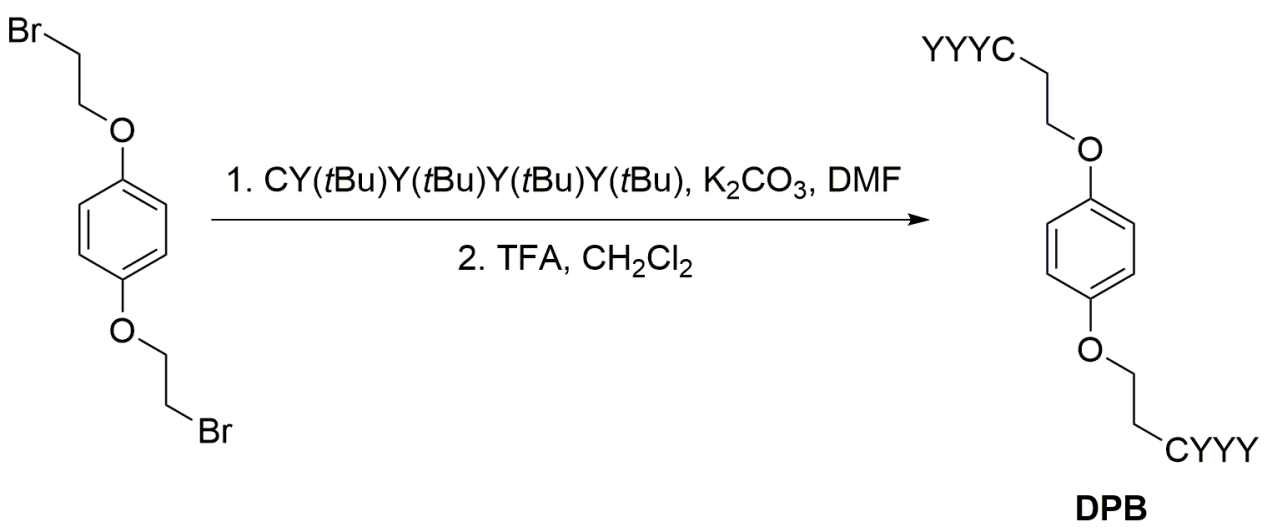

Scheme S2. Synthetic route of DPB.

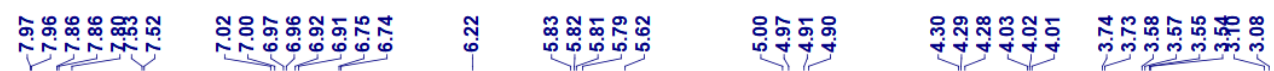

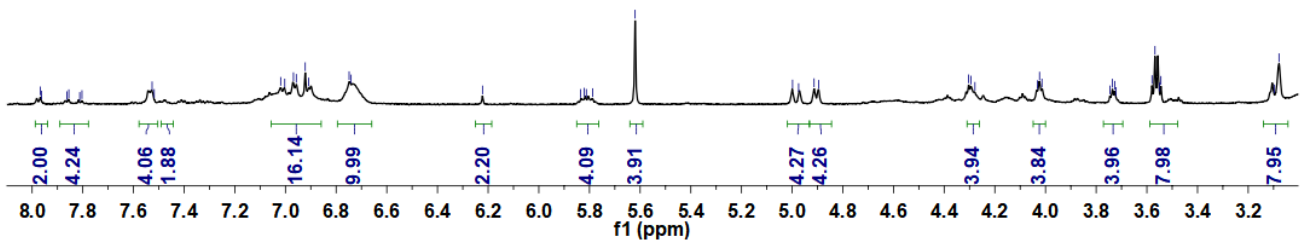

Figure S19. ${ }^{1} \mathrm{H}$ NMR spectra $\left(600 \mathrm{MHz}\right.$, acetone- $\left.d_{6}, 298 \mathrm{~K}\right)$ of DPB. 


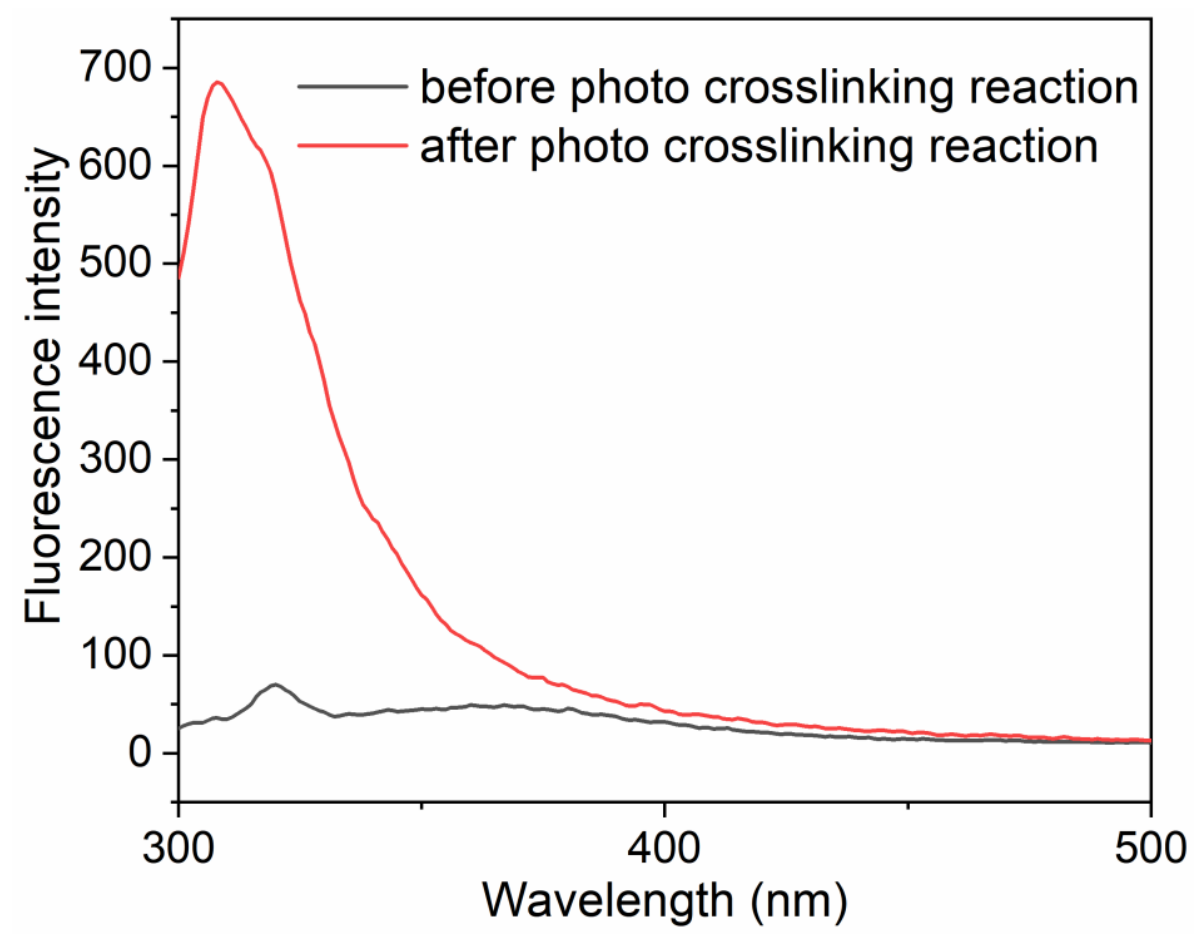

Figure S20. Fluorescence spectra of DPB before and after photo crosslinking reaction $(1.00 \mathrm{mg} / \mathrm{mL})$.

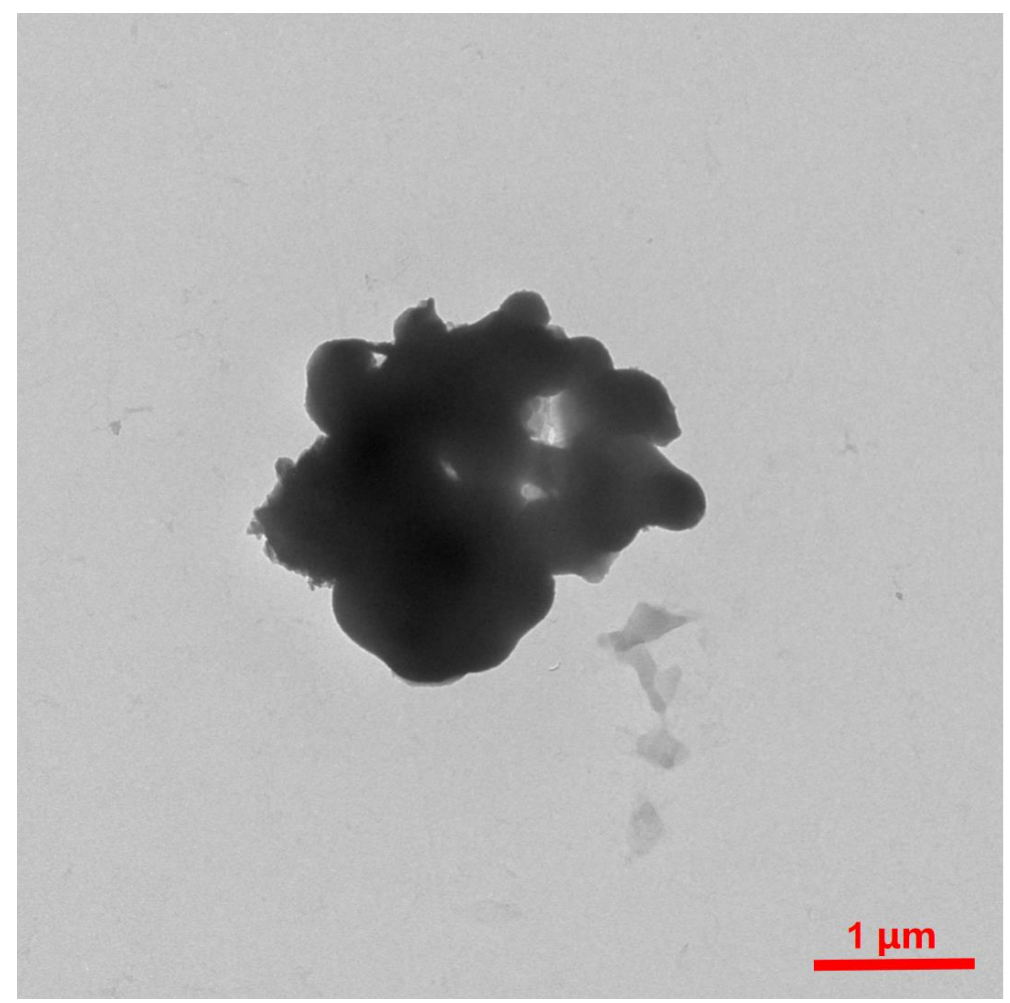

Figure S21. TEM image of DPB $(1.00 \mathrm{mg} / \mathrm{mL})$. 


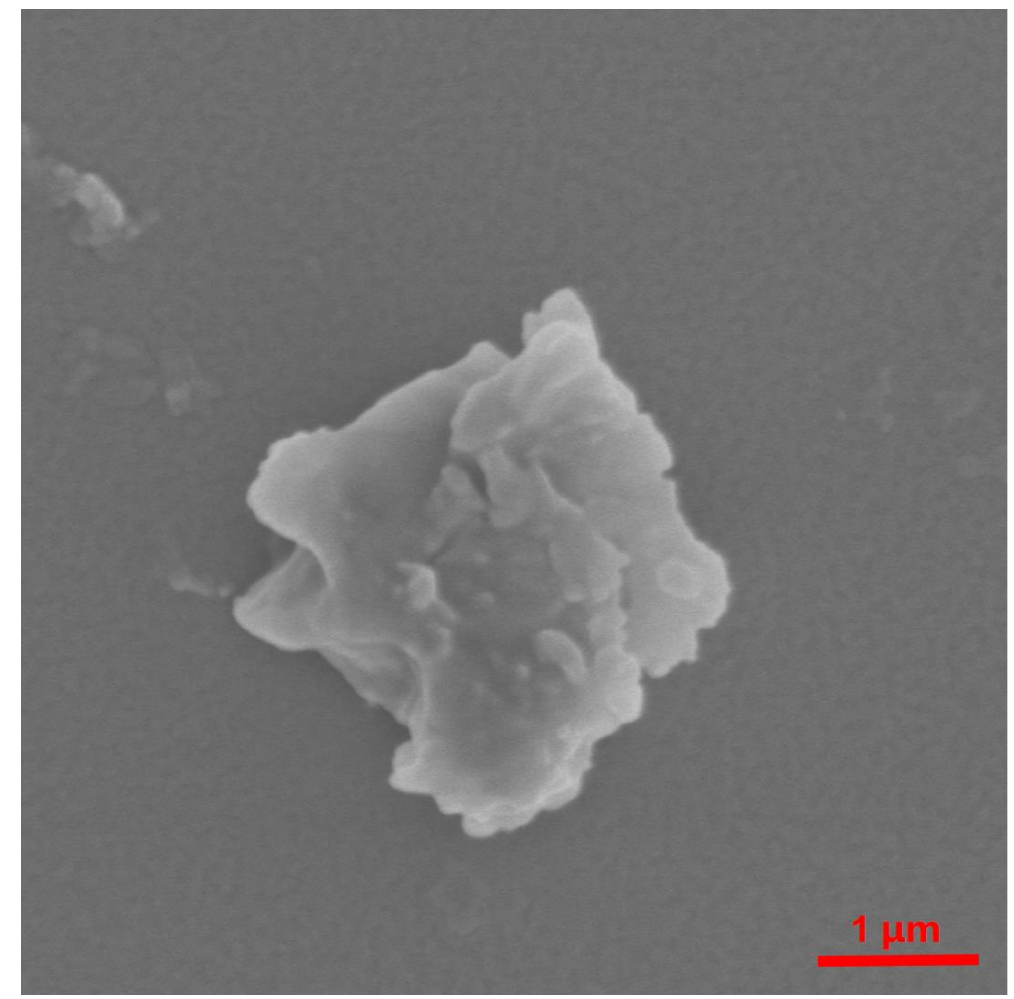

Figure S22. SEM image of DPB $(1.00 \mathrm{mg} / \mathrm{mL})$.

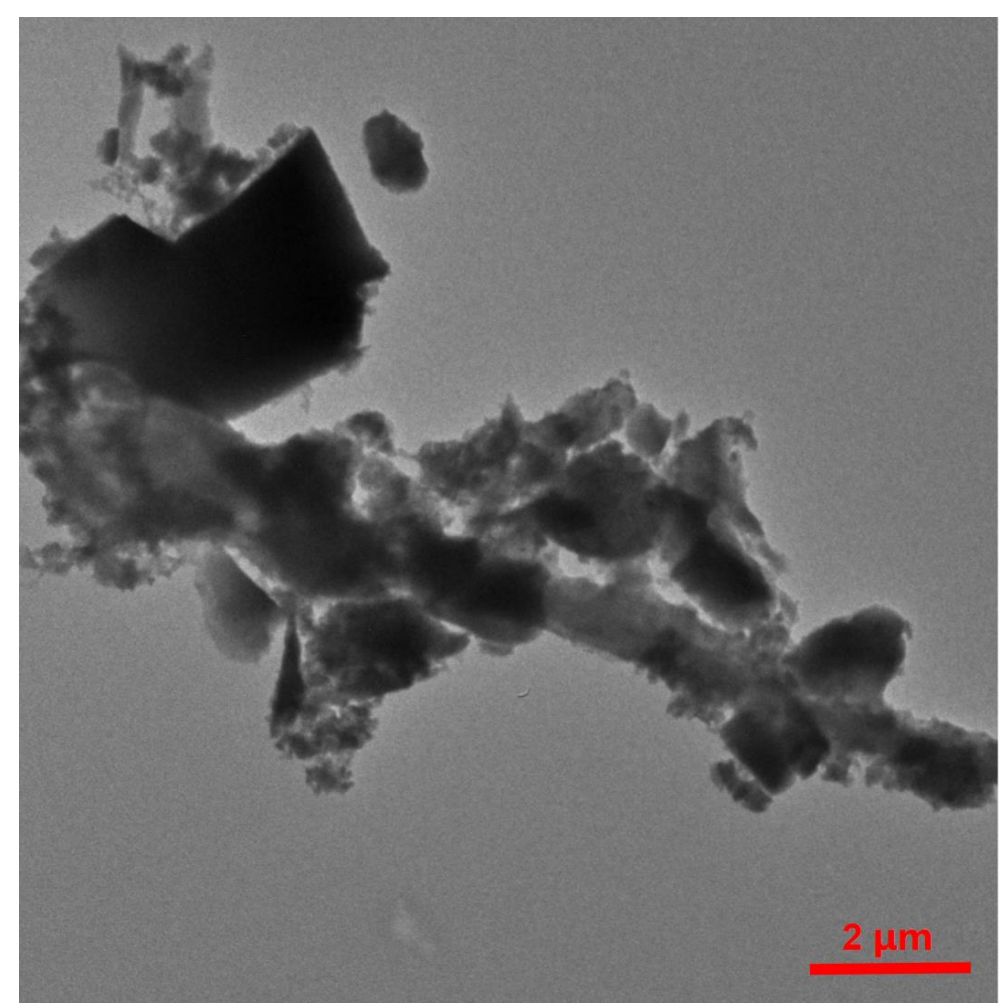

Figure S23. TEM image of the assemblies prepared by the crosslinking reaction of DPB. 


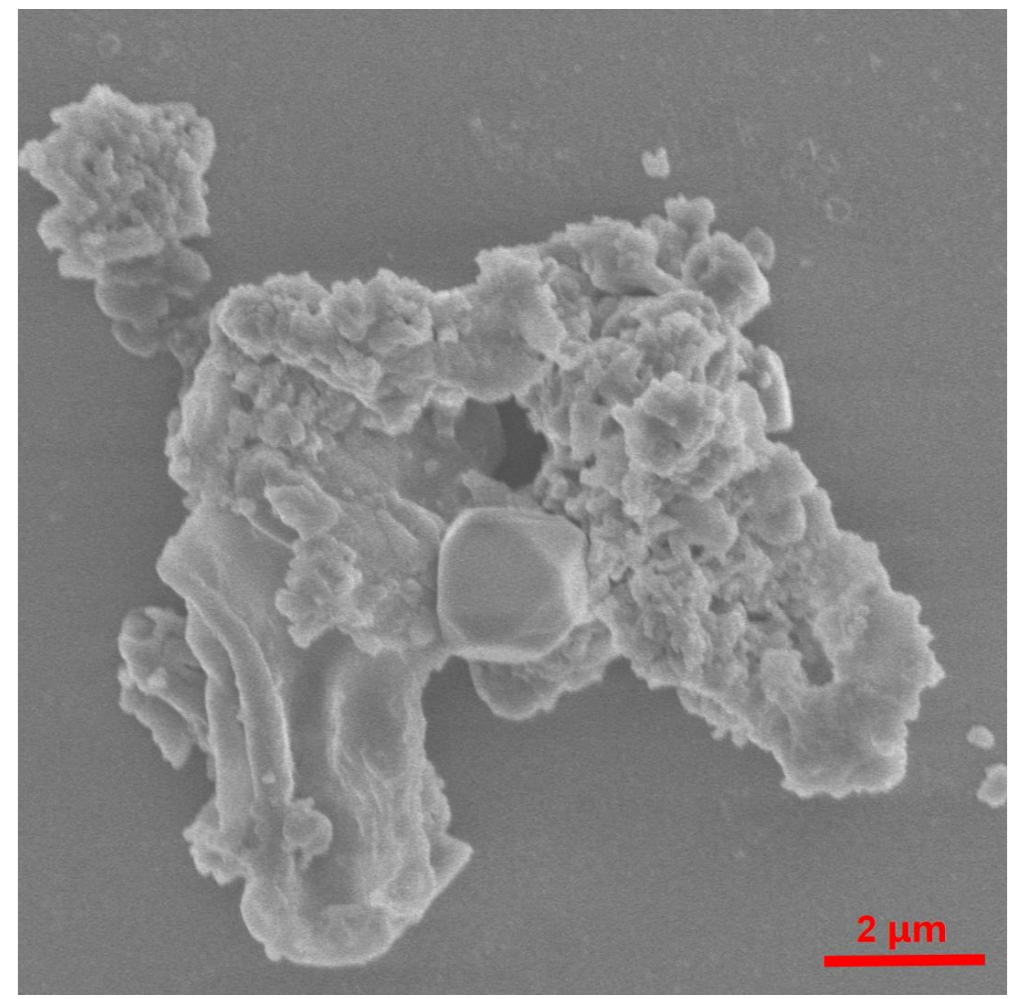

Figure S24. SEM image of the assemblies prepared by the crosslinking reaction of DPB.

\section{Characterizations of Pt/PPN}

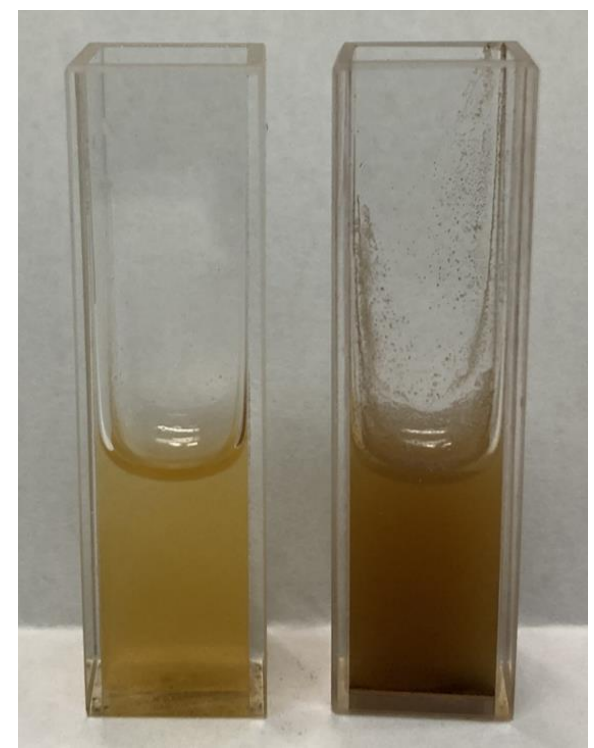

Figure S25. Photos of PPN solution (left) and Pt/PPN hybrid solution (right) at $1.00 \mathrm{mg} / \mathrm{mL}$. 


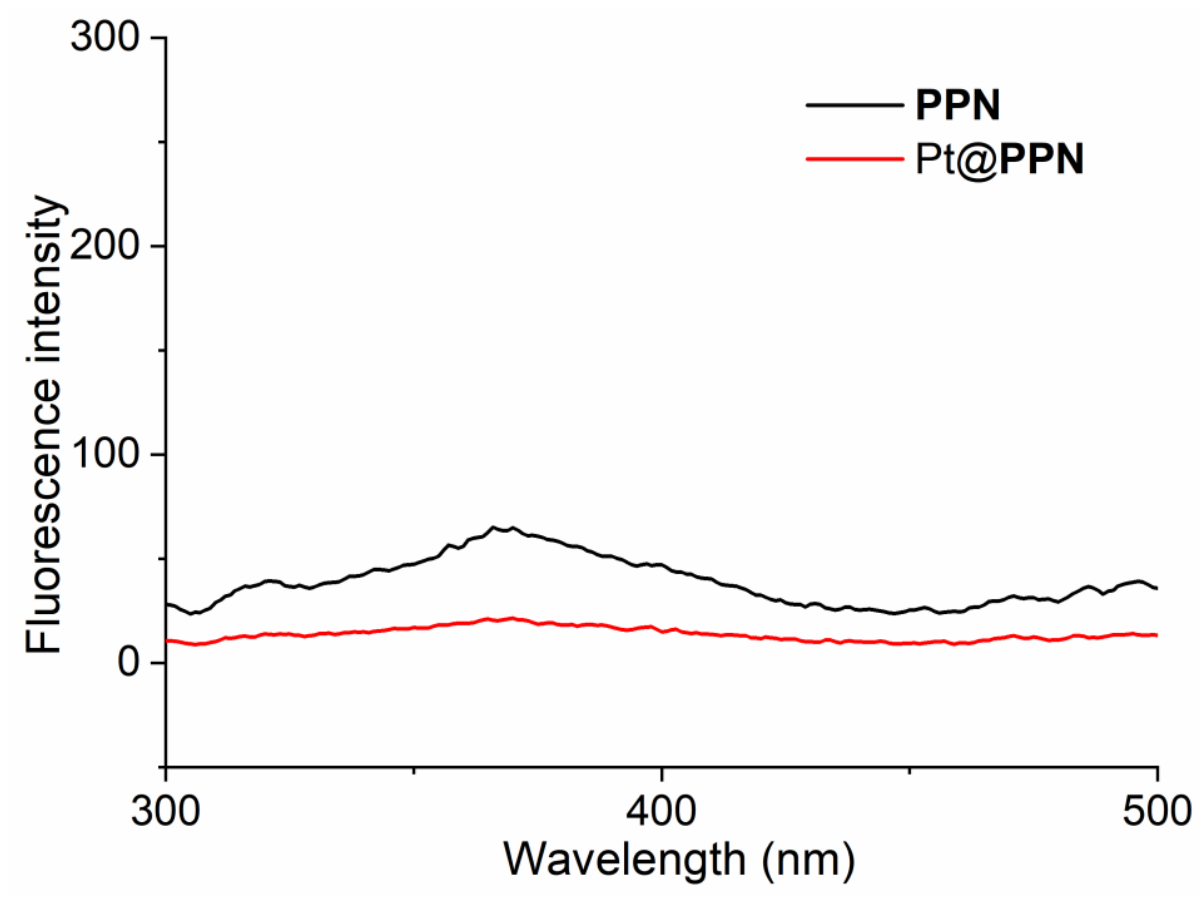

Figure S26. Fluorescence spectra of PPN and Pt/PPN hybrid $(1.00 \mathrm{mg} / \mathrm{mL})$.

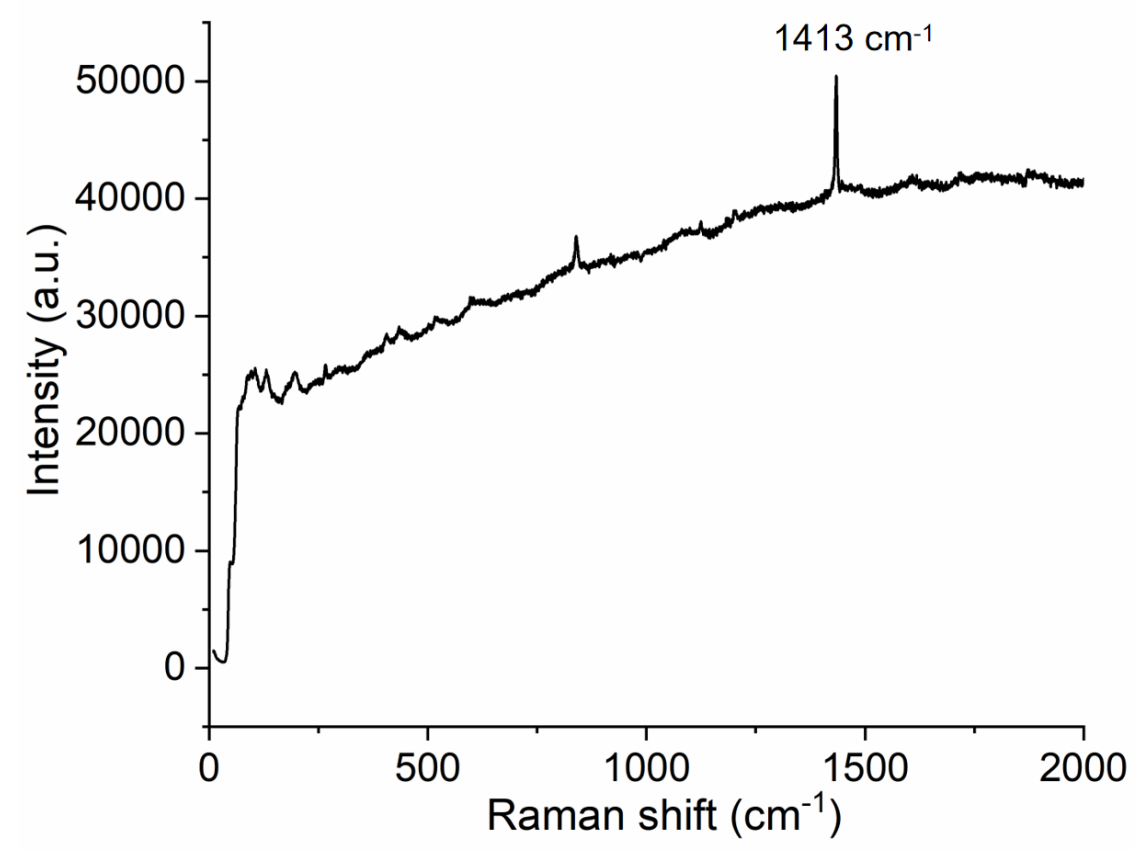

Figure S27. Raman spectrum of solid sample of Pt/PPN. 


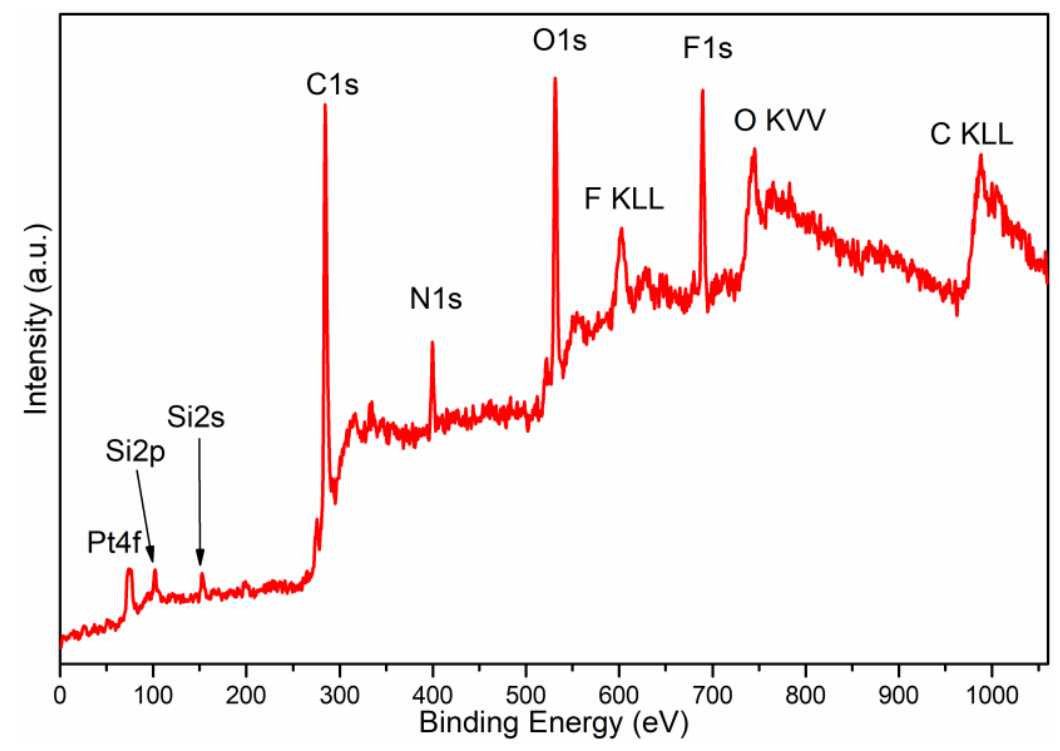

Peak Analysis

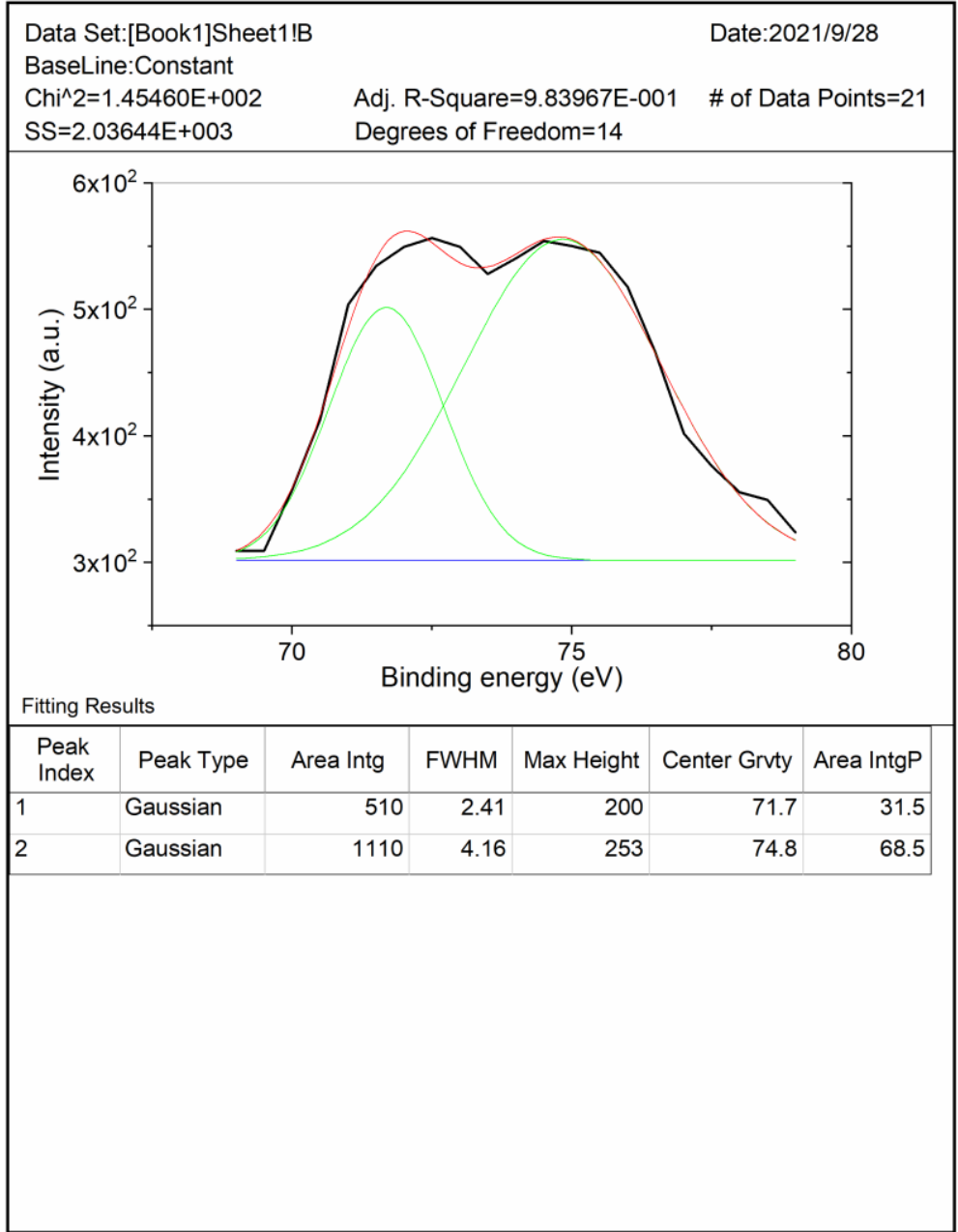

Figure S28. XPS spectrum of Pt/PPN hybrid and partial spectrum after peak analysis. 


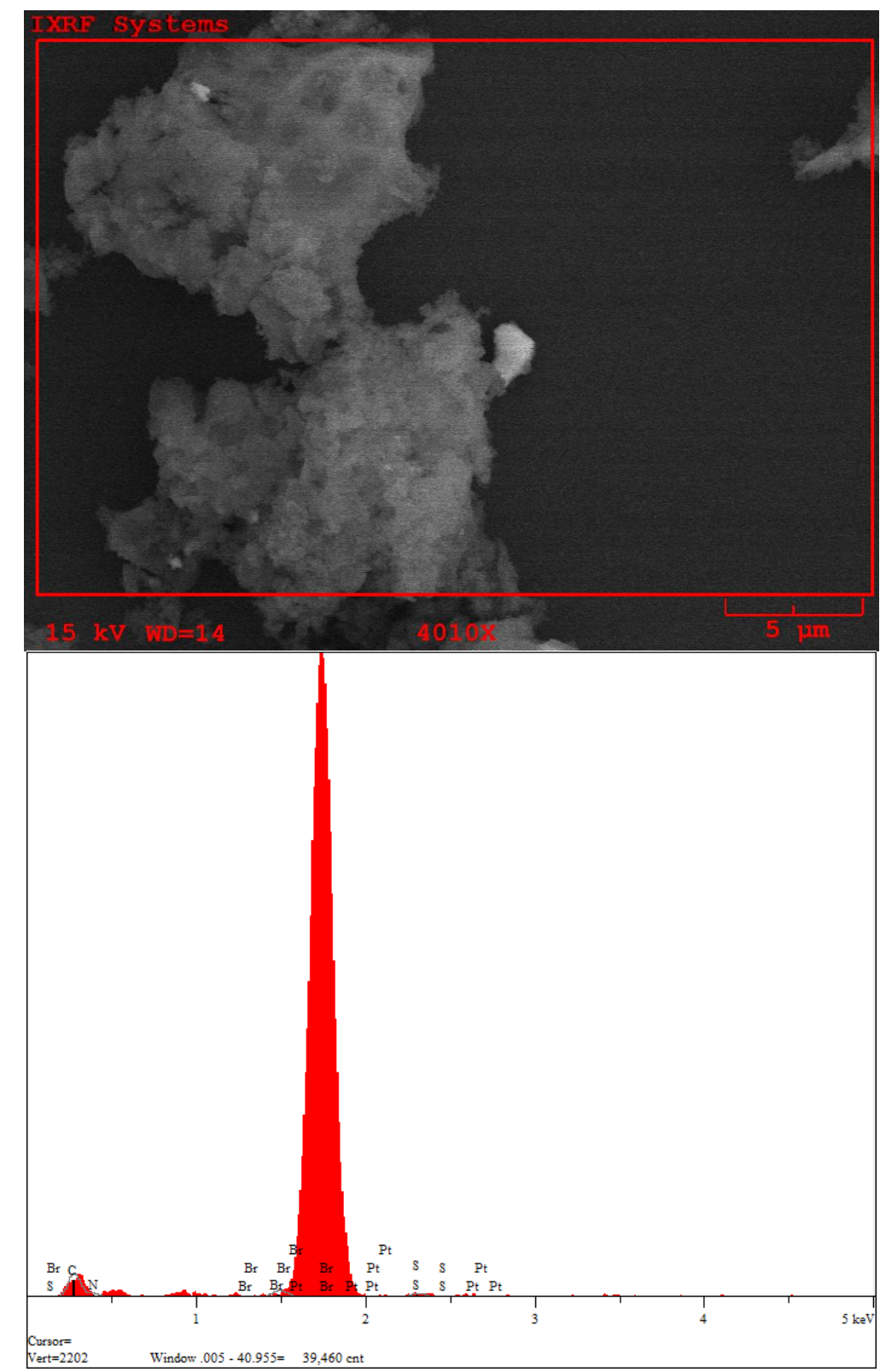

\begin{tabular}{|c|c|c|c|c|c|c|}
\hline Elt. & Line & Intensity(c/s) & Atomic \% & Conc. (wt.\%) & Error2-sig & MDL3-sig \\
\hline $\mathrm{C}$ & $\mathrm{Ka}$ & 36.3 & 65 & 26 & 3 & 3 \\
\hline $\mathrm{N}$ & $\mathrm{Ka}$ & 5.4 & 14 & 7 & 3 & 3 \\
\hline $\mathrm{S}$ & $\mathrm{Ka}$ & 6.9 & 1 & 1 & 0.4 & 0.5 \\
\hline $\mathrm{Br}$ & $\mathrm{Ka}$ & 1.3 & 18 & 47 & 19 & 28 \\
\hline $\mathrm{Pt}$ & $\mathrm{La}$ & 1.4 & 3 & 18 & 11 & 12 \\
\hline
\end{tabular}

Figure S29. EDX analysis of Pt/PPN. The SEM image showed the areas for EDX analysis. The spectrum showed the analyzed elements, and the table showed the approximate content of each element. The peaks of platinum indicated the platinum species were successfully loaded within the materials. The peaks of bromine were ascribed to the unreacted 2-bromoethyl group in BrP6. The peaks of silicon came from the silicon wafer used in SEM. 


\begin{tabular}{|c|c|c|}
\hline Sample Id & $\mathbf{P t}(\mathbf{p p m})$ & $\mathbf{P t}(\mathbf{m g} / \mathbf{m l})$ \\
\hline $\mathrm{Pt} / \mathbf{P P N}-1$ & 57.2 & 0.0572 \\
\hline $\mathrm{Pt} / \mathbf{P P N}-2$ & 57.3 & 0.0573 \\
\hline $\mathrm{Pt} / \mathbf{P P N}-3$ & 57.0 & 0.0570 \\
\hline average & 57.2 & 0.0572 \\
\hline
\end{tabular}

Figure S30. ICP-MS analysis of solution for evaluating the amount of Pt catalyst loading. The solution was diluted for ICP-MS analysis.

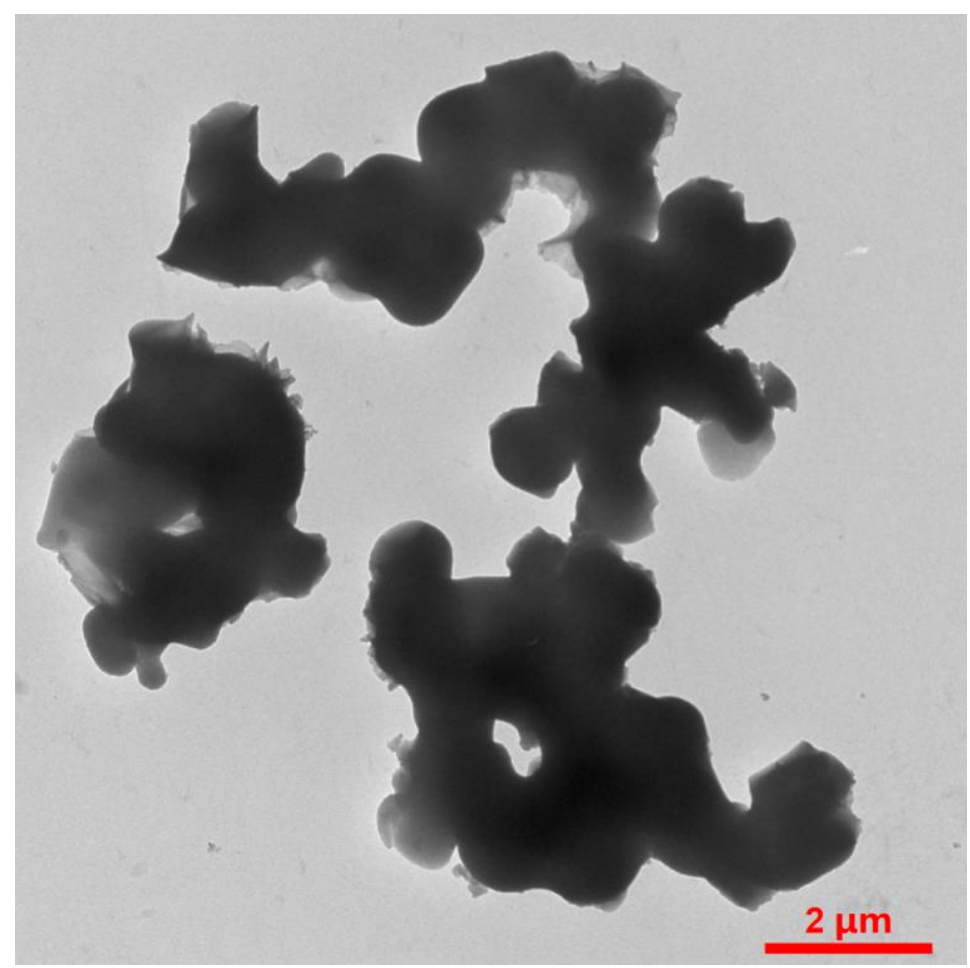

Figure S31. TEM image of Pt/PPN aggregates produced from directly mixing P6-CYYY (1.00 mg/mL) with $\mathrm{PtCl}_{2}(0.100 \mathrm{mg} / \mathrm{mL})$ solution without the prior formation of PPN after irradiation of visible light for $30 \mathrm{~min}$ and UV for $30 \mathrm{~min}$, respectively. 


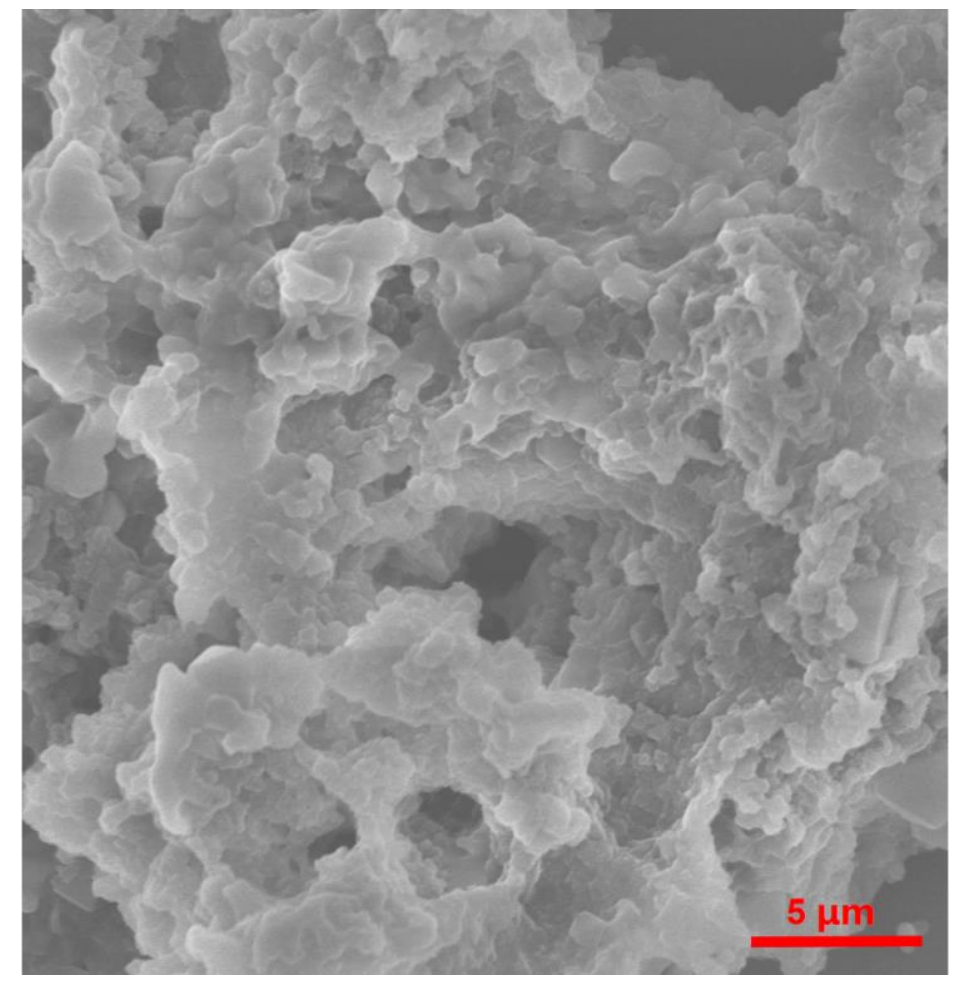

Figure S32. SEM image of Pt/PPN aggregates produced from directly mixing P6-CYYY (1.00 mg/mL) with $\mathrm{PtCl}_{2}(0.100 \mathrm{mg} / \mathrm{mL})$ solution without the prior formation of PPN after irradiation of visible light for $30 \mathrm{~min}$ and UV for $30 \mathrm{~min}$, respectively.

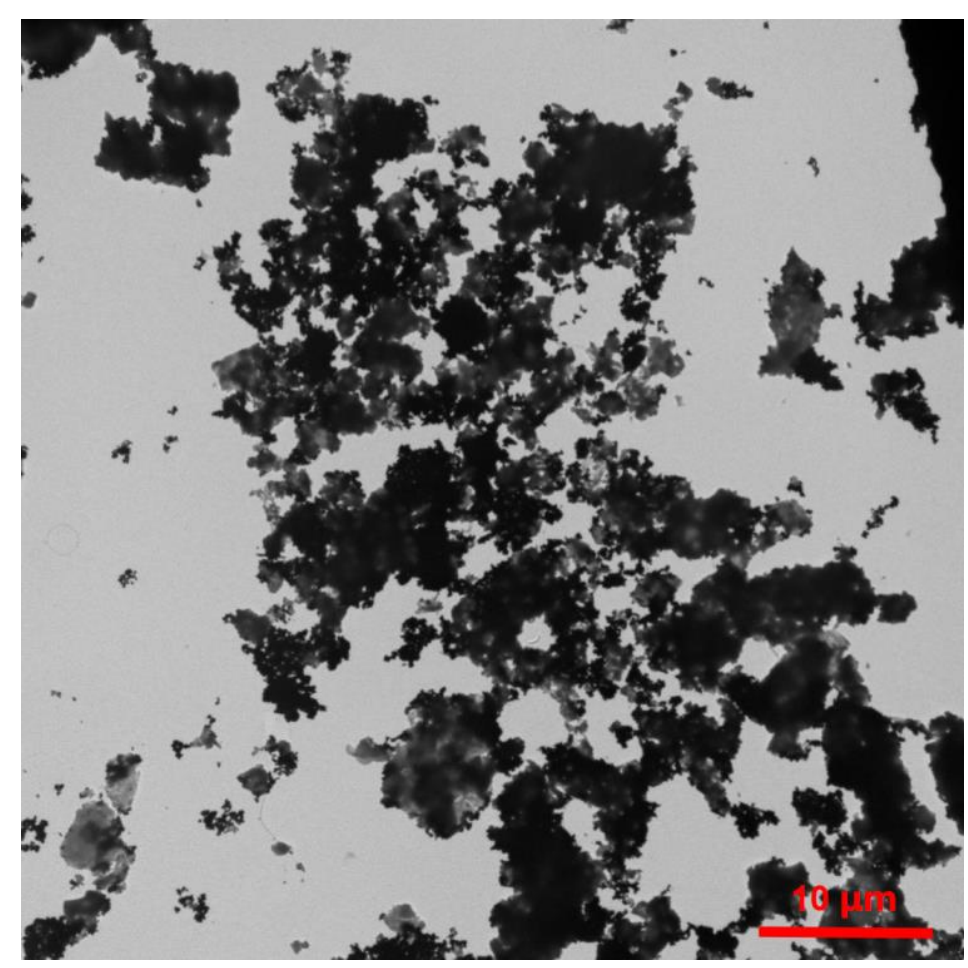

Figure S33. TEM image of ill-defined Pt/PPN. The high concentration of $\mathrm{PtCl}_{2}(10.0 \mathrm{mM})$ led to irregular aggregates of the ill-defined Pt/PPN nanostructure. The concentration of PPN was $1.00 \mathrm{mg} / \mathrm{mL}$. 


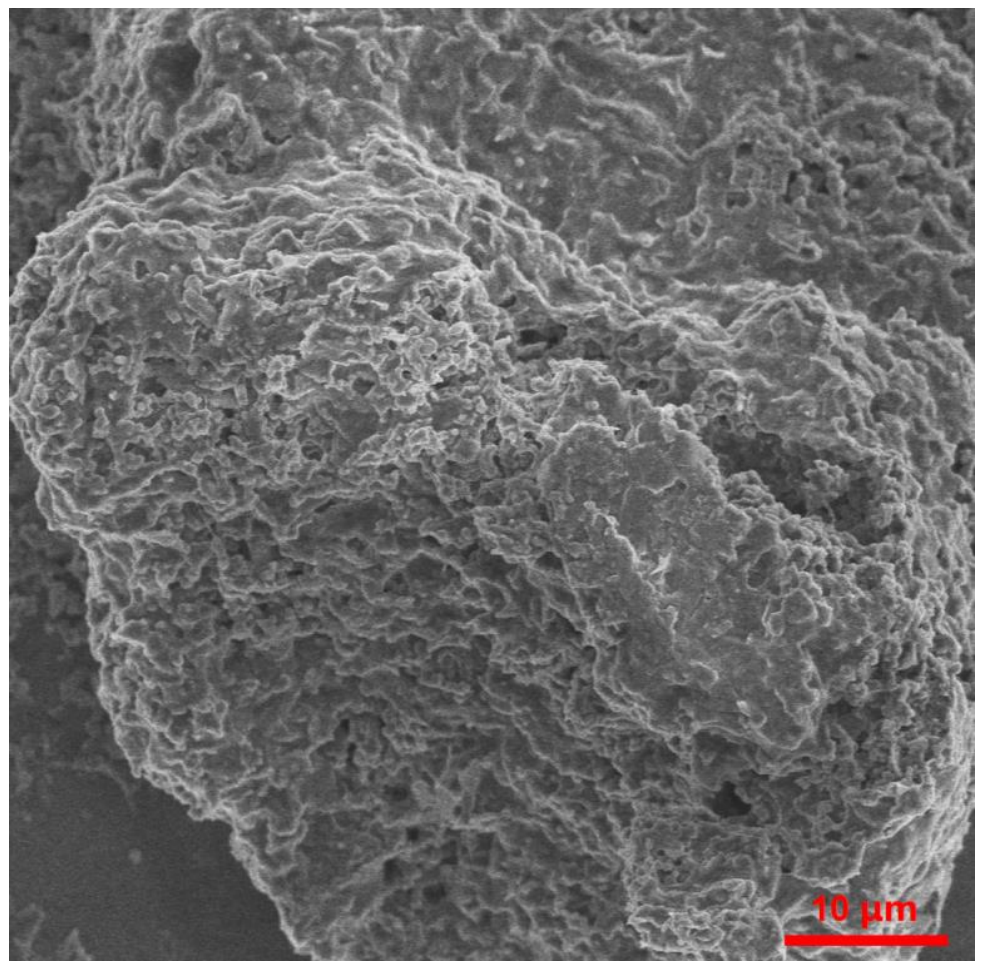

Figure S34. SEM image of ill-defined Pt/PPN. The high concentration of $\mathrm{PtCl}_{2}(10.0 \mathrm{mM})$ led to aggregates of the ill-defined Pt/PPN nanostructure. The concentration of PPN was $1.00 \mathrm{mg} / \mathrm{mL}$.

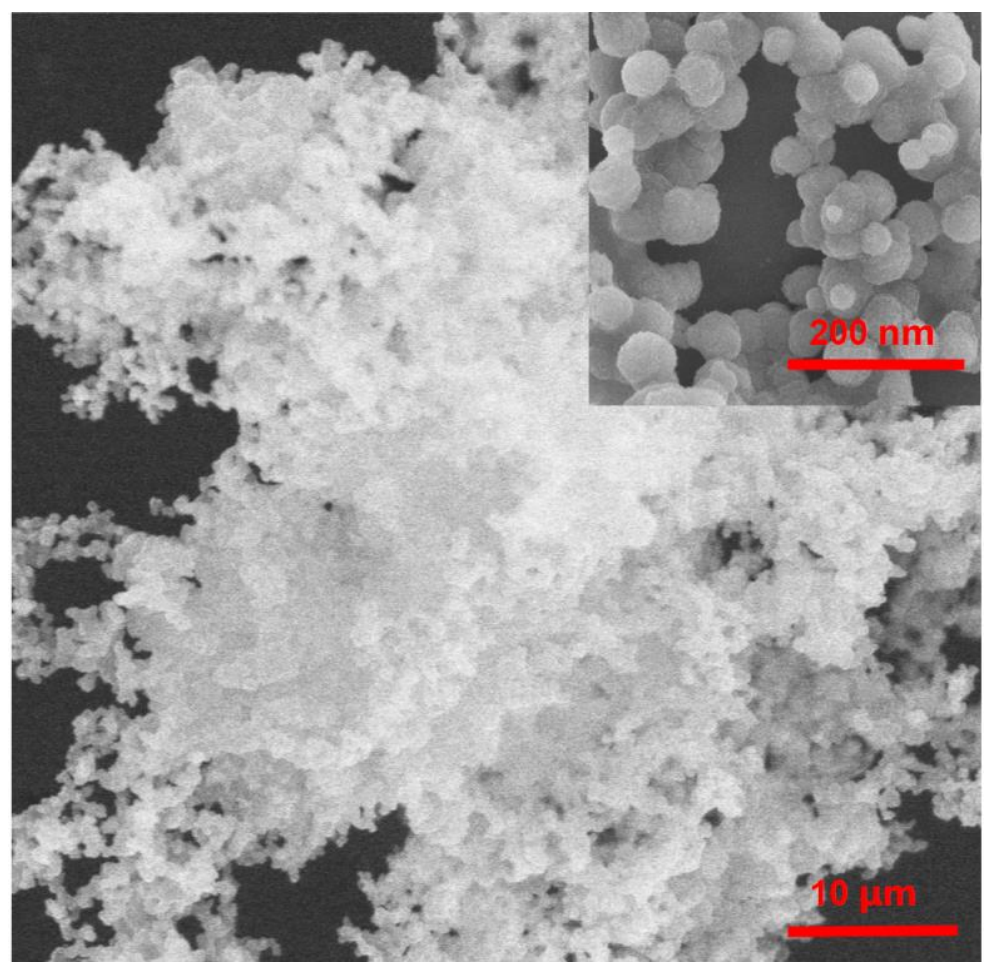

Figure S35. SEM image of Pt/PPN. The concentration of $\mathrm{PtCl}_{2}$ was $0.100 \mathrm{mM}$. The concentration of PPN was $1.00 \mathrm{mg} / \mathrm{mL}$. 


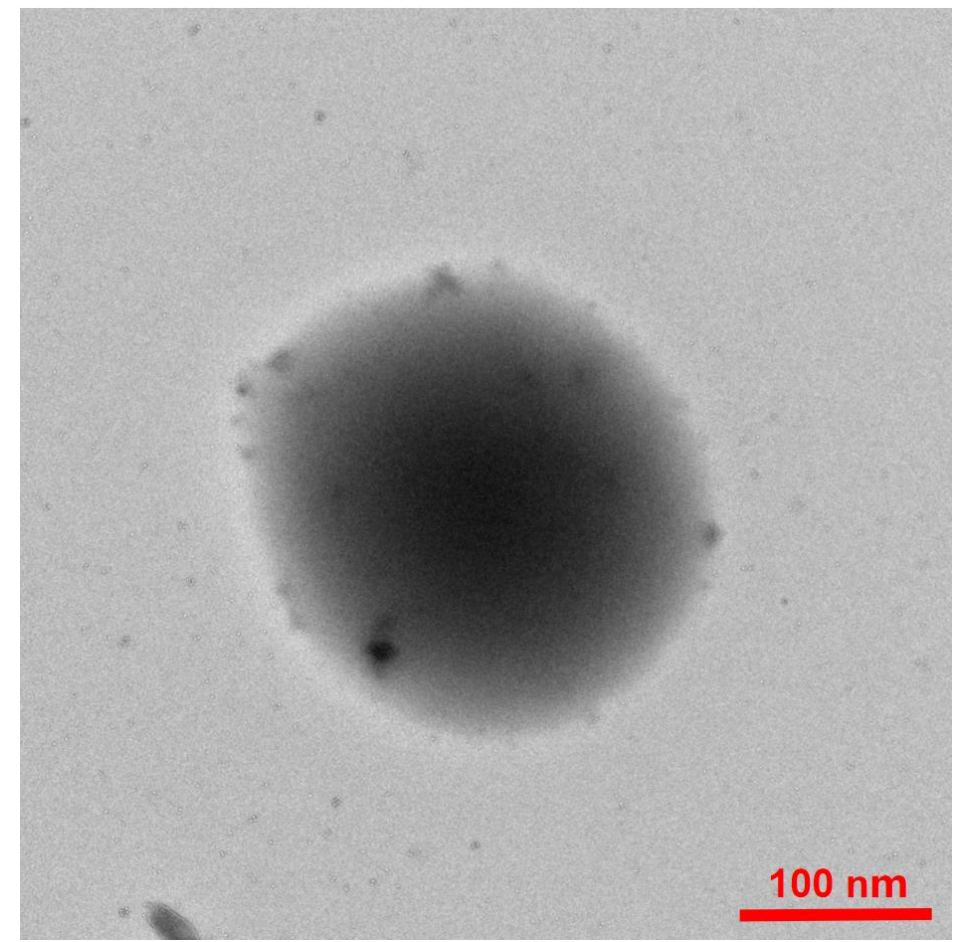

Figure S36. TEM image of Pt/PPN. The concentration of $\mathrm{PtCl}_{2}$ was $0.100 \mathrm{mM}$. The concentration of PPN was $1.00 \mathrm{mg} / \mathrm{mL}$.

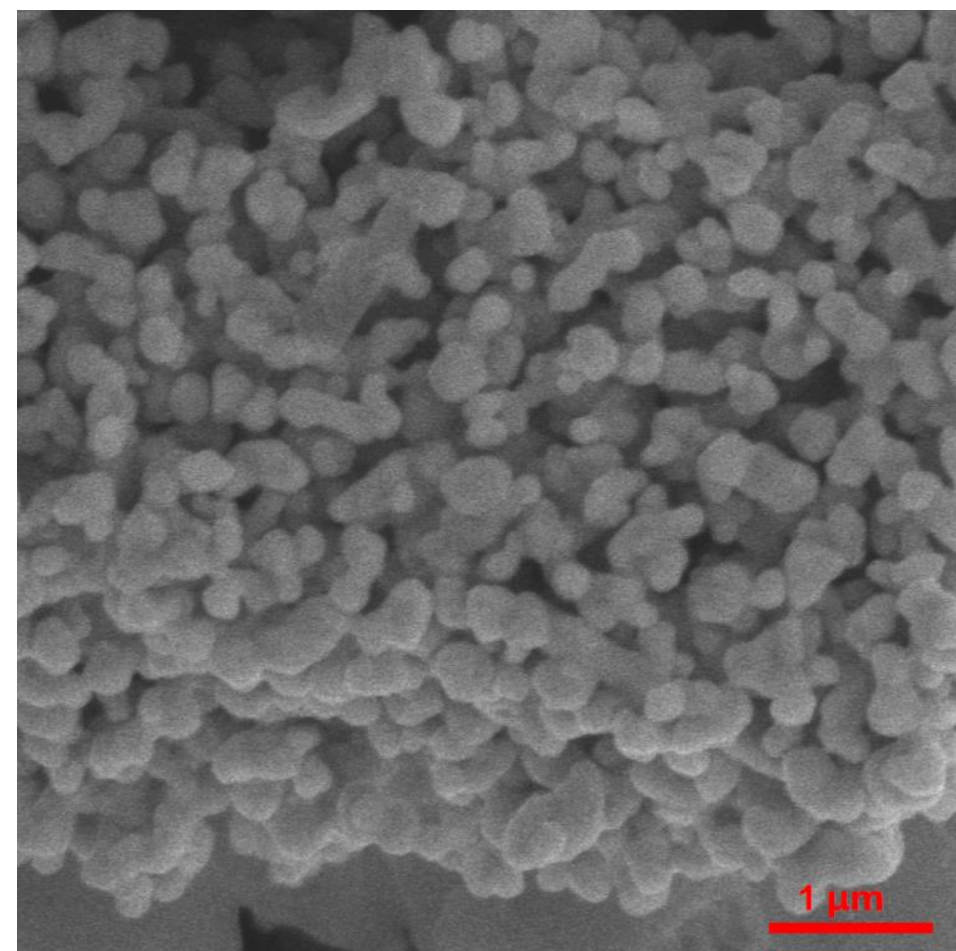

Figure S37. SEM image of less uniform Pt/PPN. The concentration of $\mathrm{PtCl}_{2}$ was $1.00 \mathrm{mM}$. The concentration of PPN was $10.0 \mathrm{mg} / \mathrm{mL}$. 
7. Catalytic reduction of p-nitrophenol

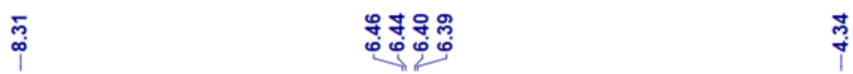
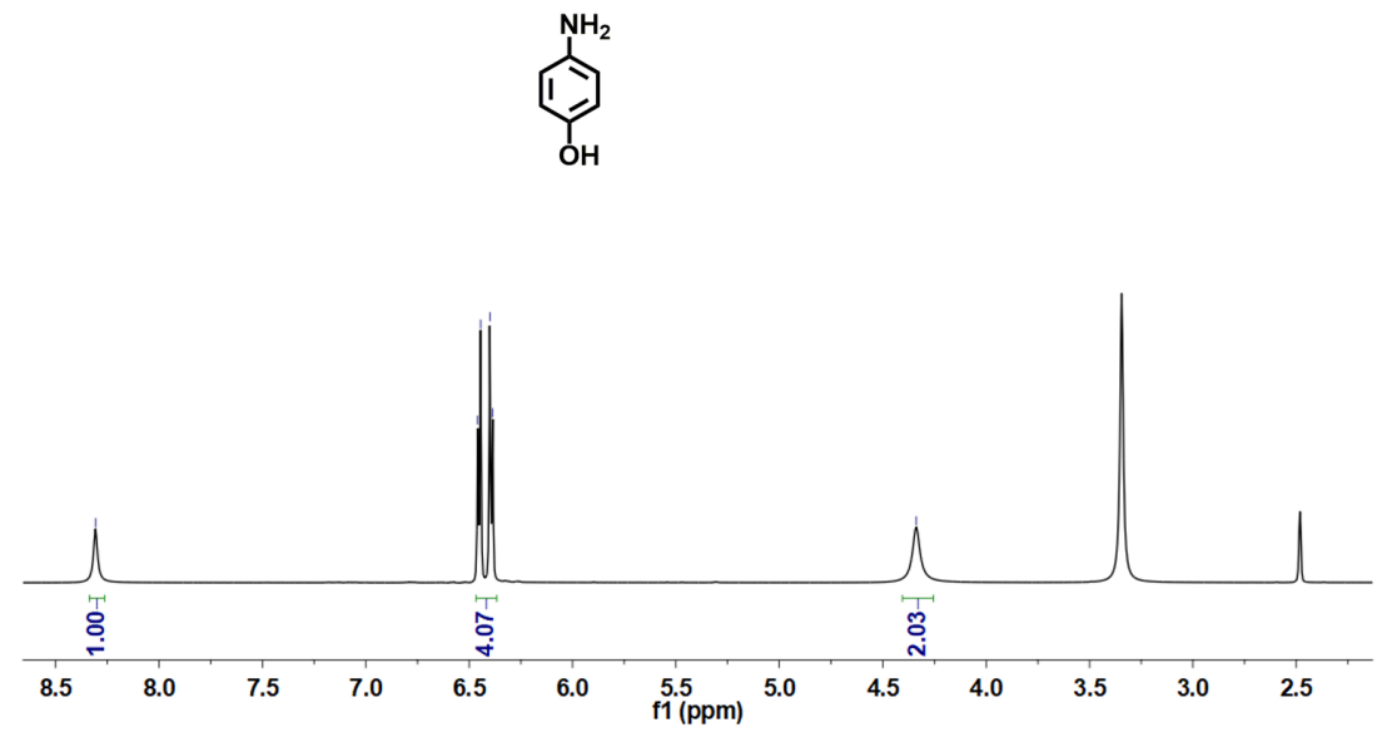

Figure S38. ${ }^{1} \mathrm{H}$ NMR spectrum $\left(600 \mathrm{MHz}, \mathrm{DMSO}-d_{6}, 298 \mathrm{~K}\right)$ of $p$-aminophenol.

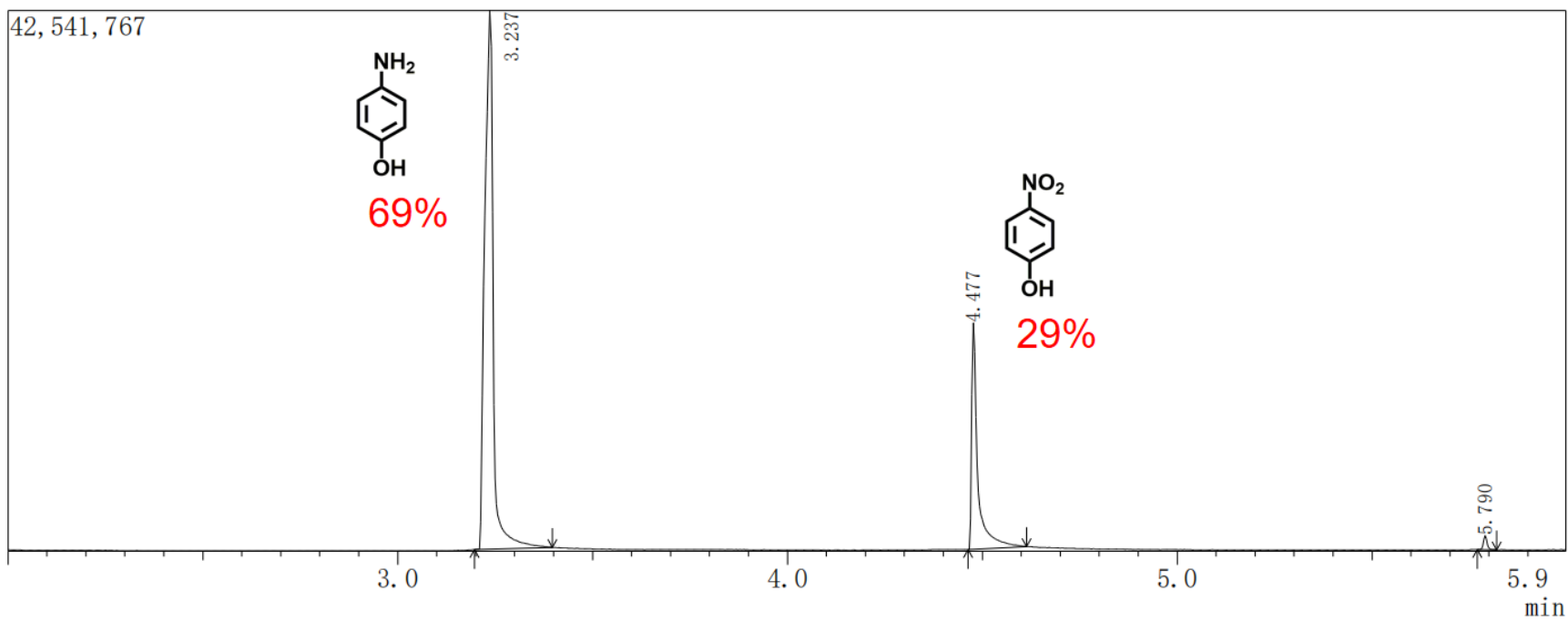

Figure S39. GC-MS results of the product mixture obtained after reaction for $30 \mathrm{~min}$, showing that the reactant $p$-nitrophenol (peak at $4.48 \mathrm{~min}$ ) was converted to $p$-aminophenol (peak at $3.24 \mathrm{~min}$ ). 


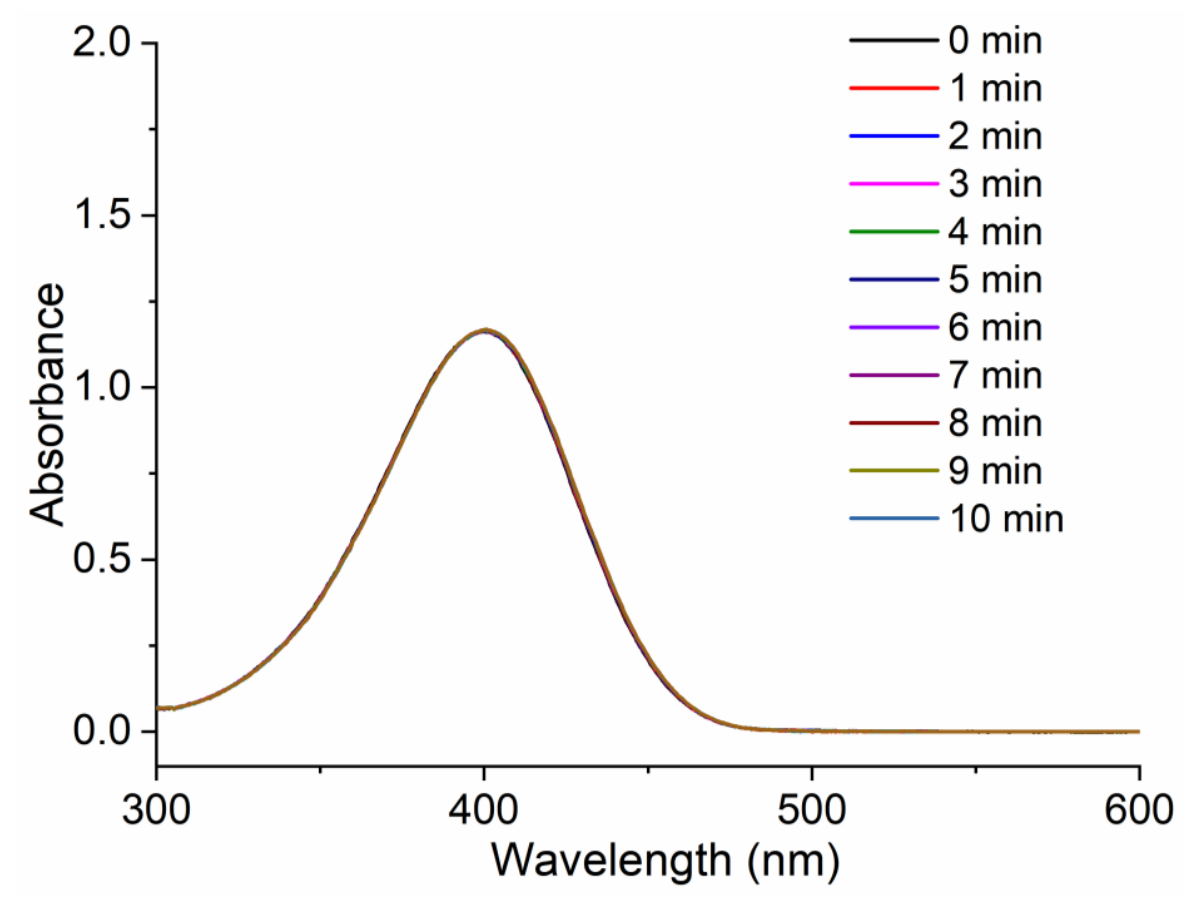

Figure S40. UV-vis spectra of catalytic reduction of $p$-nitrophenol to $p$-aminophenol in the presence of PPN without Pt nanoparticles as a control experiment, showing no changes in the absorption at various reaction times.

8. Characterizations of recycled Pt/PPN 


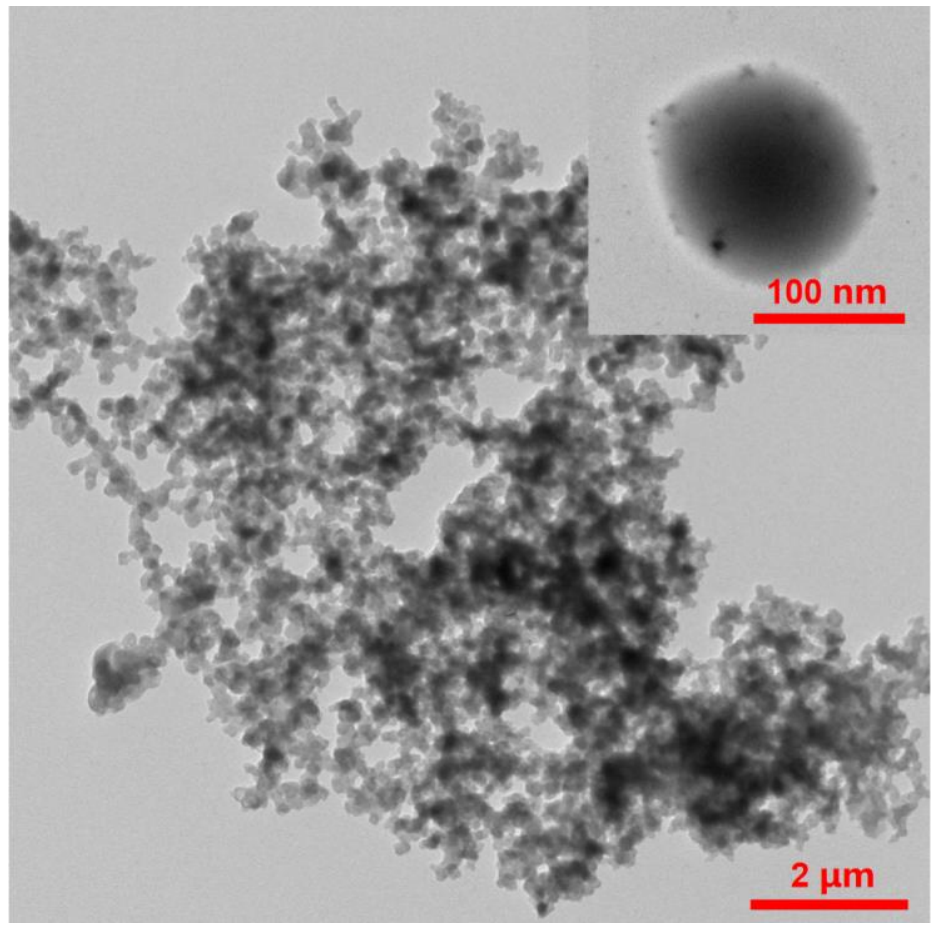

Figure S41. TEM image of recycled Pt/PPN.

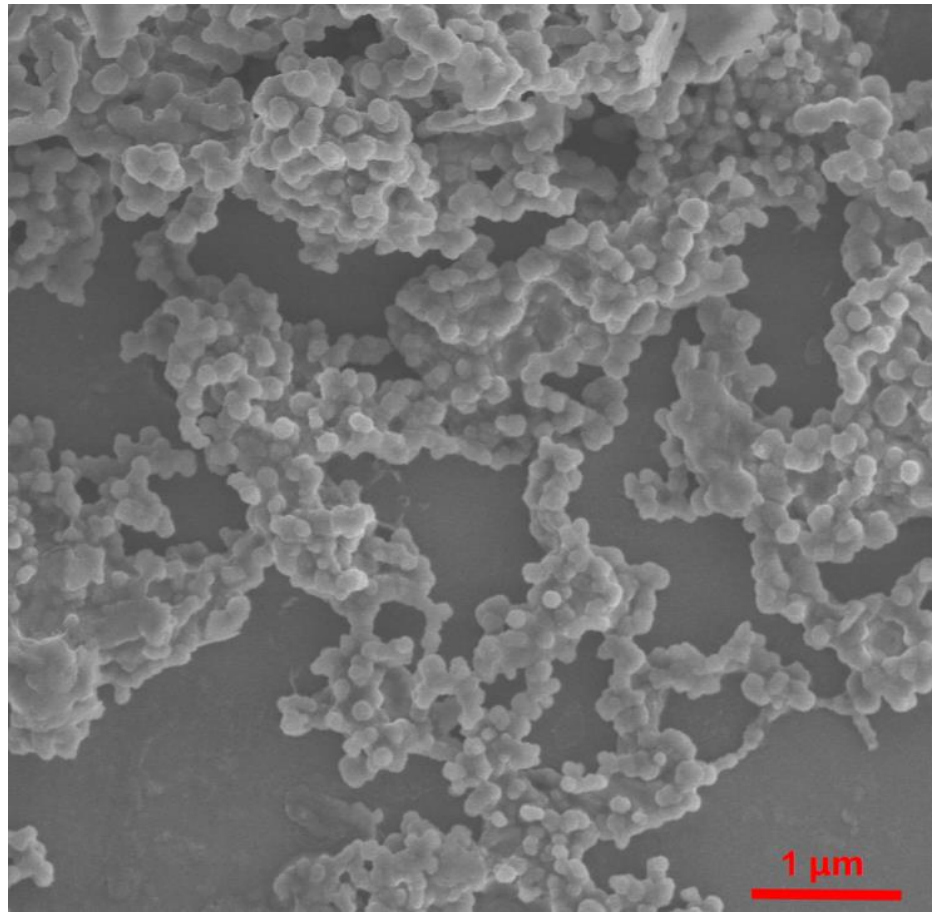

Figure S42. SEM image of recycled Pt/PPN. 


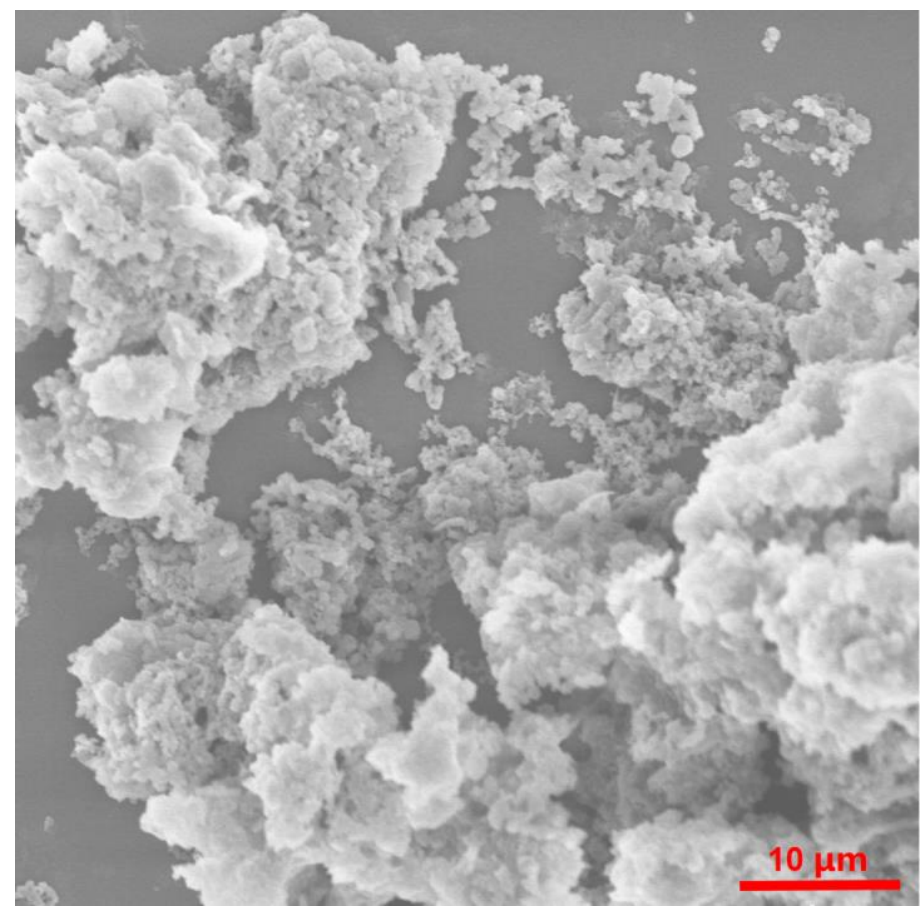

Figure S43. SEM image of recycled Pt/PPN.

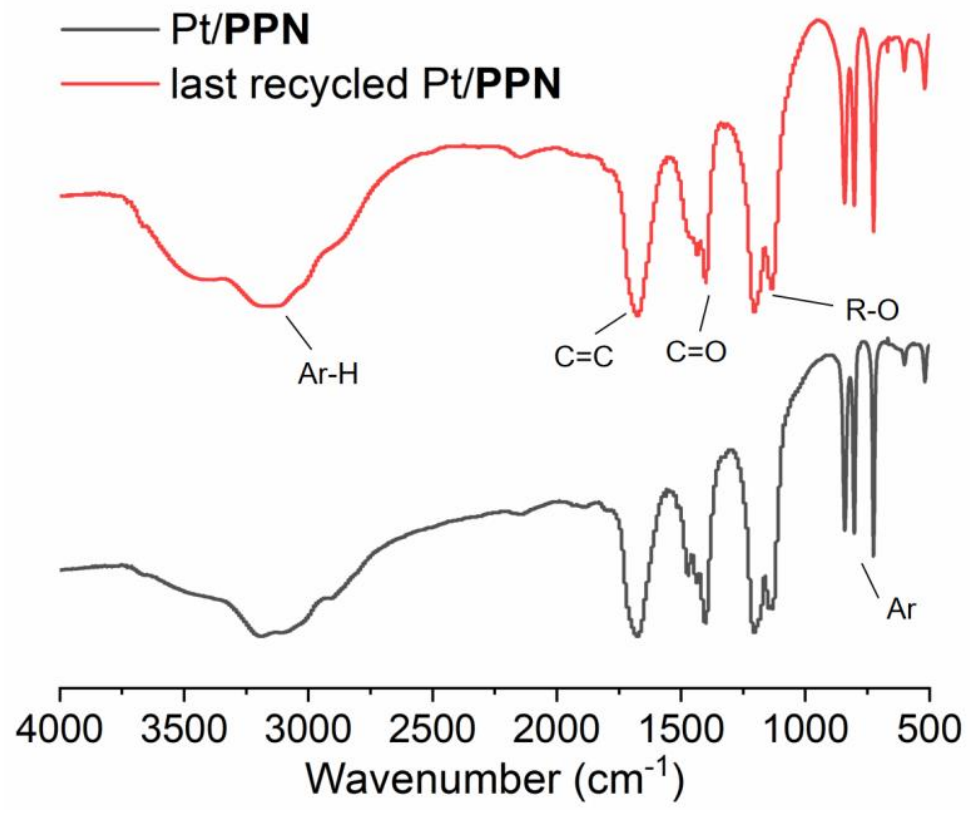

Figure S44. FT-IR spectra of Pt/PPN and last recycled Pt/PPN. 


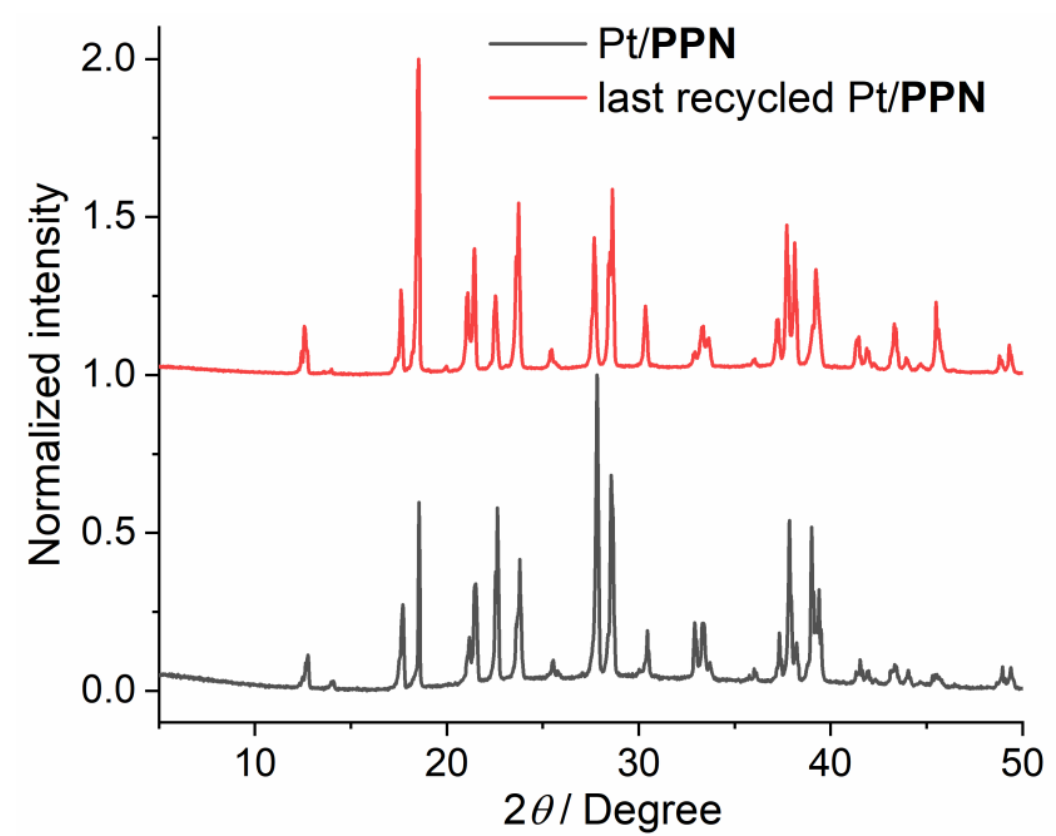

Figure S45. Powder X-ray diffraction patterns of of Pt/PPN and last recycled Pt/PPN.

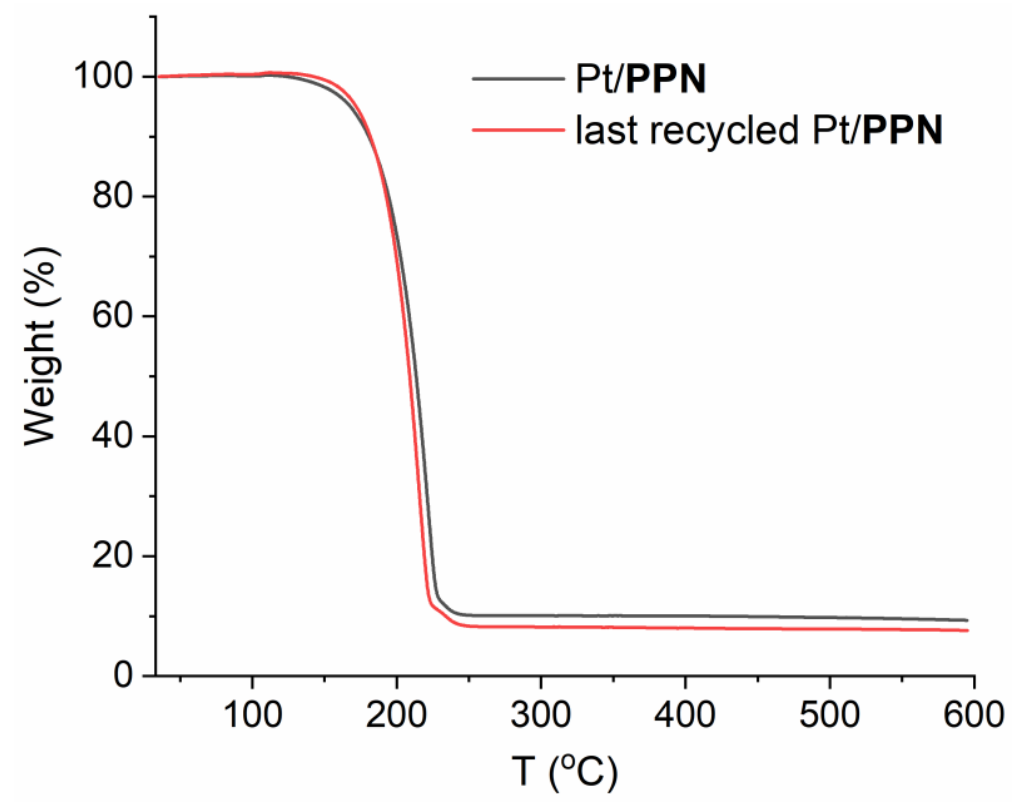

Figure S46. Thermogravimetric analysis of Pt/PPN and last recycled Pt/PPN. 


\begin{tabular}{|c|c|c|c|c|c|c|c|c|}
\hline Name & Method & Weight (mg) & N area & C area & H area & N (\%) & C (\%) & H (\%) \\
\hline Pt/PPN & 2 mgChem70s & 2.00 & 5998 & 7549 & 5014 & 10.2 & 18.0 & 3.38 \\
\hline Recycled Pt/PPN & 2mgChem70s & 2.09 & 6182 & 7758 & 5064 & 10.1 & 17.7 & 3.27 \\
\hline
\end{tabular}

Figure S47. Elemental analysis of Pt/PPN and last recycled Pt/PPN

\begin{tabular}{|l|c|c|}
\hline \multicolumn{1}{|c|}{ Sample Id } & $\mathbf{P t}(\mathbf{p p m})$ & $\mathbf{P t}(\mathbf{m g} / \mathbf{m l})$ \\
\hline The $1^{\text {st }}$ recycle & 55.2 & 0.0552 \\
\hline The $5^{\text {th }}$ recycle & 54.0 & 0.0540 \\
\hline The $10^{\text {th }}$ recycle & 53.5 & 0.0535 \\
\hline
\end{tabular}

Figure S48. ICP-MS analysis after reaction for evaluating the catalyst leaching of 10 cycles. The solution was diluted for ICP-MS analysis. 
9. Characterizations of substrate scope

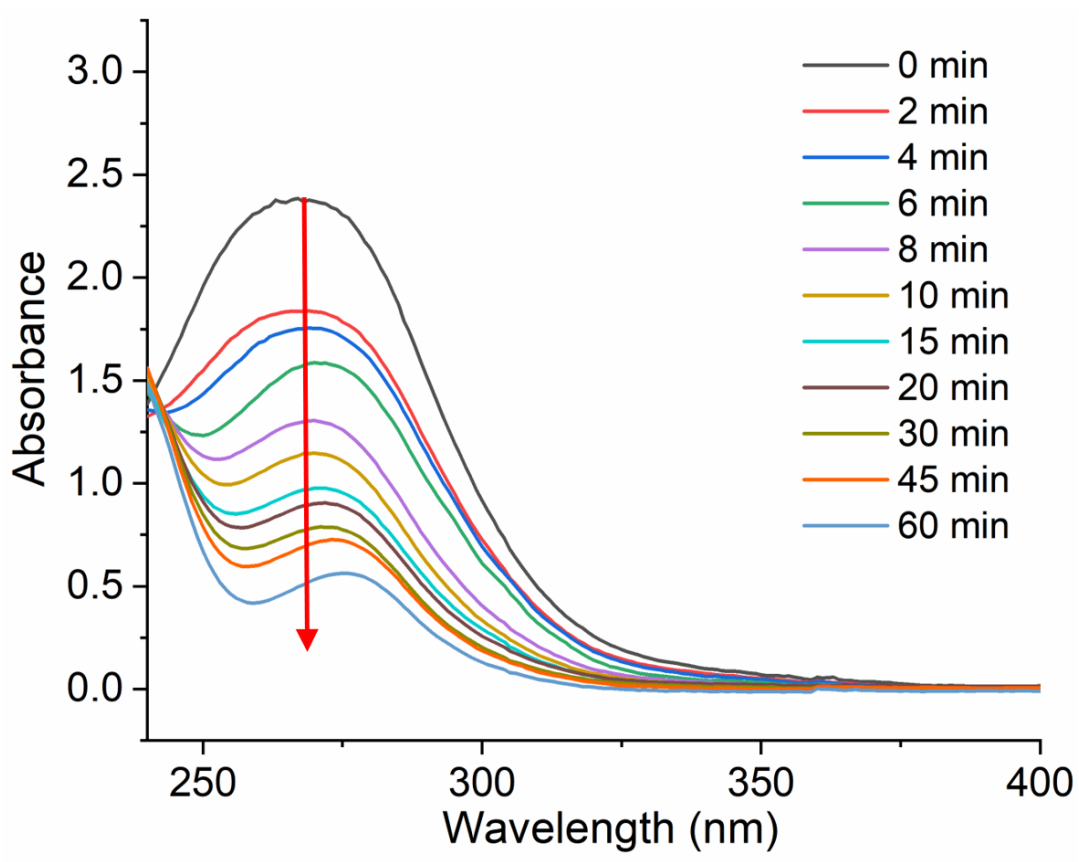

Figure S49. Time-dependent UV-vis spectra of nitrobenzene and aminobenzene in the presence of $\mathrm{Pt} / \mathbf{P P N}$.

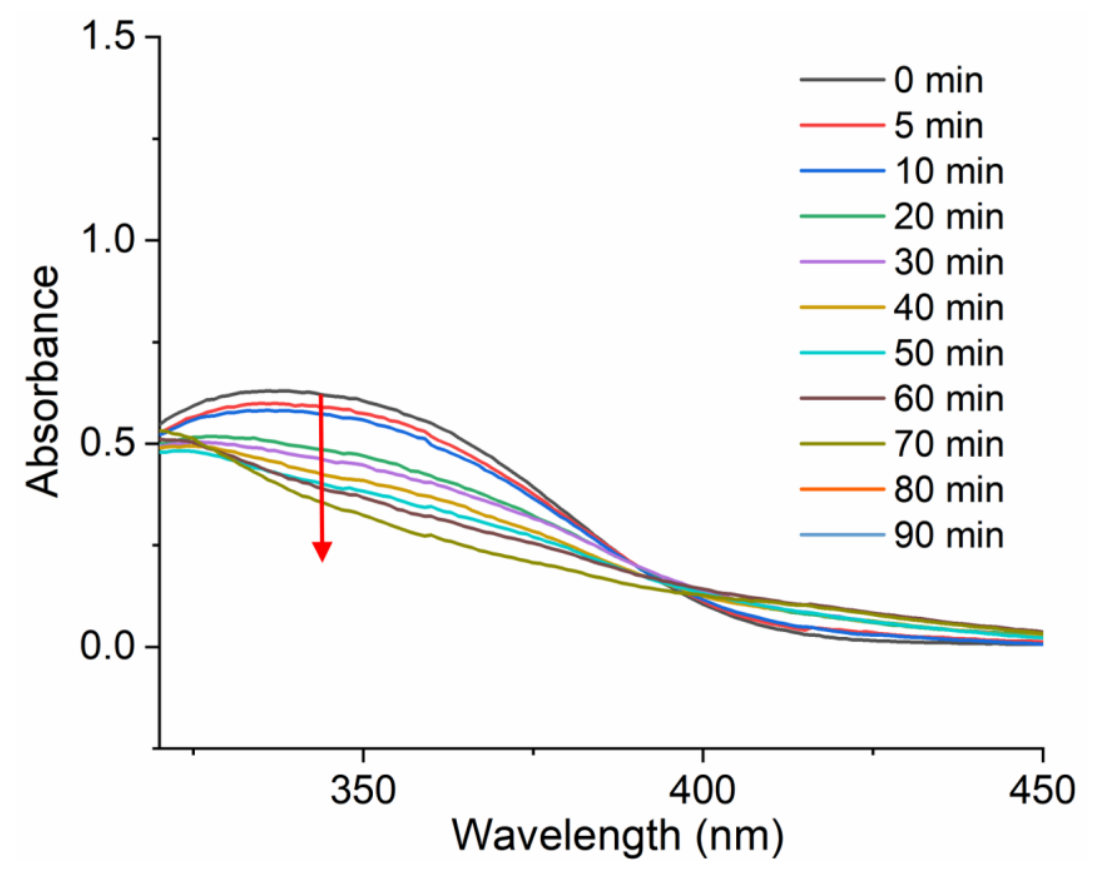

Figure S50. Time-dependent UV-vis spectra of 1-nitronaphthalene and 1-aminonaphthalene in the presence of Pt/PPN. 


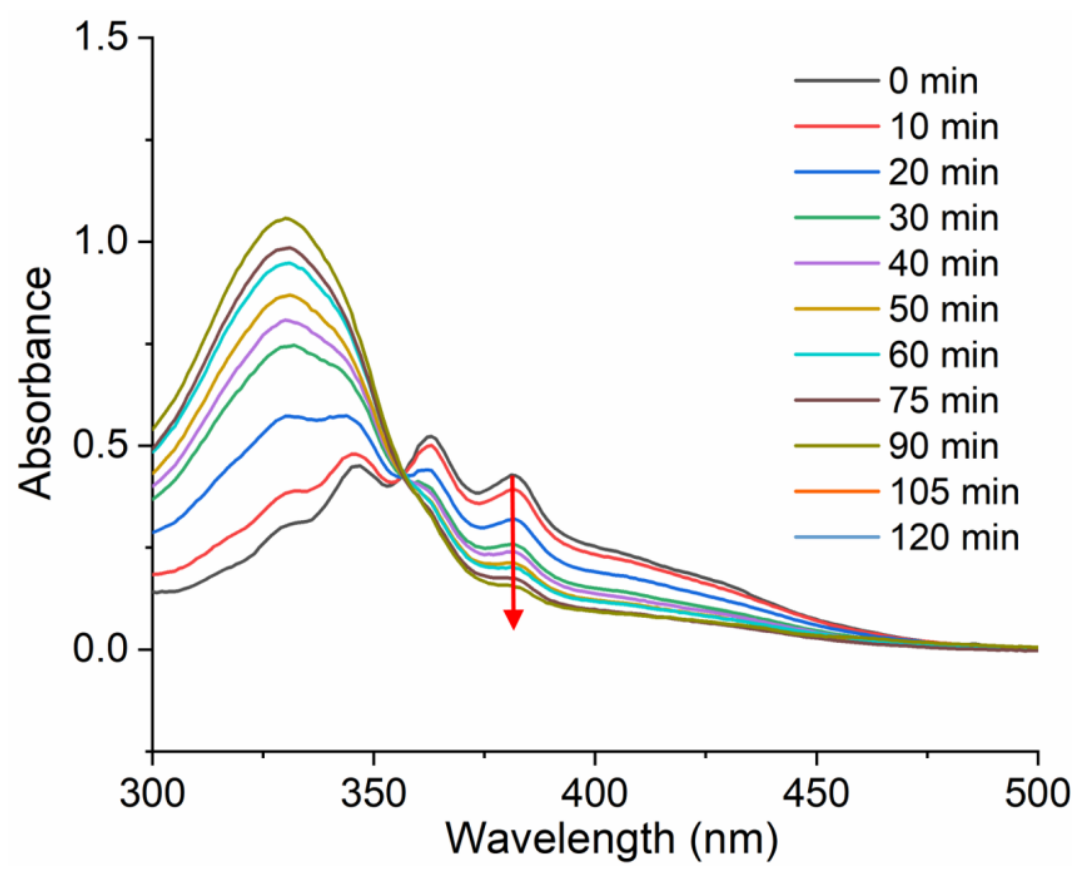

Figure S51. Time-dependent UV-vis spectra of 9-nitroanthracene and 9-aminoanthracene in the presence of Pt/PPN.

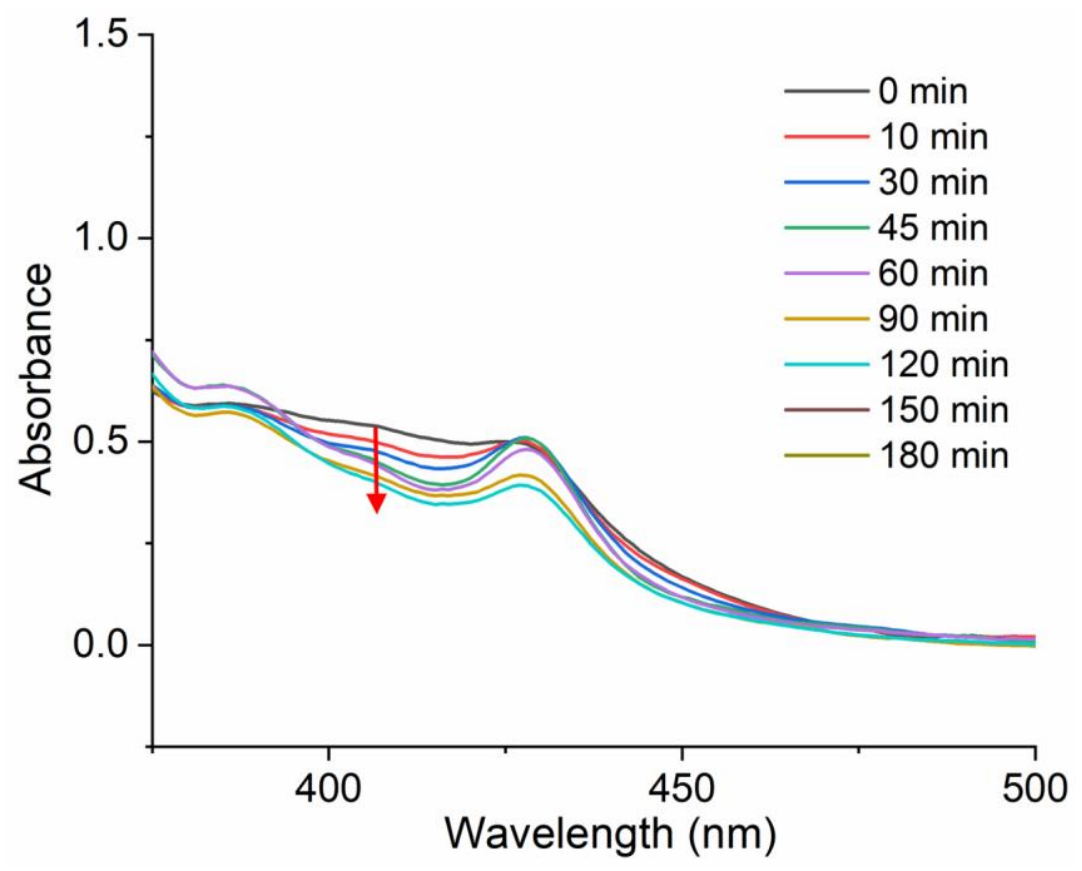

Figure S52. Time-dependent UV-vis spectra of 1-nitropyrene and 1-aminopyrene in the presence of Pt/PPN. 


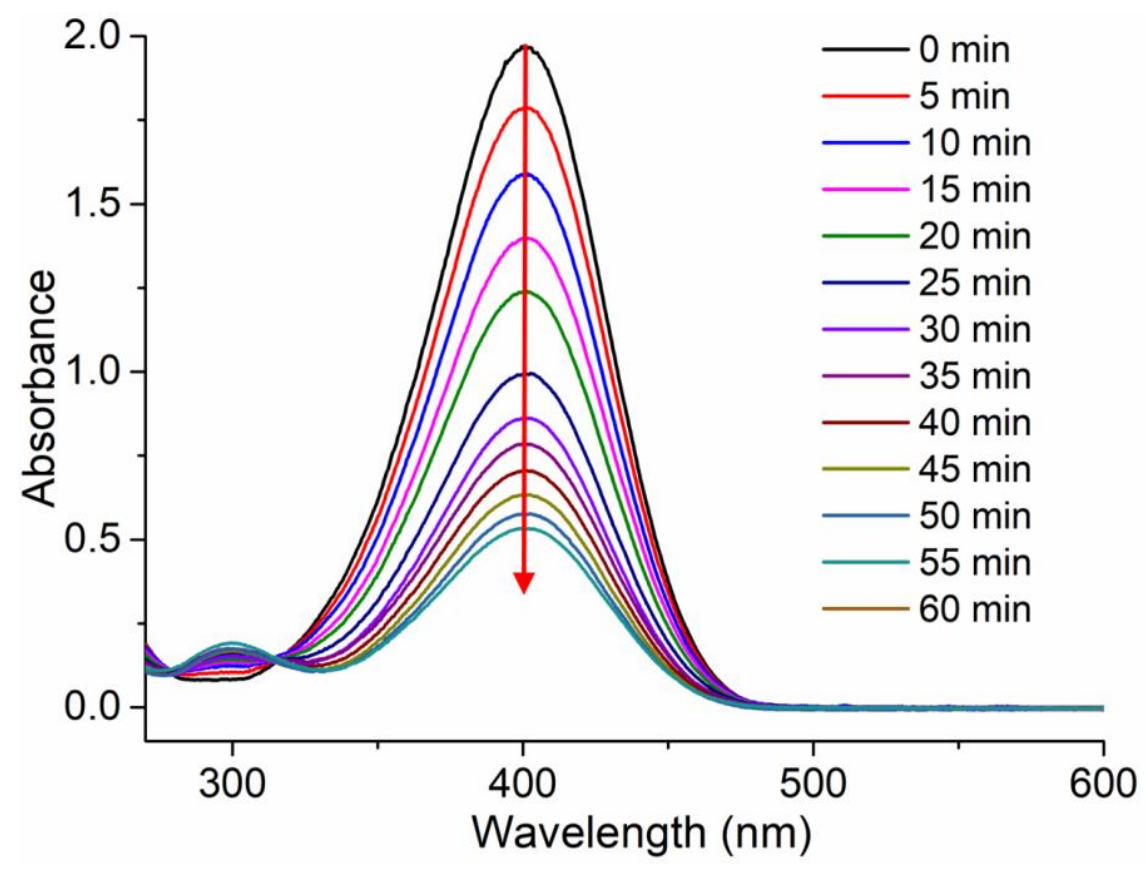

Figure S53. Time-dependent UV-vis spectra of $p$-nitrophenol and $p$-aminophenol in the presence of $\mathrm{Pt} / \mathbf{P P N}$.

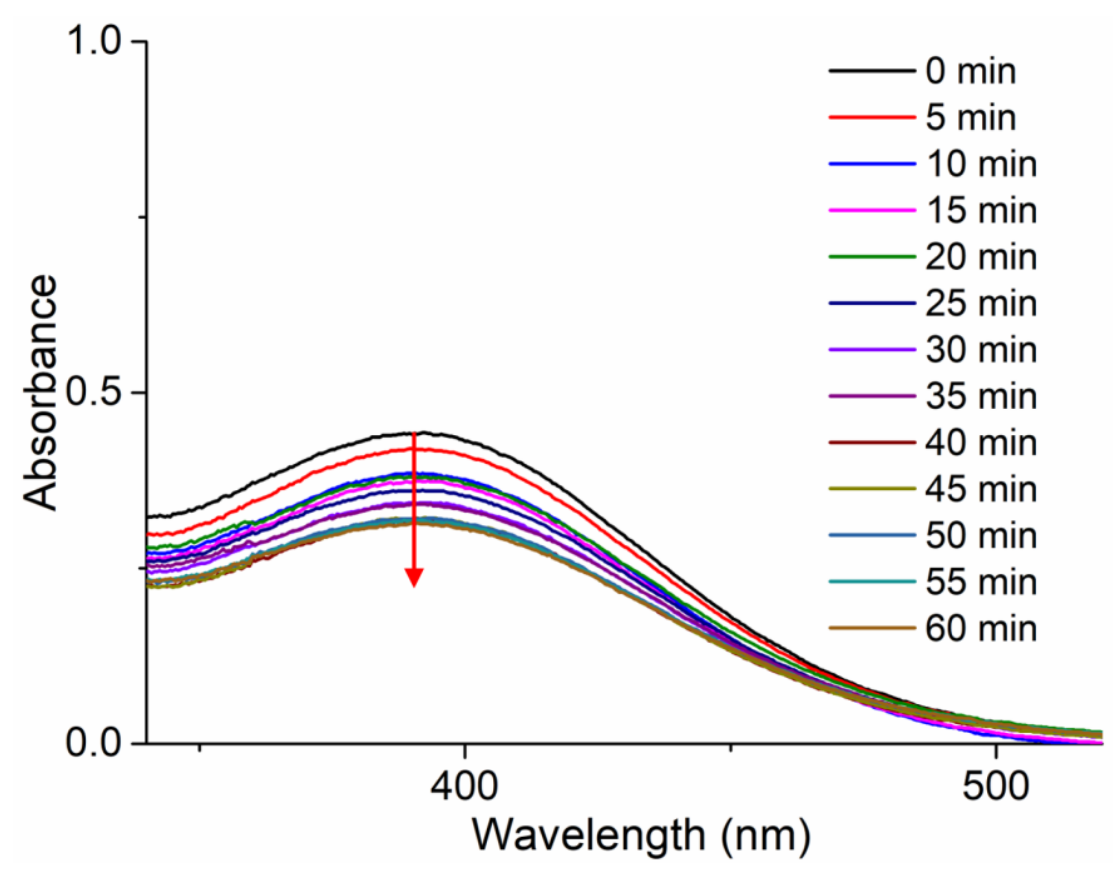

Figure S54. Time-dependent UV-vis spectra of $m$-nitrophenol and $m$-aminophenol in the presence of $\mathrm{Pt} / \mathbf{P P N}$. 


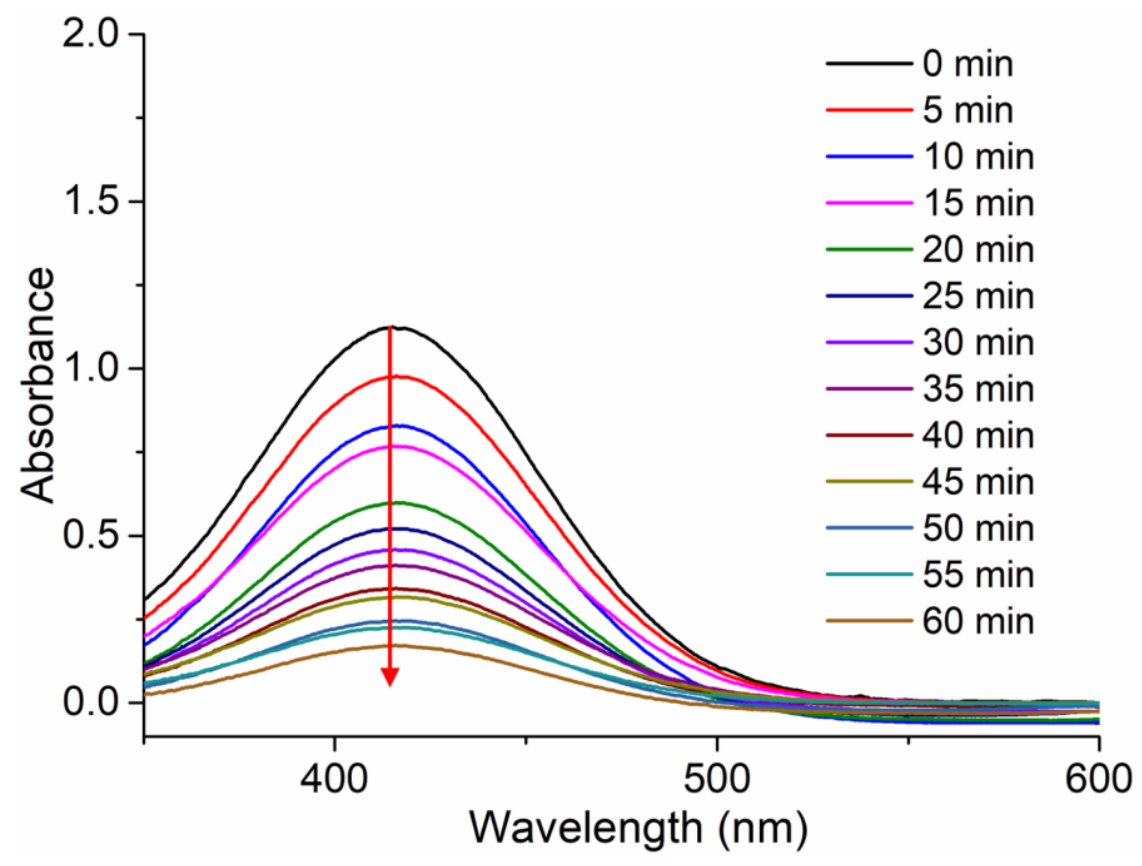

Figure S55. Time-dependent UV-vis spectra of $o$-nitrophenol and $o$-aminophenol in the presence of $\mathrm{Pt} / \mathbf{P P N}$.

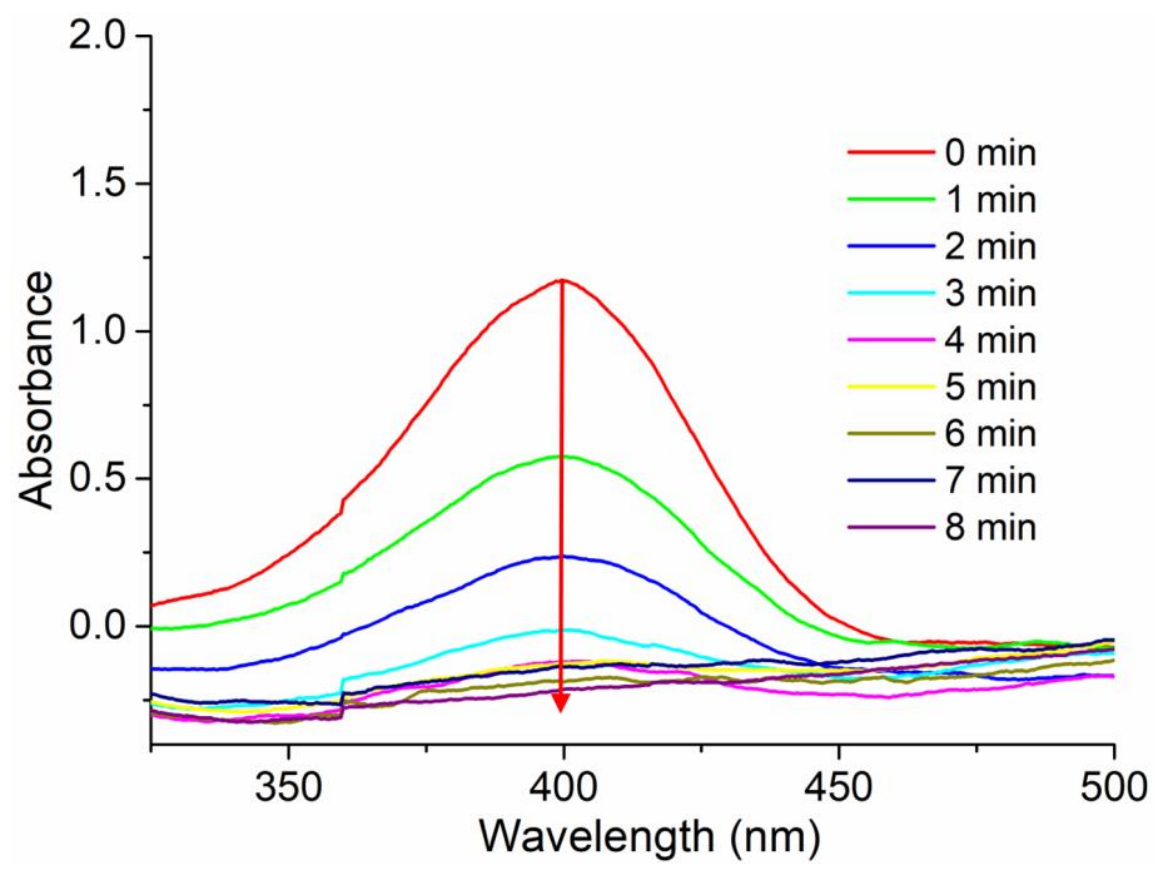

Figure S56. Time-dependent UV-vis spectra of 3-methoxy-4-nitrophenol and 3-methoxy-4-aminophenol in the presence of Pt/PPN. 


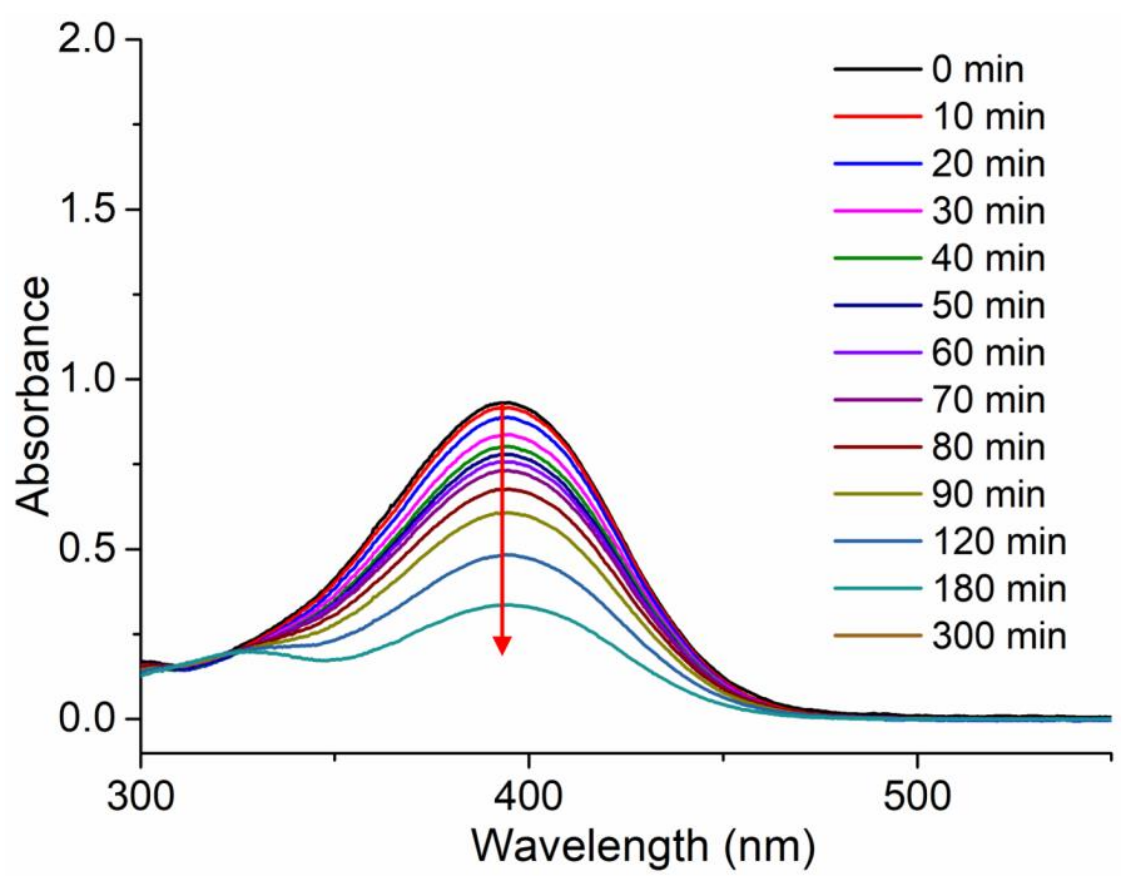

Figure S57. Time-dependent UV-vis spectra of 3-trifluoromethyl-4-nitrophenol and 3-trifluoromethyl-4-aminophenol in the presence of Pt/PPN.

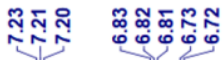<smiles>Nc1ccccc1</smiles>

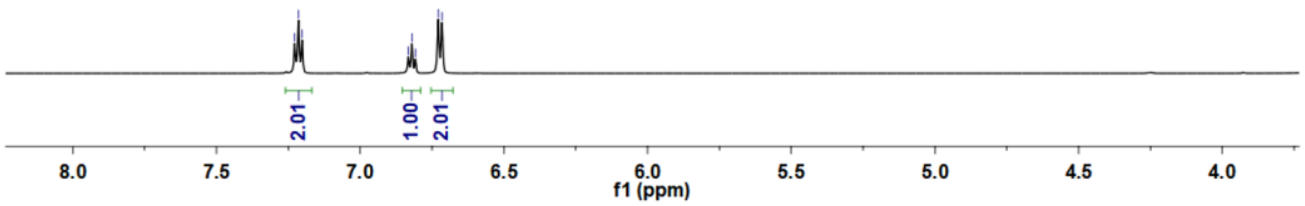

Figure S58. ${ }^{1} \mathrm{H}$ NMR spectrum $\left(600 \mathrm{MHz}, \mathrm{CDCl}_{3}, 298 \mathrm{~K}\right)$ of aminobenzene. 

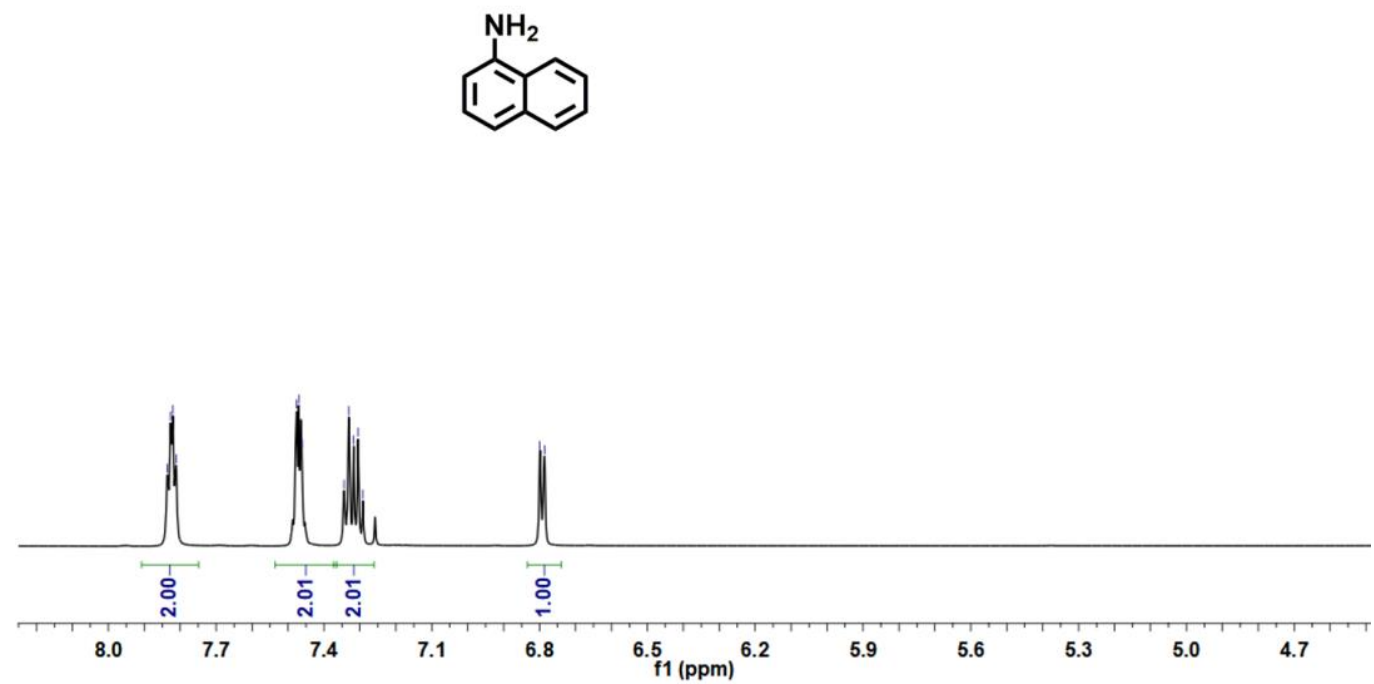

Figure S59. ${ }^{1} \mathrm{H}$ NMR spectrum $\left(600 \mathrm{MHz}, \mathrm{CDCl}_{3}, 298 \mathrm{~K}\right)$ of 1-aminonaphthalene.

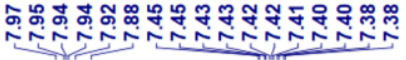
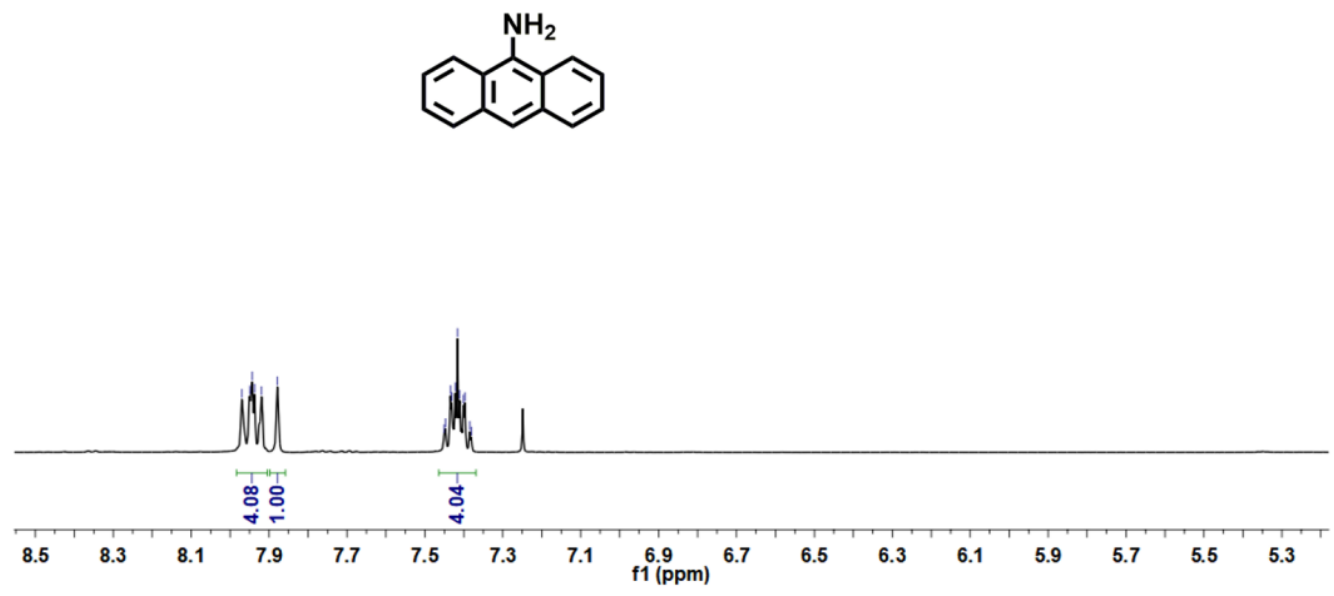

Figure S60. ${ }^{1} \mathrm{H} \mathrm{NMR}$ spectrum $\left(600 \mathrm{MHz}, \mathrm{CDCl}_{3}, 298 \mathrm{~K}\right)$ of 9-aminoanthracene. 

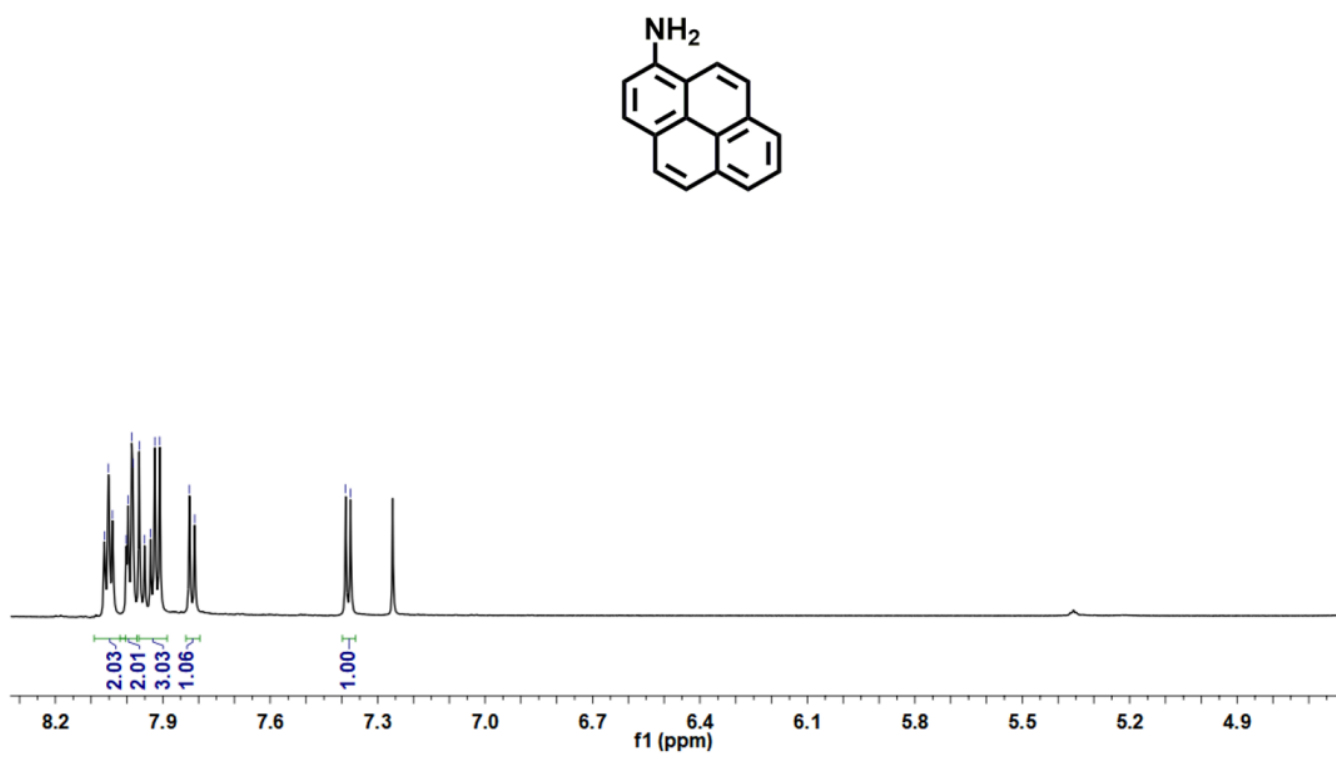

Figure S61. ${ }^{1} \mathrm{H}$ NMR spectrum $\left(600 \mathrm{MHz}, \mathrm{CDCl}_{3}, 298 \mathrm{~K}\right)$ of 1-aminopyrene.
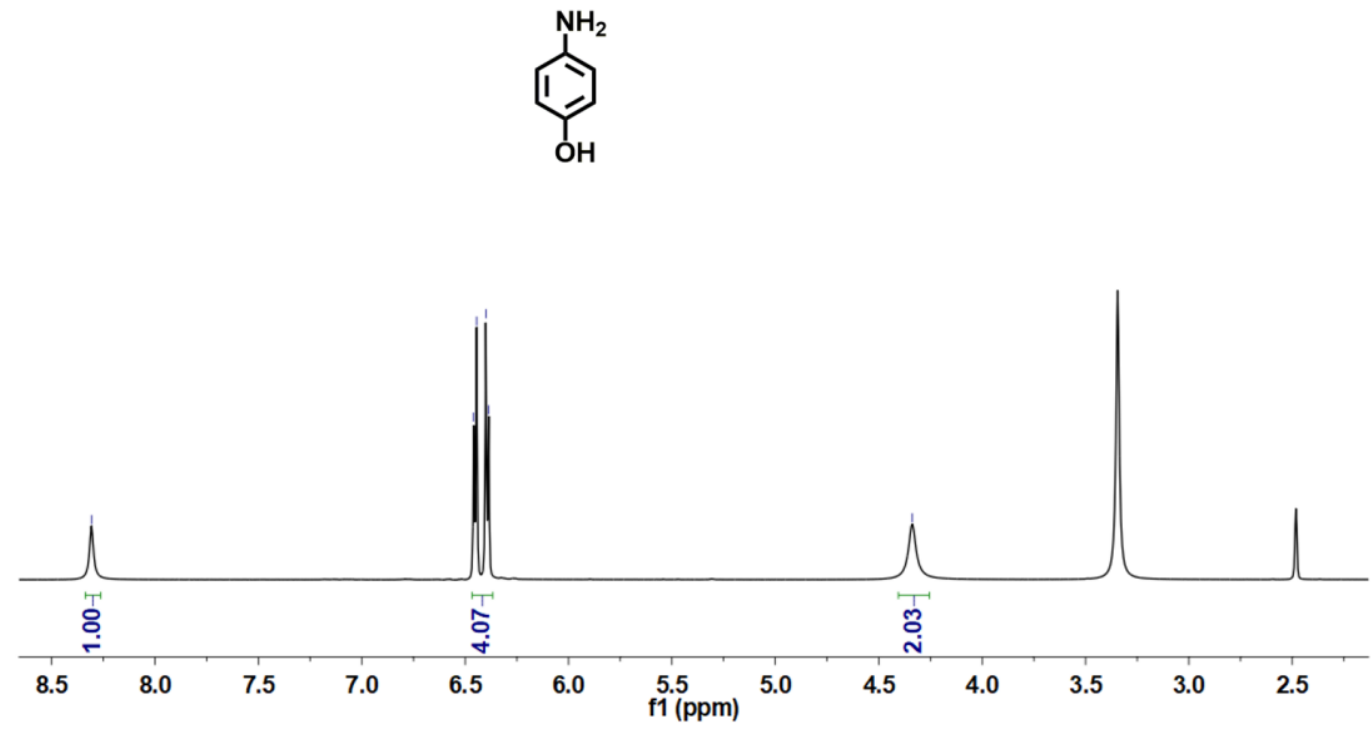

Figure S62. ${ }^{1} \mathrm{H}$ NMR spectrum $\left(600 \mathrm{MHz}, \mathrm{DMSO}-d_{6}, 298 \mathrm{~K}\right)$ of $p$-aminophenol. 


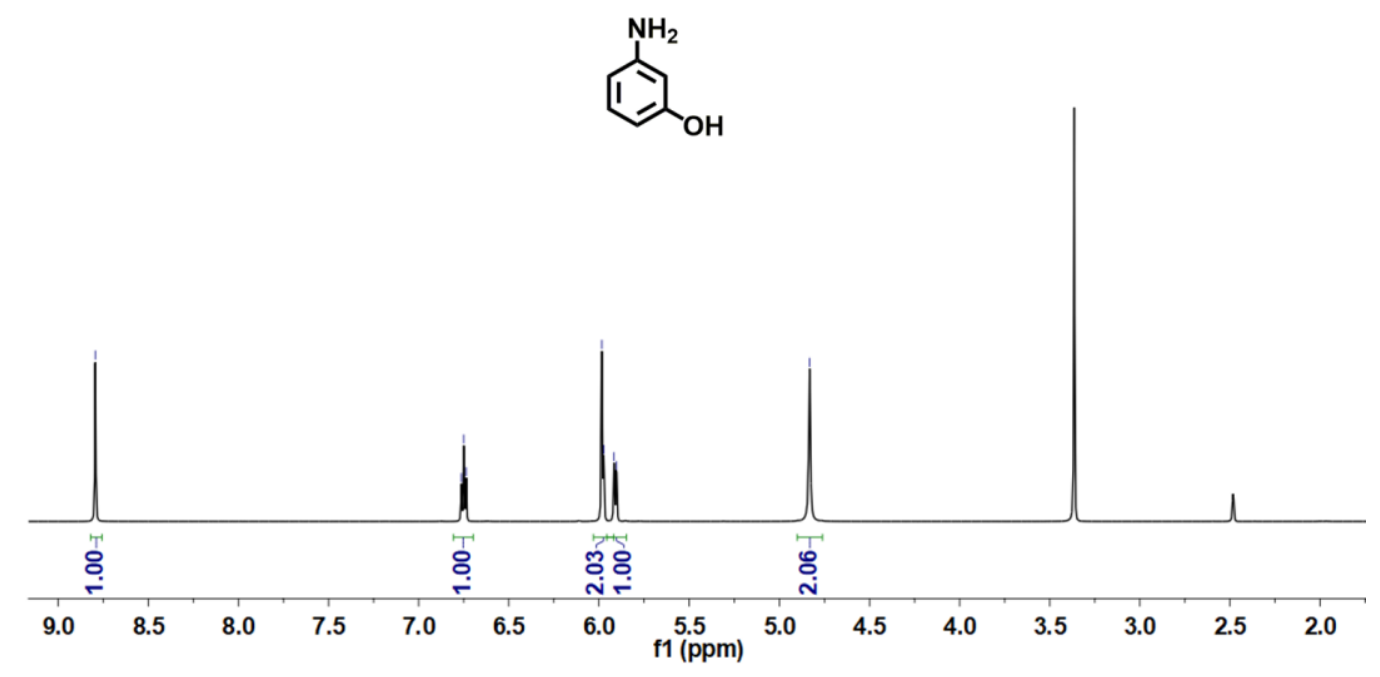

Figure S63. ${ }^{1} \mathrm{H}$ NMR spectrum $\left(600 \mathrm{MHz}, \mathrm{DMSO}-d_{6}, 298 \mathrm{~K}\right)$ of $m$-aminophenol.

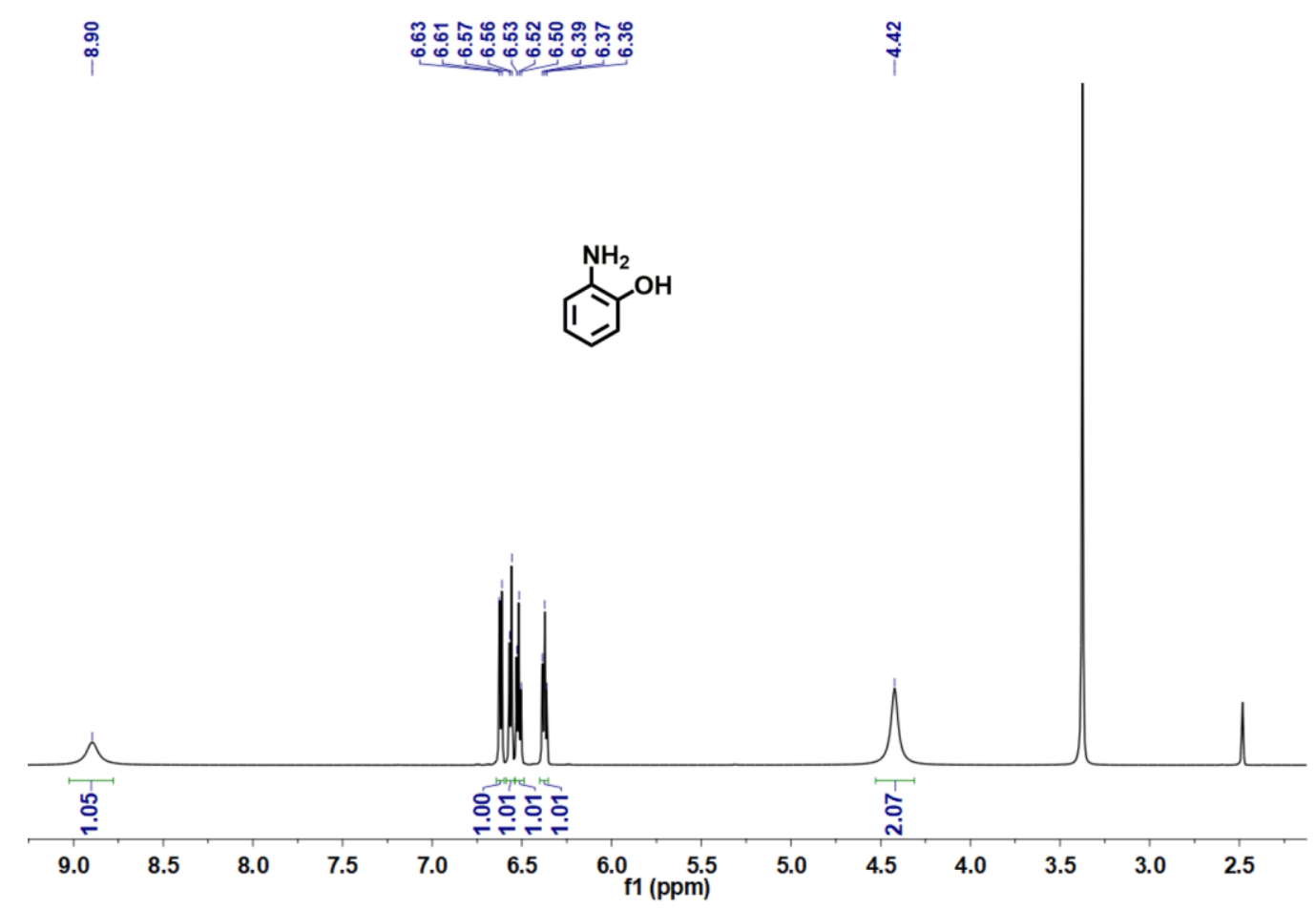

Figure S64. ${ }^{1} \mathrm{H}$ NMR spectrum $\left(600 \mathrm{MHz}, \mathrm{DMSO}-d_{6}, 298 \mathrm{~K}\right)$ of $o$-aminophenol. 


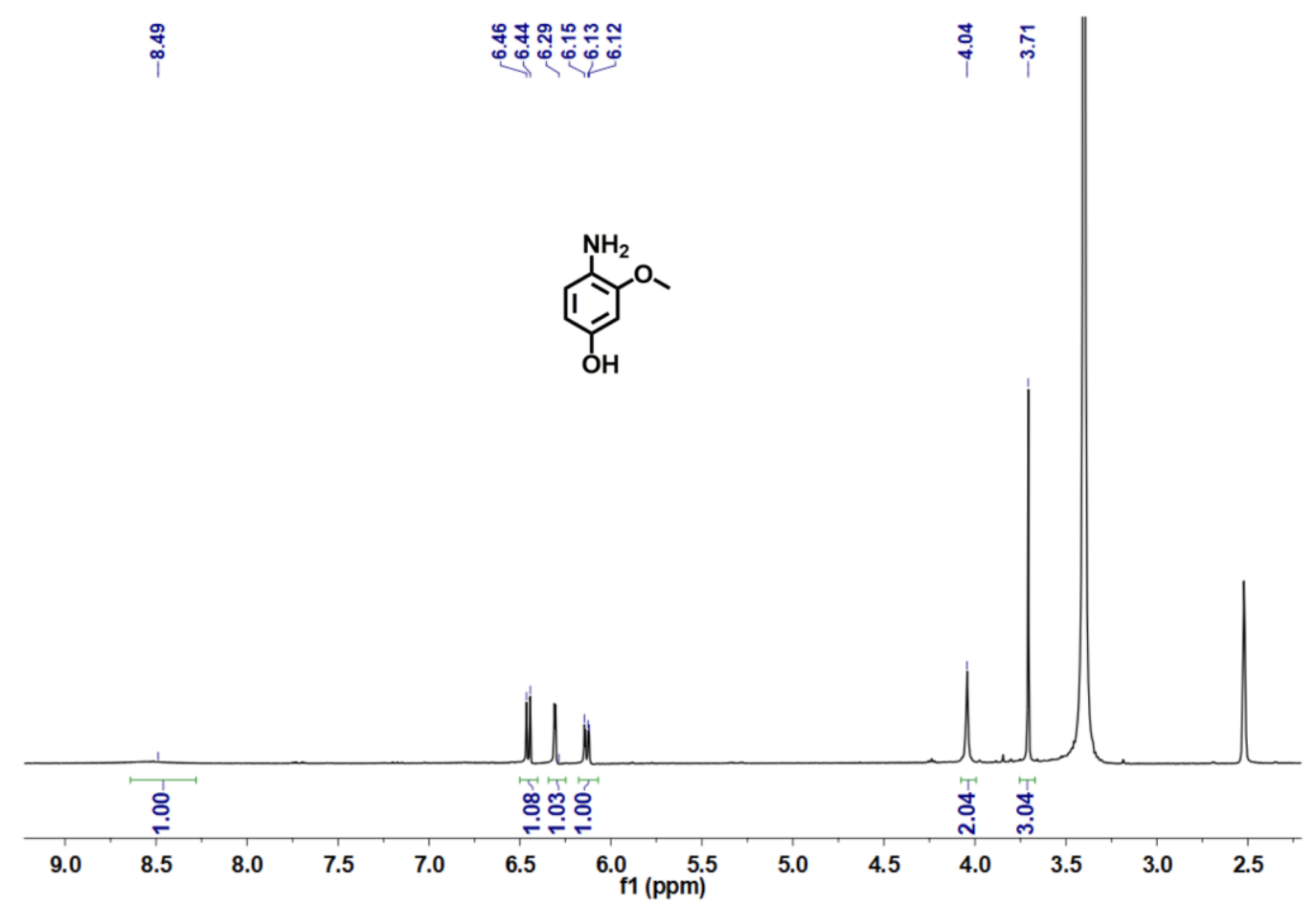

Figure S65. ${ }^{1} \mathrm{H}$ NMR spectrum (600 MHz, DMSO-d6, $298 \mathrm{~K}$ ) of 3-methoxy-4-aminophenol.

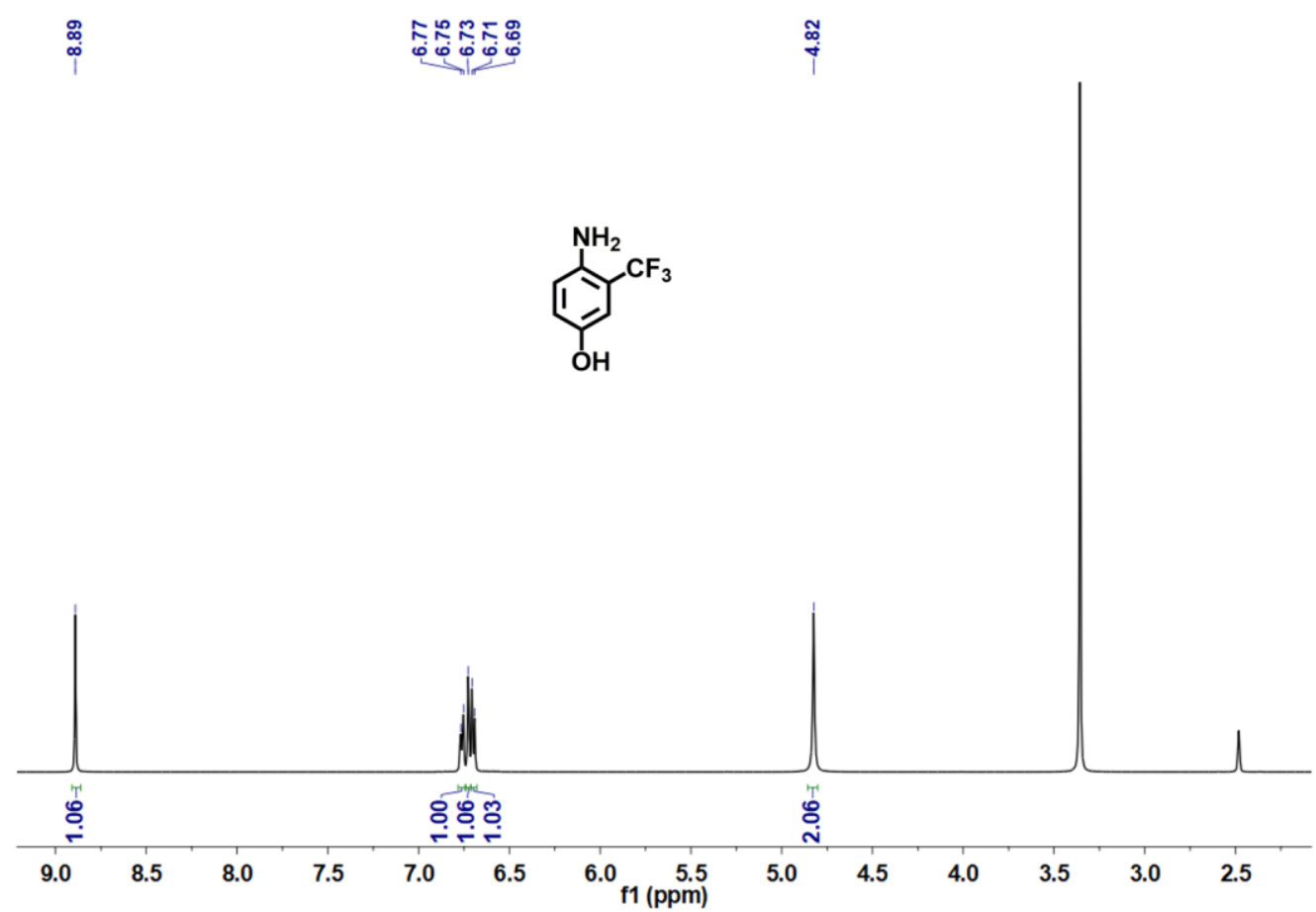

Figure S66. ${ }^{1} \mathrm{H}$ NMR spectrum $\left(600 \mathrm{MHz}\right.$, DMSO- $\left.d_{6}, 298 \mathrm{~K}\right)$ of 3-trifluoromethyl-4-aminophenol. 


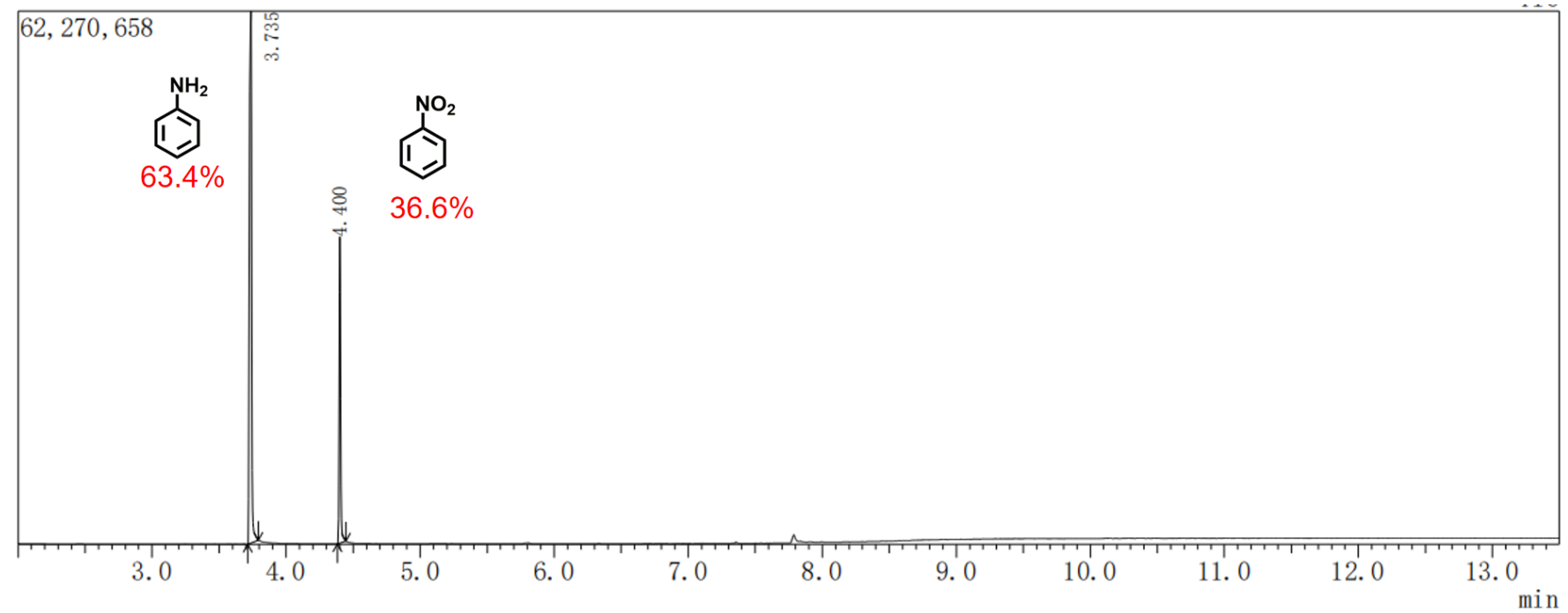

Figure S67. GC-MS results of the product mixture obtained after reaction for $30 \mathrm{~min}$ in the water-ethyl acetate biphasic mixture, showing that the reactant $p$-nitrobenzene (peak at $4.40 \mathrm{~min}$ ) was converted to p-aminobenzene (peak at $3.74 \mathrm{~min}$ ).

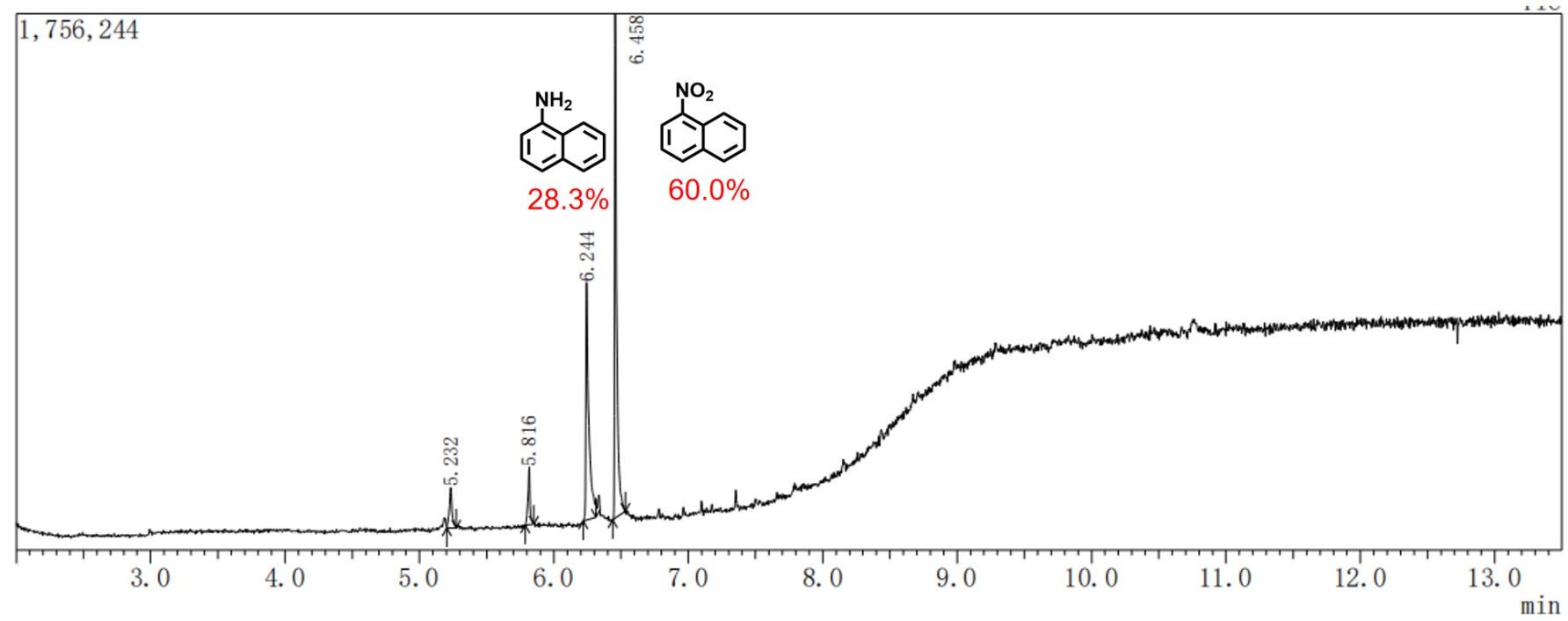

Figure S68. GC-MS results of the product mixture obtained after reaction for $30 \mathrm{~min}$ in the water-ethyl acetate biphasic mixture, showing that the reactant 1-nitronaphthalene (peak at $6.46 \mathrm{~min}$ ) was converted to 1-aminonaphthalene (peak at $6.24 \mathrm{~min}$ ). 


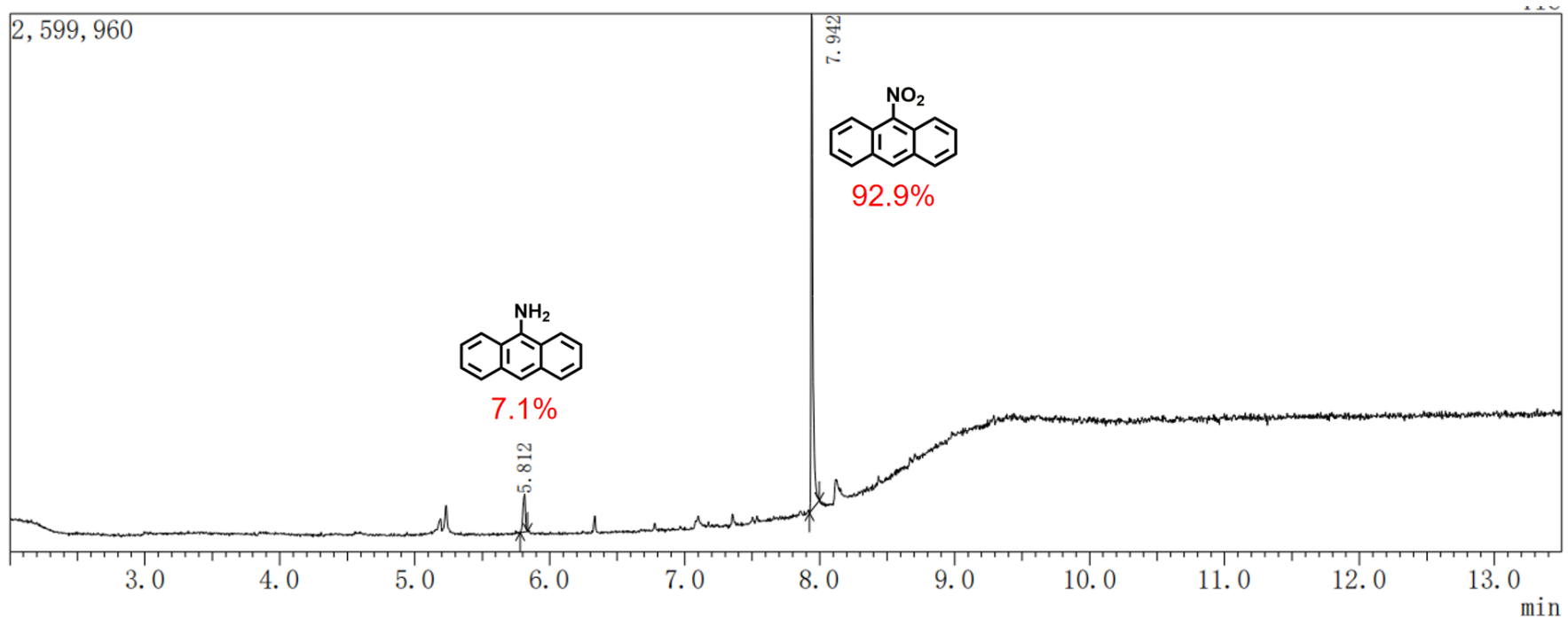

Figure S69. GC-MS results of the product mixture obtained after reaction for $30 \mathrm{~min}$ in the water-ethyl acetate biphasic mixture, showing that the reactant 9-nitroanthracene (peak at $7.94 \mathrm{~min}$ ) was converted to 9-aminoanthracene (peak at $5.81 \mathrm{~min}$ ).

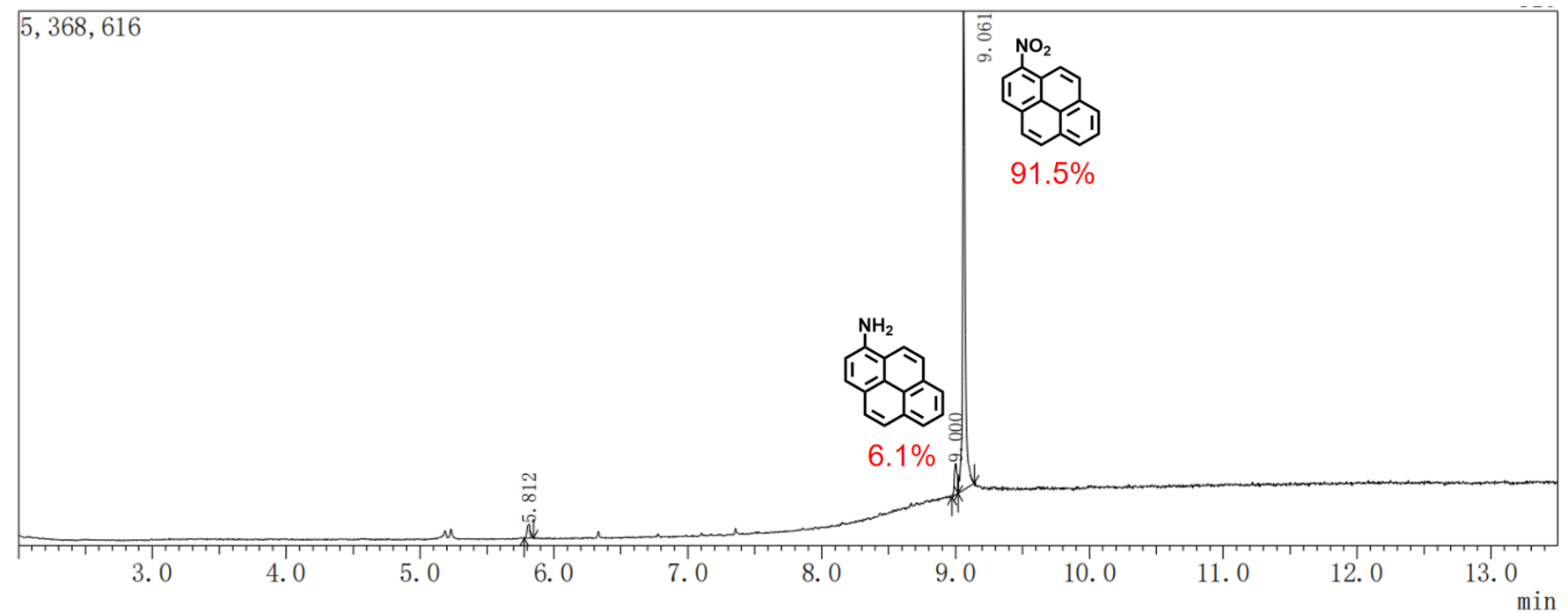

Figure S70. GC-MS results of the product mixture obtained after reaction for $30 \mathrm{~min}$ in the water-ethyl acetate biphasic mixture, showing that the reactant 1-nitropyrene (peak at $9.06 \mathrm{~min}$ ) was converted to 1-aminopyrene (peak at $9.00 \mathrm{~min}$ ). 


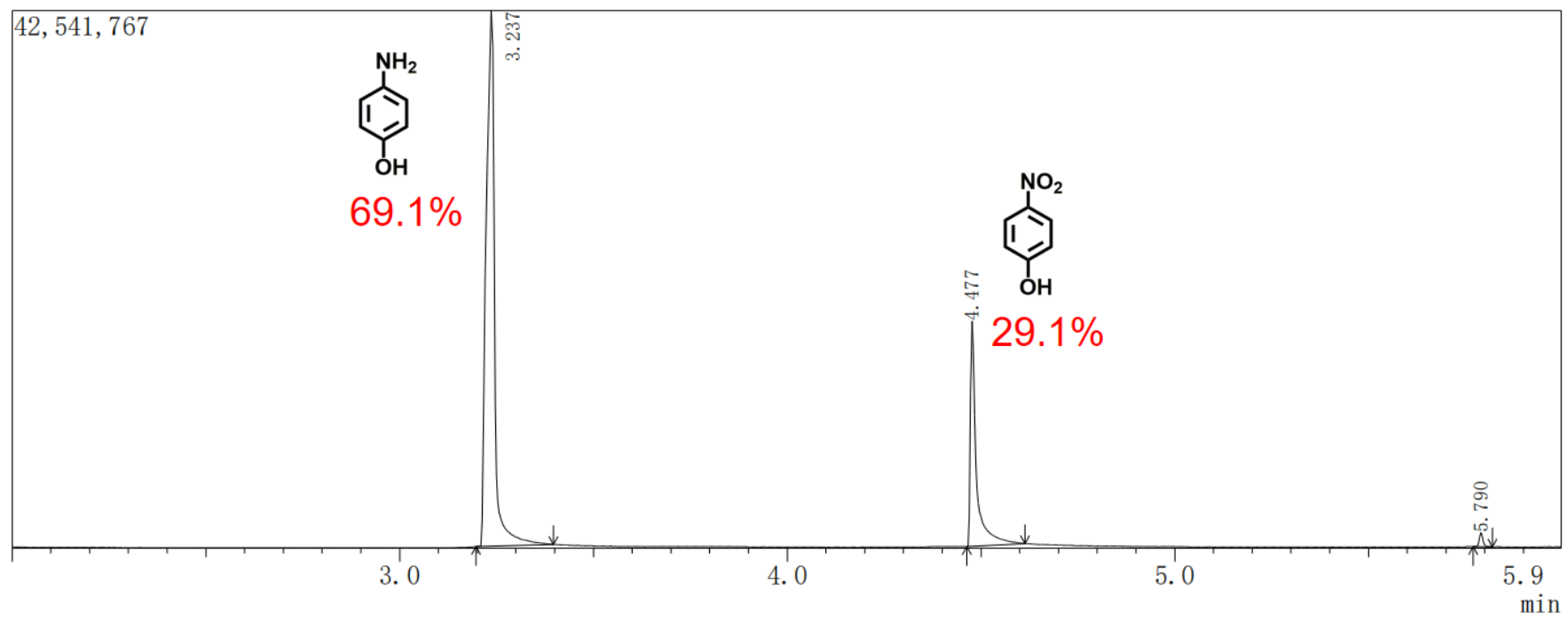

Figure S71. GC-MS results of the product mixture obtained after reaction for $30 \mathrm{~min}$ in the water-ethyl acetate biphasic mixture, showing that the reactant $p$-nitrophenol (peak at $4.48 \mathrm{~min}$ ) was converted to p-aminophenol (peak at $3.24 \mathrm{~min}$ ).

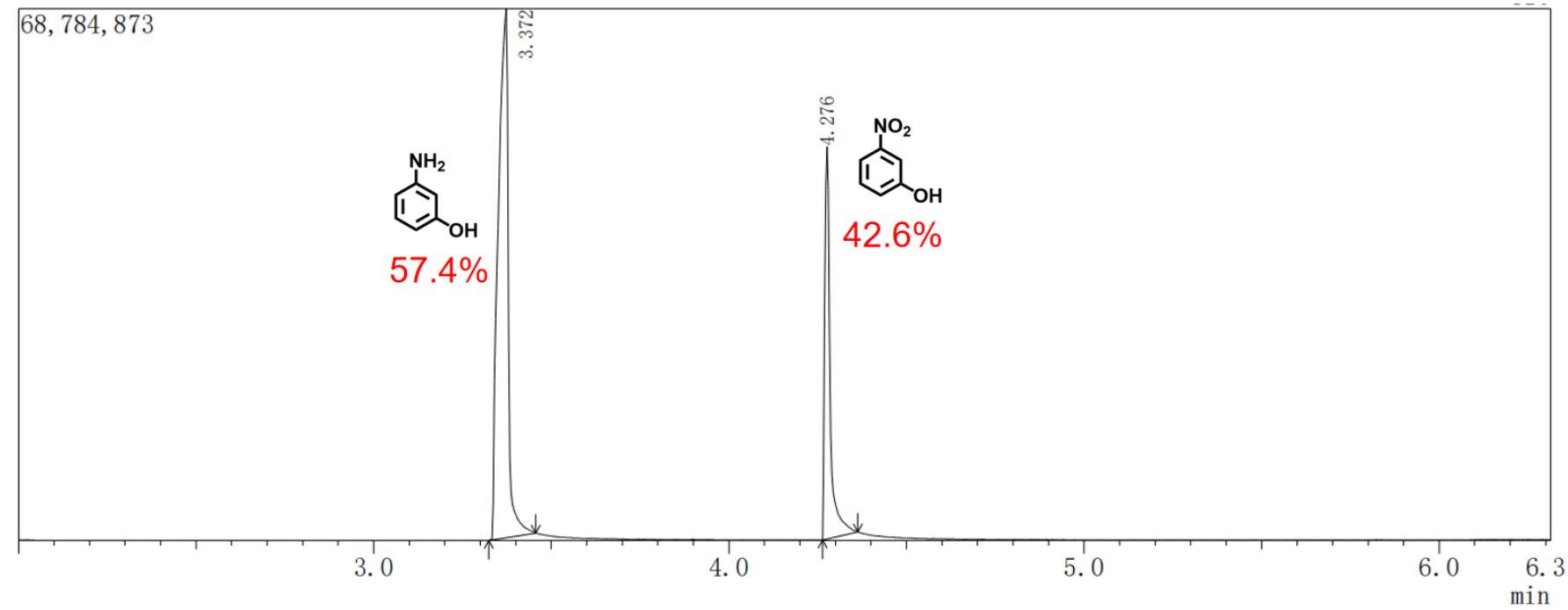

Figure S72. GC-MS results of the product mixture obtained after reaction for $30 \mathrm{~min}$ in the water-ethyl acetate biphasic mixture, showing that the reactant $m$-nitrophenol (peak at $4.28 \mathrm{~min}$ ) was converted to $m$-aminophenol (peak at $3.37 \mathrm{~min}$ ). 


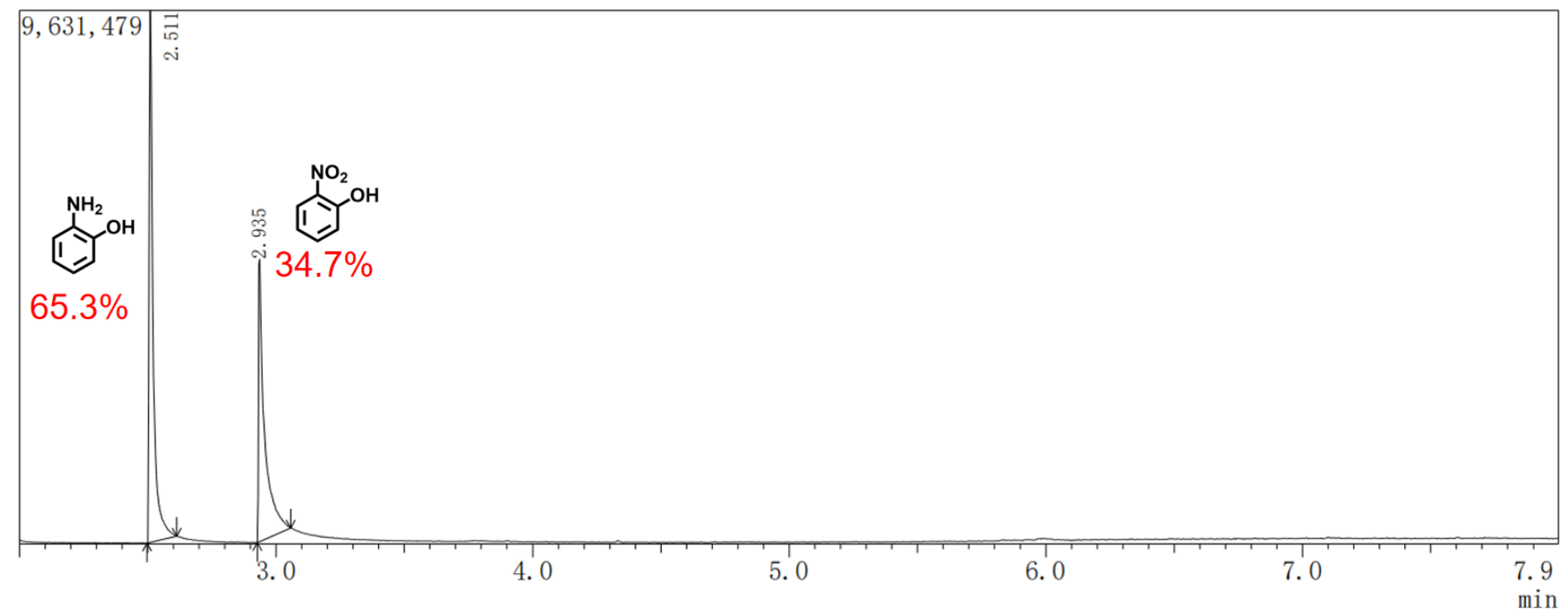

Figure S73. GC-MS results of the product mixture obtained after reaction for $30 \mathrm{~min}$ in the water-ethyl acetate biphasic mixture, showing that the reactant $o$-nitrophenol (peak at $2.94 \mathrm{~min}$ ) was converted to $o$-aminophenol (peak at $2.51 \mathrm{~min}$ ).

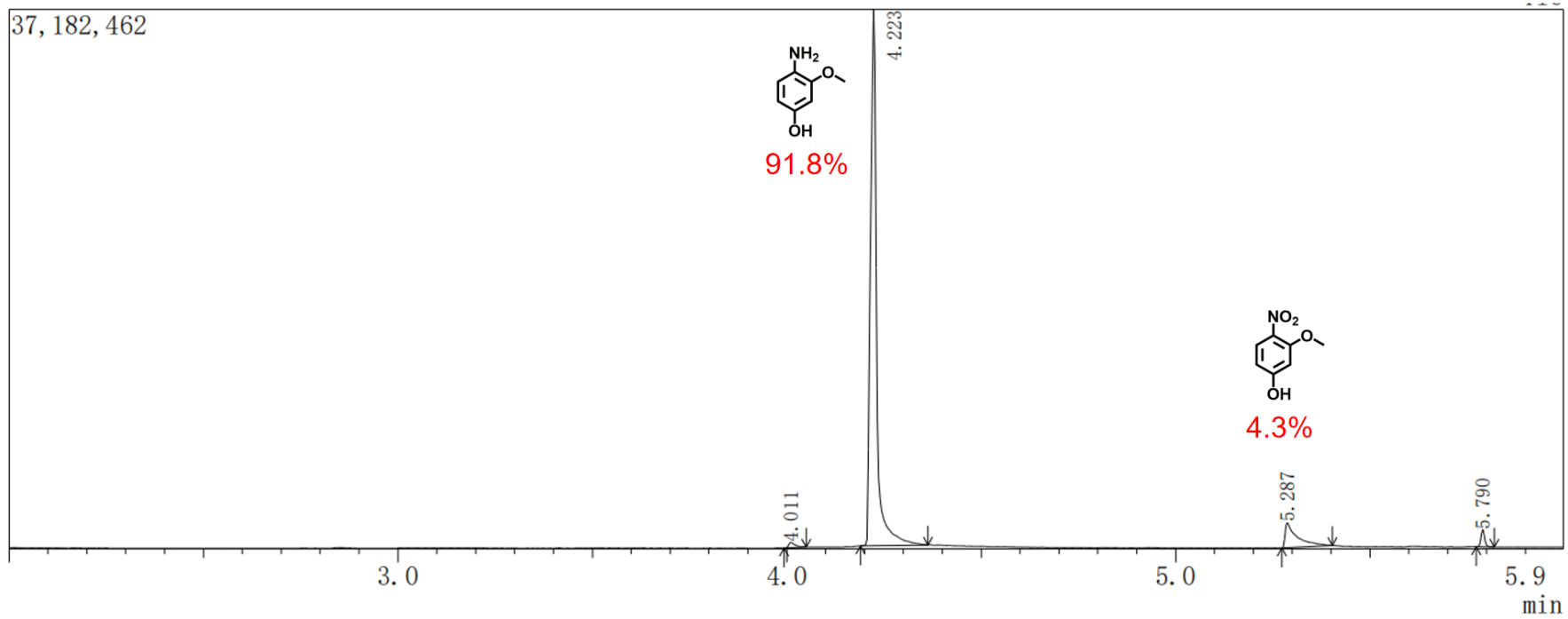

Figure S74. GC-MS results of the product mixture obtained after reaction for $30 \mathrm{~min}$ in the water-ethyl acetate biphasic mixture, showing that the reactant 3-methoxy-4-nitrophenol (peak at 5.29 min) was converted to 3-methoxy-4-aminophenol (peak at $4.22 \mathrm{~min}$ ). 


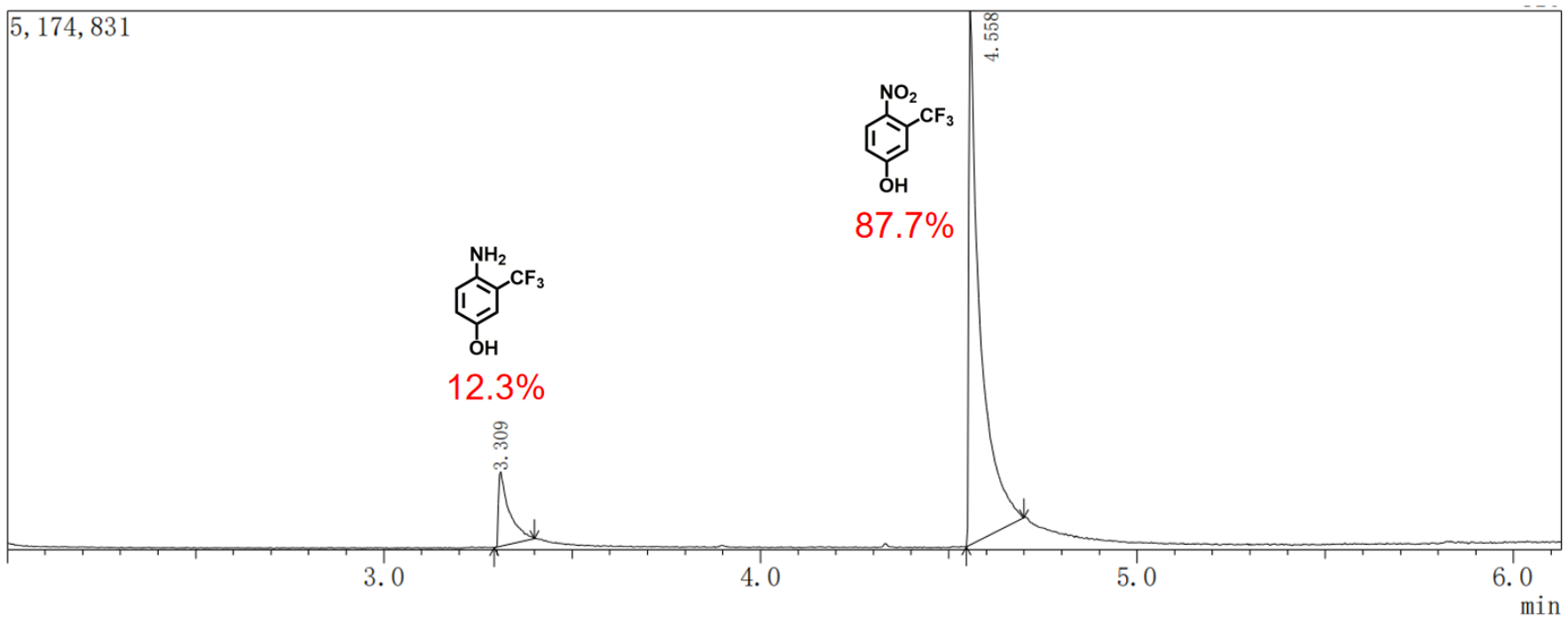

Figure S75. GC-MS results of the product mixture obtained after reaction for $30 \mathrm{~min}$ in the water-ethyl acetate biphasic mixture, showing that the reactant 3-trifluoromethyl-4-nitrophenol (peak at $4.56 \mathrm{~min}$ ) was converted to 3-trifluoromethyl-4-aminophenol (peak at $3.31 \mathrm{~min}$ ).

10. Comparison table

\begin{tabular}{|c|c|c|c|}
\hline & This work & $\begin{array}{c}\text { ACS Appl. Mater. Interfaces } \\
\mathbf{2 0 2 1}, 13,3209 .\end{array}$ & $\begin{array}{c}\text { ACS Appl. Nano Mater. } \\
\mathbf{2 0 2 0}, 3,10310 .\end{array}$ \\
\hline $\begin{array}{c}\text { Building } \\
\text { block }\end{array}$ & Pillararene and peptide & SCOF & ZnO/Fe3O4 \\
\hline preparation & Easy and fast & Time consuming & Time consuming \\
\hline catalyst & Pt/PPN & Ag NPs@SCOF & Pd@L-dopa-ZnO/Fe3O4 \\
\hline \multirow{2}{*}{$\begin{array}{c}\text { morphology } \\
\text { spherical }\end{array}$} & $\begin{array}{c}\text { Stable, environmental- } \\
\text { friendly,controllable }\end{array}$ & spherical & irregular \\
\hline
\end{tabular}

Table S1. Comparison with the previously similar published articles 
11. Reference

[S1] Yao, Y.; Li, J.; Dai, J.; Chi, X.; Xue, M. A Water-Soluble Pillar[6]arene: Synthesis, Host-Guest

Chemistry, Controllable Self-Assembly, and Application in Controlled Release. RSC Adv. 2014, 4, 9039-9043. 